Universidade de São Paulo

Instituto de Física

\title{
Sobre a Força de Lorentz, os Conceitos de Campo e a "Essência" do Eletromagnetismo Clássico
}

\author{
José Edmar Arantes Ribeiro
}

Dissertação apresentada como parte

dos requisitos para a obtenção do título de Mestre em Ciências

Comissão Examinadora:

Prof. Dr. Alvaro Vannucci (orientador) - IFUSP

Prof. Dr. Manoel Roberto Robilotta - IFUSP

Prof. Dr. José David Mangueira Vianna - UnB

S. Paulo -2008 


\section{FICHA CATALOGRÁFICA}

Preparada pelo Serviço de Biblioteca e Informação do Instituto de Física da Universidade de São Paulo

Ribeiro, José Edmar Arantes

Sobre a força de Lorentz, os conceitos de campo e a "essência" do eletromagnetismo clássico - São Paulo, 2008.

Dissertação (Mestrado) - Universidade de São Paulo. Instituto de Física - Depto. de Física Aplicada

Orientador: Prof. Dr. Álvaro Vannucci

Área de Concentração: Física

Unitermos: 1. Fundamentos de Mecânica; 2. Força de Lorentz; 3. Eletromagnetismo.

USP/IF/SBI-034/2008 
À memória de meu avô paterno, Sebastião Maciel Ribeiro, e de minha mãe, Maria Celeste Arantes, talvez novamente entre nós... 

(...) Com razão alguém disse: “onde estiver teu tesouro, estará também teu coração”.

Nosso tesouro está onde estão as colméias do nosso conhecimento. Estamos sempre a caminho delas, sendo por natureza criaturas aladas e coletoras do mel do espírito (...) Nas experiências presentes, receio, estamos sempre "ausentes": nelas não temos nosso coração - para elas não temos ouvidos. Antes, como alguém divinamente disperso e imerso em si, a quem os sinos acabam de estrondear no ouvido as doze batidas do meio-dia, $e$ súbito acorda e se pergunta "o que foi que soou?”, também nós por vezes abrimos depois os ouvidos e perguntamos, surpresos e perplexos inteiramente, “o que foi que vivemos?", $e$ também “quem somos realmente?”, e em seguida contamos, depois, como disse, as doze vibrantes batidas da nossa vivência, da nossa vida, nosso ser - ah! e contamos errado... Pois continuamos necessariamente estranhos a nós mesmos, não nos compreendemos, temos que nos mal-entender, a nós se aplicará para sempre a frase: "Cada qual é o mais distante de si mesmo" - para nós mesmos somos “homens do desconhecimento”...

Friedrich Nietzsche no "Prólogo" de Genealogia da Moral - uma polêmica (tradução de Paulo César de Souza; S. Paulo: Companhia das Letras, 1998)

(...) Não digas que duas simples horas de vida valem mais que duas páginas escritas; a escritura é mais pobre, porém mais clara (...)

Franz Kafka em Cartas a Milena (tradução de Torrieri Guimarães; S. Paulo: Livraria Exposição do Livro, s.d.)

(...) But with the development of quantum electrodynamics, the vacuum has come to be regarded as the seat of the 'zero-point' oscillations of the electromagnetic field, of the 'zero-point' fluctuations of electric charge and current, and of a 'polarisation' corresponding to a dielectric constant different from unity. It seems absurd to retain the name 'vacuum' for an entity so rich in physical properties, and the historical word 'aether' may fitly be retained.

Sir Edmund Whittaker em A History of the Theories of Aether and Electricity, vol. I ( London: Thomas Nelson and Sons Ltd., 1951 [revised and enlarged edition of the publication of 1910] ) 



\section{AGRADECIMENTOS}

Gostaria de agradecer ao Prof. Dr. Álvaro Vannucci, pela paciência, pelo apoio e pelas sugestões na redação deste trabalho; ao Prof. Dr. André K. T. Assis, da Unicamp, por ter indicado a força de Lorentz como um interessante tema de pesquisa e pelo fornecimento de dois relevantes artigos sobre as primeiras pesquisas teóricas relacionadas ao movimento de partículas carregadas em regiões caracterizadas por campos magnéticos; ao colega Rone Peterson de Andrade, por nossas conversas sobre os aspectos mais fundamentais da Física; e às secretárias Lia e Inês, pelo auxílio constante.

Também agradeço aos meus familiares, a todos aqueles que de alguma maneira contribuíram para este trabalho e não foram mencionados, e ao $\mathbf{C N P q}$, pela ajuda financeira. 



\section{RESUMO}

Este trabalho aponta os caminhos distintos que foram utilizados historicamente para a obtenção da expressão hoje denominada força de Lorentz e analisa os conceitos de força propostos por Newton e Mach e os vários significados já propostos para campo. Além disso, realiza uma comparação entre as teorias de Lorentz e Einstein sobre o Eletromagnetismo, descreve um modelo de éter do início do século XX que parece não ter sido ainda refutado, e faz um esboço das concepções de alguns renomados físicos sobre o éter. Como conclusões gerais, constatamos que por vezes os fundamentos da Dinâmica e do Eletromagnetismo não são exatamente apresentados de uma perspectiva histórica nos livros

didáticos, que ocorrem alguns equívocos históricos nestes livros, e que a hipótese de existência de um éter merece maiores estudos.

Palavras-chave: Dissertações. Conceito de força. Leis de Newton. Força de Lorentz. Conceito de campo. Livros didáticos. Éter. 



\begin{abstract}
In this work the Lorentz's force historical backgrounds was investigated. Moreover, the concepts of force as proposed by Newton and Mach were analyzed, and the several already proposed meanings for field were also compared. A comparison between the theories of Lorentz and Einstein on the foundations of Electromagnetism was also carried out. A model of ether proposed in the beginning of the century XX was discussed and it seems it has not been refuted so far. Outlines of the conceptions of famous physicists on ether had been supplied. As general conclusions we observe that sometimes the bases of the Dynamic and the Electromagnetism in nowadays text books do not seem to be exactly presented from a historical perspective, that some historical mistakes are found within these books, and that the hypothesis about the existence of some kind of ether deserves more studies.
\end{abstract}

Key words: Dissertations. Concept of force. Newton's laws. Lorentz's force. Concept of field. Text books. Ether. 



\section{SUMÁRIO}

INTRODUÇÃ̃

1 - APONTAMENTOS SOBRE FORÇA .................................................................... 3

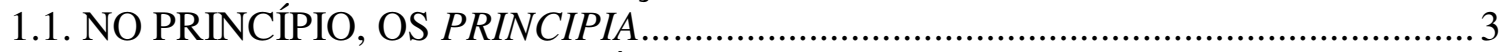

1.2 OS FUNDAMENTOS DA DINÂMICA SEGUNDO MACH....................................... 16

2 - HISTÓRIA DA FORÇA DE LORENTZ ..............................................................19

2.1 "A DYNAMICAL THEORY OF THE ELECTROMAGNETIC FIELD",

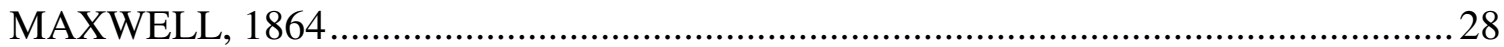

2.2 OS TRABALHOS DE J. J. THOMSON E HEAVISIDE ……………...........................

2.3 A DEDUÇÃO DE HENDRIK LORENTZ ……………........................................ 35

2.4 O PRINCÍPIO DA MÍNIMA AÇÃO (ABORDAGEM DE JOSEPH LARMOR E

KARL SCHWARZSCHILD) ............................................................................... 41

3 - CAMPO: DEFINIÇÕES MÚLTIPLAS E TRATAMENTO NOS LIVROS

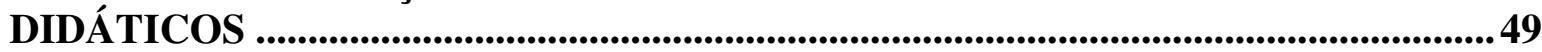

3.1 UMA QUESTÃO LINGÜÍSTICA: AS NOÇÕES DE CAMPO ONTEM E HOJE.. 49

3.2 IMPRECISÕES, INCOERÊNCIAS E DISTORÇÕES HISTÓRICAS EM ARTIGOS

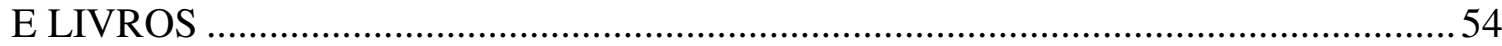

3.3 A RELAÇÃO ENTRE ENERGIA E CAMPO NOS LIVROS DIDÁTICOS ............66

4 - E PARA ALÉM DO FORMALISMO MATEMÁTICO? ...........................................69

4.1 LORENTZ E EINSTEIN: VISÕES DIFERENTES SOBRE OS FUNDAMENTOS

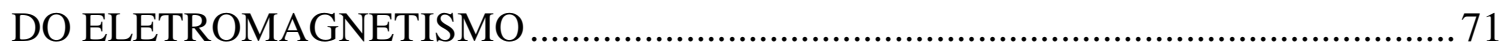

4.1.1 Os fundamentos do Eletromagnetismo segundo Lorentz ......................................71

4.1.2 Os fundamentos do Eletromagnetismo segundo Einstein ....................................76

4.1.3 Comparando as idéias de Lorentz e Einstein .......................................................... 80

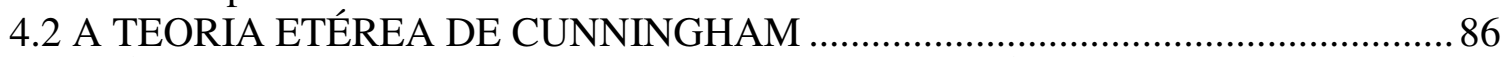

4.3 IDÉIAS DE LARMOR, LODGE E DIRAC SOBRE O ÉTER …………….............89

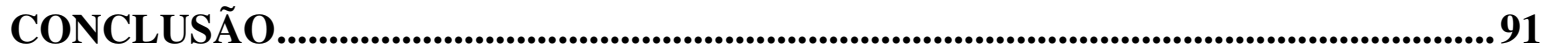

BIBLIOGRAFIA ..........................................................................................................................95 



\section{INTRODUÇÃO}

Nesta dissertação, procuramos, dentro do possível, compulsar os trabalhos originais sobre os temas em estudo e apresentar a evolução histórica das idéias envolvidas. Pensamos que os conceitos e as descobertas devem ser apresentados tais quais ocorreram, da maneira como foram, não como poderiam ter sido.

Tratamos inicialmente sobre a noção de força em Física, realizando apontamentos sobre os trabalhos de Newton e Mach e indicando falhas nas discussões sobre as leis de Newton nos livros didáticos utilizados nos dias de hoje. No segundo capítulo, discutimos sobre a força de Lorentz. Iniciamos este capítulo com o apontamento de duas impropriedades: a de que o campo vetorial $\mathbf{B}(\mathbf{r}, \mathrm{t})$ teria sido originalmente definido a partir da força de Lorentz, e a de que a parte magnética da força de Lorentz teria sido logo obtida da expressão para a força sobre um fio conduzindo corrente e sujeito a um $\mathbf{B}^{[1]}$ perpendicular a ele. Depois, apresentamos as maneiras utilizadas para a obtenção da força de Lorentz $(\mathbf{F}=q \mathbf{E}+q \mathbf{v} \times \mathbf{B})$, analisando conjuntamente a questão dos referenciais aos quais se referem $\mathbf{v}, \mathbf{E}$ e $\mathbf{B}$.

A terceira parte de nosso trabalho consistiu em mostrar a multiplicidade de significados atribuídos à palavra campo em livros e artigos de Física, bem como no apontamento das incoerências conceituais e distorções históricas que permeiam os livros didáticos relacionados aos fundamentos da Eletrodinâmica Clássica. Entendemos que um especial cuidado para a construção de um todo coerente deveria ser ponto comum entre todas as ciências, a Física inclusa. Porém, no que diz respeito aos fundamentos da Mecânica Clássica e da Eletrodinâmica Clássica apresentados nos livros didáticos, esta coerência almejada não chega a lograr pleno êxito, segundo nosso ponto de vista. $\mathrm{Na}$ Eletrodinâmica Clássica, notamos, por exemplo, distorções históricas quanto à definição de campo magnético, problemas em certas "deduções" da força de Lorentz, e utilização do conceito de campo de forma que não nos parece muito adequada. Estas questões, que a princípio podem parecer restritas aos livros didáticos, acabam transcendendo, direta ou

\footnotetext{
${ }^{1}$ Por economia, utilizaremos freqüentemente os símbolos $\mathbf{E}$ e $\mathbf{B}$ para representar os campos vetoriais $\mathbf{E}(\mathbf{r}, \mathrm{t})$ e $\mathbf{B}(\mathbf{r}, \mathrm{t})$.
} 
indiretamente, o universo do ensino/aprendizado, refletindo-se genericamente em artigos sobre Epistemologia e Física Teórica.

Por fim, levantamos questionamentos sobre a realidade por detrás de $\mathbf{E}$ e B. Estas funções vetoriais são simples ferramentas matemáticas, "subprodutos" de um meio (éter) ou "facetas representativas" de um novo ente físico?

Desejamos que esta dissertação possa contribuir para que haja maior rigor conceitual e maior clareza quando se for abordar os aludidos assuntos em livros, artigos ou salas de aula. Os grifos nas citações são meus, e as referências são apresentadas entre colchetes, em geral na forma autor / número da página do trabalho original em que o trecho (ou a idéia nele contida) se encontra, sendo que maiores informações sobre o trabalho original são fornecidas na Bibliografia, procurando-se pelo nome do autor. 


\section{1 - APONTAMENTOS SOBRE FORÇA}

Como esta dissertação analisa, principalmente, a força de Lorentz, achamos apropriada uma discussão prévia a respeito do conceito de força utilizado em Física.

É de conhecimento geral, entre os físicos, a equação $\mathbf{F}=d(m \mathbf{v}) / d t=d \mathbf{p} / d t$, que explicita a relação entre a quantidade vetorial $\mathbf{F}$, comumente denominada força, e a variação temporal do momento linear de determinado corpo. Aparentemente ingênua, esta equação suscita, porém, vários questionamentos. Como medir $m$ ? A velocidade $\mathbf{v}$ é relativa a que referencial? A equação representa uma lei ou uma definição? Se for uma lei, como saber a priori que uma força está atuando sobre o corpo? Isto resolvido, seria possível saber de antemão a expressão matemática desta força?

Para tentarmos responder a estas perguntas, é sensato que, antes, analisemos o contexto original em que a idéia da equação $\mathbf{F}=d \mathbf{p} / d t$ apareceu.

\subsection{NO PRINCÍPIO, OS PRINCIPIA...}

Podemos dizer, sem exageros, que a obra de Isaac Newton (1642-1727) Philosophiae Naturalis Principia Mathematica, publicada em Londres em 1687, foi um divisor de águas para a Física. Realizando um tratamento matemático dos fenômenos mecânicos, Newton deixou à posteridade um tratado que foi a base de todo o desenvolvimento posterior da Física. Malgrado isto, temos a impressão que este livro continua um grande desconhecido para os físicos...

Faremos uma breve análise da parte inicial dos Principia, onde se estabelecem definições e são propostas leis de movimento. Para isto, nos baseamos na versão inglesa, Mathematical Principles of Natural Philosophy, traduzida do latim por Andrew Motte em 1729.

Antes de estabelecer seus "axiomas do movimento", Newton parte de oito definições, que foram seguidas de um scholium (comentário). A primeira definição nos diz: 


\section{DEFINITION I.}

The quantity of matter is the measure of the same, arising from its density and bulk conjunctly. [Newton : 9]

O papel de uma definição, em geral, é o de descrever os atributos essenciais do elemento a ser definido em termos de elementos de conhecimento mais popular, digamos assim, que estarão resumidamente implícitos sob a expressão definida. Conquanto a noção de densidade de matéria possa ser tomada como básica para corpos de mesma composição $o^{[2]}$, uma vez que podemos afirmá-los como possuidores de "algo" em comum (o que nos permitiria dizer que eles têm a mesma densidade), de forma genérica a noção de densidade de matéria necessita de um conhecimento anterior de quantidade de matéria. Isto faz com que a definição acima, de quantidade de matéria (conceito genericamente mais simples que o de densidade de matéria), não satisfaça a condição que enunciamos no início deste parágrafo, uma vez que utiliza a noção de densidade de matéria. Entretanto, poderíamos considerar o seguinte:

... If Newton's definition is not taken as an ignotum per ignotius, one has to conclude that for Newton the notion of density was primary and anterior to the concept of mass $^{[3]}$. This interpretation has been advocated by Rosenberger ${ }^{[4]}$ and also by Bloch ${ }^{[5]}$, who mentions in this connection Boyle's famous experiments on the compressibility of air in which Newton was undoubtedly familiar. [Jammer : 66]

Notemos que somente assumindo o conceito densidade de matéria como anterior ao conceito quantidade de matéria podemos evitar que a definição I de Newton seja mera tautologia. Mas não parece ser aceitável este procedimento. A "circularidade" do conceito de massa (quantidade de matéria) é notável nos Principia. No corolário 4 da proposição VI do livro III ("The System of the World") dos Principia, Newton nos diz:

... By bodies of the same density I mean those whose vires inertix are in the proportion of their bulks. [Newton : 333]

\footnotetext{
${ }^{2}$ Mas ainda assim haveria o problema de se reconhecer quando corpos teriam a mesma composição.

${ }^{3}$ Neste ponto Jammer inseriu um indicador de uma nota de rodapé que não transcreveremos.

${ }^{4}$ Aqui, o mesmo autor inseriu um indicador de uma nota de rodapé que informava: "Ferdinand Rosenberger, Isaac Newton und seine physikalischen Principien (Leipzig, 1895), part 3, pp. 173, 192".

${ }^{5}$ Neste ponto constava um indicador de uma nota de rodapé que trazia a seguinte informação: "Leon Bloch, La philosophie de Newton (Paris, 1908), p.140".
} 
Mas o que significa vires inertice? Para descobrirmos isto precisamos recorrer à definição III dada por Newton e sua explicação sucessiva:

\section{DEFINITION III.}

The vis insita, or innate force of matter, is a power of resisting, by which every body, as much as in it lies, endeavours to persevere in its present state, whether it be of rest, or of moving uniformly forward in a right line.

This force is ever proportional to the body whose force it is; and differs nothing from the inactivity of the mass, but in our manner of conceiving it. A body, from the inactivity of matter, is not without difficulty put out of its state of rest or motion. Upon which account, this vis insita may, by a most significant name, be called vis inertiæ, or force of inactivity. (...) [Newton : 9-10]

Mas, como body, neste contexto, é apenas um outro nome para mass ou quantity of matter, conforme trecho da explicação da definição I ("It is this quantity [quantity of matter] that I mean hereafter everywhere under the name of body or mass"), acabamos por mostrar a formação de um círculo:

- Quantidade de matéria $\equiv$ densidade de matéria $\times$ volume (Def. I). Mas precisamos ainda saber como medir densidade de matéria... O único ponto nos Principia que faz menção a isto diz:

- Densidade de matéria $\approx$ vis inertiæ/volume (Cor. 4 da Prop. VI do Livro III). Mas como medir vis inertia? Do comentário à definição desta expressão consta que:

- Vis inertiæ $\approx$ quantidade de matéria (Comentário à Def. III)...

Em resumo: a definição I nada define.

Alguns autores propõem uma alternativa para o estabelecimento de medidas da grandeza massa que, na nossa opinião, é tão problemática quanto a definição de Newton. Discutiremos isso mais adiante.

Abaixo transcrevemos as outras definições de Newton e o comentário de duas delas. Tais apontamentos servirão de base para análises posteriores. 
The quantity of motion is the measure of the same, arising from the velocity and quantity of matter conjunctly. (Def. II)

An impressed force is an action exerted upon a body, in order to change its state, either of rest, or of moving uniformly forward in a right line. (Def. IV)

This force consists in the action only; and remains no longer in the body when the action is over. For a body maintains every new state it acquires by its vis inertiæ only. Impressed forces are of different origins, as from percussion, from pressure, from centripetal force. (Comentário à Def. IV)

A centripetal force is that by which bodies are drawn or impelled, or any way tend, towards a point as a centre. (Def. V)

Of this sort is gravity, by which bodies tend to the centre of the earth; magnetism, by which iron tends to the load-stone; and that force, whatever it is, by which the planets are perpetually drawn aside from the rectilinear motions, which otherwise they would pursue, and made to revolve in curvilinear orbits. (...) (Comentário à Def. V)

The absolute quantity of a centripetal force is the measure of the same proportional to the efficacy of the cause that propagates it from the centre, through the spaces round about. (Def. VI)

The accelerative quantity of a centripetal force is the measure of the same proportional to the velocity which it generates in a given time. (Def. VII)

The motive quantity of a centripetal force is the measure of it proportional to the motion which it generates in a given time. (Def. VIII)

Notemos que, uma vez que a definição II está baseada no conceito de quantidade de matéria e a definição VIII está baseada na definição II, ambas não ficam claras, uma vez que a "definição” I, de quantidade de matéria, nada define, como já mostramos.

Às definições VI-VIII, Newton acrescenta o seguinte:

These quantities of forces, we may, for brevity's sake, call by the names of motive, accelerative, and absolute forces; and, for distinction's sake, consider them, with respect to the bodies that tend to the centre; to the places of those bodies; and to the centre of force towards which they tend (...) [Newton : 12] 
É interessante observar que a palavra força é utilizada de maneira bastante genérica nos Principia. Por exemplo, Newton utiliza a expressão força inata da matéria como um sinônimo de vis insita, que seria um "poder de resistência" responsável pela preservação do estado de repouso ou de movimento retilíneo uniforme dos corpos. A palavra força aparece também na designação da ação exercida sobre um corpo capaz de retirá-lo do estado de repouso ou movimento retilíneo uniforme (força impressa). Além disso, no caso da expressão força centrípeta, que Newton define como "a força (mais uma vez aqui observamos o caráter genérico deste termo) pela qual os corpos são atraídos, ou impelidos, ou de algum modo tendem em direção a um ponto central", são diferenciadas três quantidades a ela associadas: a quantidade absoluta, a quantidade acelerativa e a quantidade motiva, às quais, por economia, Newton denomina força absoluta, força acelerativa e força motiva. $\mathrm{O}$ vetor $\mathbf{F}$ que mencionamos no início deste capítulo corresponde ao que o físico inglês designa por força motiva.

No scholium que segue às definições, o autor dos Principia utiliza também a palavra força para designar o "esforço" de corpos em movimentos circulares (absolutos) para recuarem do eixo de movimento. Como vemos, a noção de força nos Principia é bastante dependente do contexto.

Ainda no mesmo scholium, Newton deixa claro que o movimento referido em algumas de suas definições deveria ser entendido em sentido absoluto, ou seja, movimento de um lugar absoluto a outro. Por lugar absoluto deveríamos entender a parte do espaço absoluto que o corpo ocupa. O espaço absoluto, por sua vez, "in its own nature, without regard to anything external, remains always similar and immovable". Assim, o movimento mencionado nas definições não poderia ser estabelecido diretamente por nossos sentidos. Tentativas para resolver este problema foram levadas a cabo pelo próprio Newton, mas são questionáveis.

Percebendo o caráter não-empírico do movimento absoluto, o físico inglês passa então a nos fornecer meios para podermos diferenciar o que é relativo do que é absoluto, no que diz respeito ao movimento. Segundo ele, o movimento (ou o repouso) absoluto poderia ser distinguido do relativo por suas propriedades, causas e efeitos. Como propriedades do repouso e do movimento absolutos cita que eles não podem ser observados tomando-se como referenciais corpos próximos à Terra. Como causa distintiva de movimento relativo e 
absoluto cita a presença de forças impressas: o movimento absoluto seria sempre gerado por estas forças, enquanto que o relativo poderia ser gerado e alterado sem qualquer força impressa. Como efeito distintivo entre movimento relativo e absoluto, Newton faz menção à tendência dos corpos de se afastarem do eixo de movimentos circulares absolutos; não existiriam estas "tendências" em movimentos circulares relativos. Neste último caso, o físico inglês exemplifica com seu experimento do balde, que agora descreveremos sucintamente. Um balde com água posto para girar não transmite, inicialmente, seu movimento à água: neste caso, temos apenas um movimento circular relativo da água, em relação ao balde. Depois de algum tempo, o movimento do balde é transmitido à água, quando então a superfície da mesma torna-se côncava: este efeito (concavidade), segundo Newton, seria próprio de movimentos circulares absolutos.
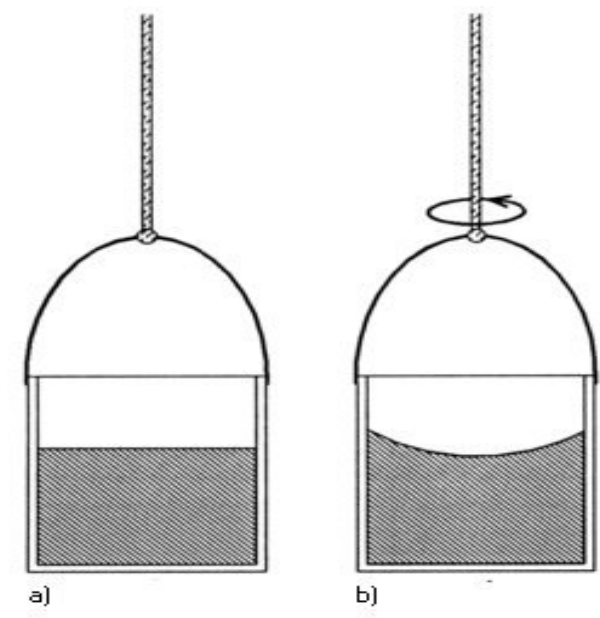

Fig. 1 - “Baldes de Newton”. a) O balde com água antes de ser posto para girar; b) $O$ balde com água depois de algum tempo girando.

Quanto à causa distintiva de movimento relativo e absoluto, vale afirmar que, dizendo que forças impressas servem como elementos distintivos entre movimentos absolutos e relativos, Newton contradiz sua definição IV, onde define força impressa como a ação exercida sobre um corpo para mudar seu estado de repouso ou de movimento retilíneo uniforme, o estado de movimento sendo caracterizado com relação ao "espaço absoluto". Assim sendo, temos duas alternativas:

1 - Considerar que o erro ocorreu no scholium das definições, ou seja, forças impressas não poderiam ser consideradas como elementos distintivos entre movimentos absolutos e relativos; 
2 - Considerar que o problema se encontra no comentário da definição IV, sendo percussões, pressões e forças centrípetas alguns exemplos de forças impressas (não causas, como dito na explicação da definição IV). Neste caso, a condição de existência de forças impressas não estaria restrita à definição IV, mas independeria de análises de movimento. Assim, poderíamos realmente considerar as forças impressas como elementos distintivos entre movimentos absolutos e relativos. Por hipótese, a existência de forças impressas seria condição necessária e suficiente para que o movimento gerado pudesse ser caracterizado como absoluto.

Quanto aos efeitos distintivos de movimento absoluto de relativo, como aquele relacionado ao experimento do balde (concavidade da superfície da água após algum tempo de giro do balde), é plenamente cabível as críticas feitas por Ernst Mach (1838-1916):

(...) When quite modern authors let themselves be led astray by the Newtonian arguments which are derived from the bucket of water, to distinguish between relative and absolute motion, they do not reflect that the system of the world is only given once to us, and the Ptolemaic or Copernician view is our interpretation, but both are equally actual. Try to fix Newton's bucket and rotate the heaven of fixed stars and then prove the absence of centrifugal forces. [Mach : 280]

Que prossegue, argumentando que afirmações relacionadas a espaço e movimento absolutos são apenas construções mentais, não podendo ser verificadas empiricamente:

It is scarcely necessary to remark that in the reflections here presented Newton has again acted contrary to his expressed intention only to investigate actual facts. No one is competent to predicate things about absolute space and absolute motion; they are pure things of thought, pure mental constructs, that cannot be produced in experience. All our principles of mechanics are, as we have shown in detail, experimental knowledge concerning the relative positions and motions of bodies. Even in the provinces in which they are now recognized as valid, they could not, and were not, admitted without previously being subjected to experimental tests. No one is warranted in extending these principles beyond the boundaries of experience. In fact, such an extension is meaningless, as no one possesses the requisite knowledge to make use of it. [Mach : 280]

\section{Concluindo:}

(...) Newton's experiment with the rotating vessel of water simply informs us that the relative rotation of the water with respect to the sides of the vessel produces no noticeable 
centrifugal foces, but that such forces are produced by its relative rotation with respect to the mass of the earth and the other celestial bodies. No one is competent to say how the experiment would turn out if the sides of the vessel increased in thickness and mass till they were ultimately several leagues thick. The one experiment only lies before us, and our business is to bring it into accord with the other facts known to us, and not with arbitrary fictions of our imagination. [Mach : 284-85]

Continuemos com os Principia. Após "Definitions", segue "Axioms, or Laws of Movement", onde Newton estabelece suas leis. Façamos uma breve análise das duas primeiras leis.

Every body perseveres in its state of rest, or of uniform motion in a right line, unless it is compelled to change that state by forces impressed thereon. (Lei I)

Esta "lei" é uma tautologia da definição IV e sua explicação seguinte, que nos informam que força impressa é uma ação exercida para mudar o estado de repouso ou de movimento retilíneo uniforme de um corpo qualquer e que mudanças destes estados somente ocorrem se existirem forças impressas. Assim, não estamos de pleno acordo com a visão esboçada por H. Moysés Nussenzveig em seu Curso de Física Básica, vol 1 Mecânica:

$A 1^{\mathrm{a}}$ Lei é a Lei da Inércia:

"Todo corpo persiste em seu estado de repouso, ou de movimento retilíneo uniforme, a menos que seja compelido a modificar esse estado pela ação de forças impressas sobre ele".

Que significa realmente esta lei? Como podemos saber que não existem "forças impressas sobre o corpo"? Pelo fato de que permanece em repouso ou em movimento retilíneo uniforme? Se ${ }^{[6]}$ assim fosse, Eddington teria tido razão quando criticou o enunciado da $1^{a}$ lei, dizendo ser equivalente a "... persiste ... exceto quando não persiste" (o que corresponderia à bem conhecida predição meteorológica: "Tempo bom, salvo se chover"). Esta crítica é injusta. [Nussenzveig ${ }^{(a)}: 69$ ]

A crítica de Arthur Eddington (1882-1944), a nosso ver, não parece injusta. A lei I é realmente tautológica, uma vez que já está inclusa na definição IV e sua explicação subseqüente. $\mathrm{O}$ fato de Nussenzveig não mencionar as definições que antecedem às ditas leis, como faz, igualmente, a absoluta maioria dos autores de livros didáticos modernos de

\footnotetext{
${ }^{6}$ Neste ponto, talvez por um erro tipográfico, apareceu $\underline{s} e$.
} 
Mecânica, dificulta que muitos leitores verifiquem a pertinência da referida crítica. Ele somente conseguiu contornar o fato de que a lei I é puramente tautológica porque apresentou os fundamentos da Dinâmica com algumas adaptações. Por exemplo, diferentemente de Newton, Nussenzveig parte de uma noção intuitiva de força ${ }^{[7]}$. E a medida da intensidade desta grandeza seria estabelecida a partir da distensão de molas tendo uma das extremidades rigidamente fixa ${ }^{[8]}$ : para uma distensão correspondente a um certo comprimento $x$, por exemplo, a força exercida sobre o corpo preso à extremidade livre da mola teria intensidade $k x$, este $k$ sendo uma constante de proporcionalidade relacionada à constituição da mola. A partir disso, Nussenzveig afirma que pode ser verificado que forças que atuam à distância, como as forças gravitacionais, por exemplo, decrescem muito rapidamente com a distância. Deste modo, ele argumenta que a existência ou não de forças atuando sobre determinado corpo poderia ser determinada independentemente de considerações sobre movimentos.

Vejamos agora o axioma II:

The alteration of motion is ever proportional to the motive force impressed; and is made in the direction of the right line in which that force is impressed. (Lei II)

Esta "lei” diz o mesmo que a definição VIII, só que com relação a forças genéricas (o que, sem embargo algum, poderia ter sido feito na própria definição VIII), não sendo portanto uma lei. Assim, não nos parece que a posição assumida por Nussenzveig em seu Curso de Física Básica, vol 1 - Mecânica quanto a este ponto seja a mais adequada. Ele diz:

\footnotetext{
7 A idéia inicial sobre força estaria então relacionada com "empurrões", com esforços musculares, e a primeira lei do movimento teria como único papel indicar os referenciais adequados para a validade das outras duas leis. Esta concepção é adotada por outros livros didáticos (veja Resnick, Halliday \& Walker : 81), mas traz consigo um problema: restringe a aplicação do primeiro axioma do movimento a objetos da crosta terrestre, a entes passíveis de serem considerados "empurrados" ou não. Assim, o conceito inicial de força não se aplicaria a planetas e estrelas, por exemplo, uma vez que não há como saber se eles estão sendo "empurrados" ou não.

${ }^{8}$ Deve ser observado que este método fundamenta-se em um laboratório terrestre.
} 
Muitas vezes se diz que a $2^{a}$ lei não passa de uma definição de força. Se assim fosse, ela seria desprovida de conteúdo físico, e não poderíamos questionar sua validade: no máximo, se poderia argumentar se é ou não uma definição conveniente.

Se $\boldsymbol{F}$ fosse dado apenas pela (4.3.3) [ $\mathbf{F}=$ ma], ela seria realmente uma definição de força. Entretanto, isto não é verdade: as forças que atuam sobre uma partícula resultam de sua interação com outras partículas, e veremos que são dadas por leis de forças, que definem $\boldsymbol{F}$ em termos da situação em que a partícula se encontra. Exemplos disso são a lei da gravitação universal e as leis que dão as forças elétricas e magnéticas que atuam sobre uma partícula carregada. (...) [Nussenzveig $\left.{ }^{(a)}: 72\right]$

Em primeiro lugar, seria interessante que o autor tivesse explicado melhor o que denomina conteúdo físico. Se definições são sempre desprovidas de conteúdo físico, como diz, aquilo que chamamos velocidade, pelo simples fato de ser definição, não teria conteúdo físico algum... Depois, a 2a "lei" nos Principia é mesmo apenas uma definição de força, e ainda assim problemática, pois leva em conta o elemento massa, cuja "definição" na obra de Newton parece-nos que ficou a desejar. Por fim, Nussenzveig se equivoca ao transmitir a idéia de que as leis de força conhecidas foram obtidas independentemente da equação $\mathbf{F}=$ ma: a própria lei da gravitação universal, citada pelo autor, constitui uma exceção a esta regra. Ao contrário do que Nussenzveig e outros autores ${ }^{[9]}$ afirmam, esta lei levou em conta o $2^{\circ}$ axioma do movimento para ser obtida. Foi utilizando dados experimentais ${ }^{[10]} e$ proposições decorrentes do $2^{\circ}$ axioma que Newton chegou à conclusão de que a força que mantém as luas de Júpiter girando ao redor do mesmo, os planetas girando ao redor do Sol e a Lua girando ao redor da Terra é proporcional à razão inversa do quadrado da distância que os une ao centro, respectivamente, de Júpiter, do Sol e da Terra ${ }^{[11]}$, generalizando depois este resultado para todos os corpos do universo. E foi também utilizando dados experimentais (obtidos por ele mesmo) e, novamente, a $2^{\mathrm{a}}$ lei do movimento que o físico inglês, através de uma generalização, chegou à conclusão que a força gravitacional entre dois corpos quaisquer do universo seria proporcional à quantidade de matéria de cada um deles ${ }^{[12]}$. Ou seja, a lei da gravitação universal tem como uma das bases justamente o $2^{\circ}$ axioma do movimento.

\footnotetext{
${ }^{9}$ Veja Resnick \& Halliday : 40.

${ }^{10}$ Dentre os quais as leis de Kepler (veja Phænomenon IV em "Phænomena or Appearances", seção do Livro III dos Principia).

${ }^{11}$ Veja os três primeiros teoremas do Livro III dos Principia.

${ }^{12}$ Veja o teorema VI do Livro III, acima citado.
} 
É importante observar que Nussenzveig não faz uso da "definição" de massa estabelecida nos Principia. Ele propõe a seguinte argumentação para estabelecer uma idéia inicial sobre essa grandeza: com uma força definida por determinada distensão de uma mola, um corpo adquire determinada aceleração em relação ao laboratório (esta aceleração poderia ser observada pelo comportamento da velocidade do corpo); colocando-se outra mola em paralelo com a primeira, e distendendo-se ambas da mesma quantidade anterior, o corpo adquire o dobro da aceleração; por fim, voltando-se ao caso com apenas uma mola, mas unindo-se ao corpo utilizado outro de mesmo material e volume, o novo objeto adquire metade da aceleração obtida pelo corpo do primeiro experimento. Com isso, sendo $m$ o coeficiente de proporcionalidade ("inércia") entre a força $\mathbf{F}$ e a aceleração adquirida $\mathbf{a}, \mathbf{o}$ autor conclui que a "inércia" de dois objetos idênticos formando um objeto único é o dobro da de um deles. $O$ "coeficiente de inércia” $\mathrm{m}$ mede portanto, nesse sentido, a "quantidade de matéria" do objeto [Nussenzveig $\left.{ }^{(a)}: 70\right]$.

Notemos, primeiramente, que este "coeficiente de inércia" foi definido tomando-se um laboratório terrestre como referencial. Além disso, o padrão de medida para esta quantidade estaria intrinsecamente ligado ao material que constitui o objeto sob análise: teríamos um padrão para corpos de chumbo, outro para corpos de ferro, e assim por diante, ou seja, uma infinidade de padrões para esta medida. Deste modo, o máximo que se poderia deduzir da experiência é que $\mathbf{F} \sim q_{i} \boldsymbol{a}$, sendo $q_{i}$ a "quantidade de matéria" do corpo estudado (medida com referência ao padrão do material). Assim, não poderíamos, por exemplo, comparar a "quantidade de matéria" de determinado corpo com a de um corpo de outro material, visto que a relação proporcional obtida é válida apenas para corpos de um mesmo material. Por outro lado, aceitando $\mathbf{F}=m a$ sem o estabelecimento de critérios comparativos para $m$ independentes de força e aceleração, estaríamos definindo $m$ em termos das grandezas mencionadas. O próprio Nussenzveig reconhece este fato [Nussenzveig ${ }^{(a)}: 71$, mas acrescenta o seguinte:

Vimos que a $2^{a}$ lei permite estabelecer uma escala de massas inerciais, e neste sentido ela pode ser considerada como permitindo definir o conceito de massa inercial, mas não é tão pouco apenas uma definição deste conceito. De fato, a idéia implícita na $2^{a}$ lei é que a massa inercial $\mathrm{m}$ é uma característica da partícula; uma vez determinada quando atua sobre a partícula uma força conhecida, devemos empregar o mesmo valor de $\mathrm{m}$ para descrever o movimento da partícula sob a ação de quaisquer outras forças. (...) [Nussenzveig ${ }^{(a)}$ : 72] 
Mas, se o autor admite que, segundo sua maneira de apresentar os fundamentos da Dinâmica, temos uma definição explícita e uma lei implícita na $2^{\text {a }}$ "lei" do movimento, acreditamos que melhor seria se ele a tivesse apresentado da maneira que segue, onde os dois aspectos envolvidos ficam bem ressaltados:

Definição - Para determinada força $\boldsymbol{F}$ atuando sobre uma partícula, podemos definir uma grandeza $\mathrm{m} \equiv|\boldsymbol{F}| /|\boldsymbol{a}|$, onde a é a aceleração da partícula em relação ao laboratório.

Lei - A grandeza m é uma característica da partícula e independe da natureza da força aplicada.

Mach procedeu dessa forma quando apresentou seus princípios da Dinâmica, procurando deixar bem claro o que seria definição e o que seria lei da natureza. Conquanto tenha definido massa de forma distinta da que apresentamos, este físico também mencionara a lei que apontamos (conforme veremos na próxima seção).

Para finalizar esta breve discussão sobre as "leis" I e II dos Principia, deixamos esta sensata consideração de Mach:

(...) We readily perceive that Laws I and II are contained in the definitions of force that precede. According to latter, without force there is no acceleration, consequently only rest or uniform motion in a straight line. Furthermore, it is wholly unnecessary tautology, after having established acceleration as the measure of force, to say again that change of motion is proportional to the force. [Mach : 302]

Trataremos agora da problemática relacionada ao espaço absoluto. No comentário ao corolário V (um dos corolários que seguem às três leis do movimento) e no scholium às leis, Newton vai de encontro à sua afirmativa de que o movimento a que ele se referira não poderia ser estabelecido por nossos sentidos (vide scholium das definições). Vejamos:

For the differences of the motions tending towards the same parts, and the sums of those that tend towards contrary parts, are, at first (by supposition), in both cases the same; and it is from those sums and differences that the collisions and impulses do arise with which the bodies mutually impinge one upon another. Wherefore (by Law II), the 
effects of those collisions will be equal in both cases; and therefore the mutual motions of the bodies among themselves in the one case will remain equal to the mutual motions of the bodies among themselves in the other. A clear proof of which we have from the experiment of a ship; where all motions happen after the same manner, whether the ship is at rest, or is carried uniformly forwards in a right line. (Comentário ao corolário V)

Aqui, Newton trata de repouso e movimento observáveis em pé de igualdade com repouso e movimento absolutos. Referindo-se a experimentos realizados em navios, diz que pode ser observado que os movimentos dos corpos envolvidos nestes experimentos acontecem da mesma forma se o navio está em repouso ou em movimento retilíneo uniforme. Fica claro do texto que o físico inglês estava considerando como referencial a Terra.

Depois, no scholium que segue às leis e corolários, Newton diz:

Hitherto I have laid down such principles as have been received by mathematicians, and are confirmed by abundance of experiment. By the first two Laws and the first two Corollaries, Galileo discovered that the descent of bodies observed the duplicate ratio of the time, and that the motion of projectiles was in the curve of a parabola; experience agreeing with both, unless so far as these motions are a little retarded by the resistance of the air. [Newton : 25]

Mais uma vez Newton faz referência a experimentos. E o referencial terrestre aparece novamente como adequado para a validade das leis estabelecidas. Ao dizer, por exemplo, que seus princípios são confirmados por inúmeros experimentos e que os resultados obtidos por Galileu ${ }^{[13]}$ para a composição dos movimentos resultavam das leis I e II e dos corolários I e II, Newton endossa o fato de que o referencial terrestre poderia ser considerado tão bom quanto o espaço absoluto para determinados fenômenos, pois os experimentos de Galileu mencionados foram todos realizados tomando-se a Terra como referencial.

No livro III dos Principia ("The System of the World"), quando passa a tratar do movimento dos corpos celestes, vemos Newton adotar o referencial das estrelas fixas como equivalente ao espaço absoluto.

\footnotetext{
${ }^{13}$ Galileu Galilei (1564-1642), físico italiano.
} 
Observamos, deste modo, que a Terra (para o caso dos corpos terrestres) e as estrelas fixas (para o caso da Terra e de outros corpos celestes), afora equivalentes em movimento retilíneo uniforme, foram os únicos sistemas de referência para os quais Newton considerou suas leis válidas em termos práticos. Assim, com Mach:

We see that the reduction to absolute space was by no means necessary, for the system of reference is just as relatively determined as in every other case. In spite of his metaphysical liking for the absolute, Newton was correctly led by the tact of the natural investigator. [Mach : 286]

E vale acrescentar:

Newton's sense of what fundamental concepts and principles were required in mechanics was admirable. The form of his enunciations, however, leaves much to be desired. [Mach : 246]

We join with the eminent physicist Thomson (Lord Kelvin) in our reverence and admiration of Newton. But we can only comprehend with difficulty his opinion that the Newtonian doctrines still remain the best and most philosophical foundation that can be given. [Mach : 306]

\subsection{OS FUNDAMENTOS DA DINÂMICA SEGUNDO MACH}

Ernst Mach, em 1867, propôs uma nova abordagem dos fundamentos da Dinâmica:

a. Experimental Proposition. Bodies set opposite each other induce in each other, under certain circumstances to be specified by experimental physics, contrary accelerations in the direction of their line of junction. (The principle of inertia is included in this.)

b. Definition. The mass-ratio of any two bodies is the negative inverse ratio of the mutually induced accelerations of those bodies.

c. Experimental Proposition. The mass-ratios of bodies are independent of the character of the physical states (of the bodies) that condition the mutual accelerations produced (...)

d. Experimental Proposition. The accelerations which any number of bodies induce in a body $\mathrm{K}$ are independent of each other. (The principle of the parallelogram of forces follows immediately from this.)

e. Definition. Moving force is the product of the mass-value of a body into the acceleration induced in that body. [Mach : 304] 
Uma questão que nos vem à mente ao analisarmos estes fundamentos está relacionada à questão dos referenciais. No trecho do livro em que Mach exibiu as proposições experimentais e as definições acima transcritas, não foram feitas menções relativas a referenciais. Porém, nós encontramo-las páginas antes no mesmo livro:

The comportment of terrestrial bodies with respect to the earth is reducible to the comportment of the earth with respect to the remote heavenly bodies. If we were to assert that the knew more of moving objects than this their last-mentioned, experimentally-given comportment with respect to the celestial bodies, we should render ourselves culpable of a falsity. [Mach : 286]

Assim, as leis acima, no caso de experimentos na crosta terrestre, são válidas tomando-se como referencial a Terra, e no caso de observações do comportamento da Terra e de outros corpos celestes, permanecem válidas adotando-se as estrelas fixas como referencial.

Em 1937, o matemático inglês C.G. Pendse publicou um artigo na Philosophical Magazine em que colocava em xeque a definição de massa proposta por Mach $^{[14]}$. Outros artigos do mesmo autor se seguiram na mesma revista, inclusive contendo também análises de problemas relacionados ao conceito de força no contexto de $\mathrm{Mach}^{[15]}$.

Posteriormente, apareceram outras revisões dos trabalhos de Mach e algumas propostas de axiomatização dos fundamentos da Mecânica Clássica. Podemos citar, por exemplo, dois trabalhos de H.A. Simon ${ }^{[16]}$ e um artigo de J.C.C. McKinsey, A.C. Sugar e P. Suppes ${ }^{[17]}$. Estes artigos mostram claramente as dificuldades de se estabelecer em bases lógicas rigorosas os fundamentos da Mecânica Clássica.

\footnotetext{
14 "A Note on the Definition and Determination of Mass in Newtonian Physics", Philosophical Magazine, 24: 1012-22, 1937.

15 "On Mass and Force in Newtonian Mechanics", Phil. Mag., 29: 477-84, 1940.

16 "The Axioms of Newtonian Mechanics", Philos. Mag. (series 7), 38: 888-905, 1946; “The Axiomatization of Physical Theories", Philosophy of Science, 37: 16-26, 1970.

17 "Axiomatic Foundations of Classical Particle Mechanics", Journal of Classical Mechanics and Analysis, 2 : 253-72, 1953.
} 


\section{2 - HISTÓRIA DA FORÇA DE LORENTZ}

Agora que já fizemos alguns apontamentos sobre força, podemos iniciar nossa apresentação histórica da chamada força de Lorentz. Antes, porém, apresentaremos algo sobre as origens dos campos vetoriais $\mathbf{E}$ e $\mathbf{H}$ e alguns equívocos em livros didáticos associados às origens dos campos mencionados e à obtenção da força de Lorentz.

O primeiro físico a fazer uso dos campos vetoriais que hoje denominamos campo elétrico $(\mathbf{E})$ e campo magnético $(\mathbf{H})^{[18]}$ parece ter sido o francês Siméon Denis Poisson (1781-1840), em 1812 e 1824, respectivamente, apesar de não ter utilizado a notação vetorial, ainda não corrente na época [Spencer : 1 ; Whittaker ${ }^{(a)}: 62-3$ ]. Uma vez que tanto $\mathbf{E}$ como $\mathbf{H}$ aparecem nos trabalhos de Maxwell ${ }^{[19]}$ e têm importância fundamental em seus estudos, podemos utilizar sua abalizada obra A Treatise on Electricity and Magnetism, originalmente publicada em 1873, como ponto de partida para a definição destes campos vetoriais. Vejamos como o físico escocês estabelece o que hoje denominamos campo elétrico (na nomenclatura de Maxwell, "intensidade elétrica”, "força elétrica" ou “intensidade eletromotiva”):

Definition. The resultant electric intensity at any point is the force which would be exerted on a small body charged with the unit of positive electricity, if it were placed there without disturbing the actual distribution of electricity. [Maxwell ${ }^{(\mathrm{b})}$ : 70 (art.68)]

Quanto ao que chamamos campo magnético (denominado "força magnética" por Maxwell), o físico escocês realizou o seguinte encadeamento de idéias:

(...) The unit-pole is a pole which points north, and is that, when placed at unit distance in air from another unit-pole, it repels it with unit force (...) A pole which points south is reckoned negative.

If $\mathrm{m}_{1}$ and $\mathrm{m}_{2}$ are the strengths of two magnetic poles, $\ell$ the distance between them, and $\mathrm{f}$ the force of repulsion, all expressed numerically, then $\mathrm{f}=\mathrm{m}_{1} \mathrm{~m}_{2} / \ell^{2}$. [Maxwell ${ }^{(\mathrm{c})}: 3$ (art.374)]

\footnotetext{
${ }^{18}$ Nos casos em que esta expressão é utilizada para denominar $\mathbf{H}(\mathrm{r}, \mathrm{t})$ o campo vetorial $\mathbf{B}(\mathrm{r}, \mathrm{t})$ é chamado indução magnética.

${ }^{19}$ James Clerk Maxwell (1831-1879), físico escocês.
} 
No trecho transcrito, Maxwell definiu um critério de medida para "pólo" magnético a partir da força magnética entre dois "pólos" magnéticos. Feito isto, passou a definir momento magnético, intensidade de magnetização e componentes de magnetização, como segue:

Magnetic Moment. The product of length of a uniformly and longitudinally magnetized bar magnet into the strength of its positive pole is called its Magnetic Moment.

Intensity of Magnetization. The intensity of magnetization of a magnetic particle is the ratio of its magnetic moment to its volume. We shall denote it by $\mathrm{I}$.

The magnetization at any point of a magnet may be defined by its intensity and its direction. Its direction may be defined by its direction-cosines $\lambda, \mu, \nu$.

Components of Magnetization. The magnetization at a point of a magnet (being a vector or directed quantity) may be expressed in terms of its three components referred to the axes of coordinates. Calling these $\mathrm{A}, \mathrm{B}, \mathrm{C}, \mathrm{A}=\mathrm{I} \lambda, \mathrm{B}=\mathrm{I} \mu, \mathrm{C}=\mathrm{I} \nu(\ldots)$ $\left[\right.$ Maxwell $^{(\mathrm{c})}: 8-9($ art.384)]

Por fim:

(...) If $1, \mathrm{~m}, \mathrm{n}$ denote the direction-cosines of the normal drawn outwards from the element of surface $\mathrm{dS},(. .$.$) now introduce two new symbols \sigma$ e $\rho$, defined by the equations $\sigma=l \mathrm{~A}+m \mathrm{~B}+n \mathrm{C}, \rho=-(d \mathrm{~A} / d \mathrm{x}+d \mathrm{~B} / d \mathrm{y}+d \mathrm{C} / d \mathrm{z})$, the expression for the potential may be written

$$
V=\iint \frac{\sigma}{r} d S+\iiint \frac{\rho}{r} d x d y d z .\left[\text { Maxwell }^{(\mathrm{c})}: 9-10\left(\operatorname{art}^{3} .385\right)\right]
$$

(...) The force exterted on a unit magnetic pole placed at any point outside the magnet is deduced from the potential by the same process of differentiation as in the corresponding electrical problem. If the components of this force ${ }^{[20]}$ are $\alpha, \beta, \gamma$,

$$
\alpha=-d V / d x, \quad \beta=-d V / d y, \quad \gamma=-d V / d z \text {. [Maxwell }{ }^{(\mathrm{c})}: 21 \text { (art.395)] }
$$

E assim ficou definida a "força magnética", que hoje denominamos campo magnético e denotamos comumente por $\mathbf{H}$.

Porém, importantes livros didáticos, a exemplo de Classical Electrodynamics, de J.D. Jackson, têm distorcido um pouco a realidade dos fatos. Nesta obra, o autor apresenta uma versão para a origem histórica de $\mathbf{B}$ na seção 1.1 ("Maxwell Equations in Vacuum, Fields, and Sources") e outra diferente na seção 5.1 ("Introduction and Definitions"): ambas não condizentes com a realidade. Na seção 1.1 diz que o campo magnético que aparece nas

\footnotetext{
${ }^{20}$ Denominada simplesmente magnetic force, conforme descrição do artigo no índice da obra ("Magnetic force defined with reference to the magnetic potential") e discussões posteriores na mesma.
} 
equações de Maxwell foi originalmente introduzido através da lei de força $\mathbf{F}=q(\mathbf{E}+\mathbf{v} \times \mathbf{B})$ [Jackson : 3]; e na seção 5.2 afirma que $\mathbf{B}$ foi definido através da equação $\mathbf{N}=\boldsymbol{\mu} \times \mathbf{B}$, sendo $\mathbf{N}$ o torque exercido sobre um dipolo magnético de momento magnético $\boldsymbol{\mu}$ [Jackson : 174]. Mas o campo B $(\mu \mathbf{H})$ das equações de Maxwell - como vimos pelas palavras do próprio Maxwell - foi originalmente definido sem quaisquer menções a partículas carregadas em movimento ou a dipolos magnéticos.

Em outros livros, como o volume 3 (Eletromagnetismo) da coleção Curso de Física Básica, de H. Moysés Nussenzveig, não fica clara a questão se B é ou não definido pela chamada "força de Lorentz". A primeira menção sobre B realizada no livro ocorre na seção 7.1. Do título da seção, Definição de $\boldsymbol{B}$, esperamos que se defina $\mathbf{B}$, obviamente. Mas vejamos o que diz o autor:

\subsection{Definição de $\mathrm{B}$}

Para definir $\boldsymbol{E}$, consideramos a força $\boldsymbol{F}=q \boldsymbol{E}$ que atua sobre uma carga puntiforme colocada num campo elétrico ${ }^{[21]}$. Já o campo magnético exerce forças sobre cargas em movimento $^{[22]}$. Verifica-se experimentalmente que a força é proporcional à carga e à magnitude da velocidade da partícula. Entretanto, a direção da força é perpendicular às direções da velocidade v e do campo magnético. [Nussenzveig ${ }^{(b)}$ : 128]

Se é verificado experimentalmente que a direção da força é perpendicular ao campo magnético, isto quer dizer que a existência ou não deste ente é estabelecida por outros meios, pois do contrário estaria havendo uma petição de princípio: na própria definição estaríamos utilizando o elemento a ser definido. Assim, o autor não se ateve ao título da seção, pois não houve definição alguma de B, que foi assumido implicitamente conhecido.

Às questões antes mencionadas, soma-se o fato de se afirmar, em alguns livros didáticos, que a expressão hoje denominada força de Lorentz foi logo obtida a partir de uma versão em termos de campo da expressão

$$
\mathrm{d} \mathbf{F}=k I \mathrm{~d} \mathbf{l} \times \oint I^{\prime} d \boldsymbol{l}^{\prime} \times \frac{\boldsymbol{r}}{r^{3}},
$$

\footnotetext{
${ }^{21}$ Aqui já observamos um problema, uma vez que, na definição de $\boldsymbol{E}$, a força $\boldsymbol{F}=q \boldsymbol{E}$ não é a força "que atua sobre uma carga puntiforme colocada num campo elétrico", mas a força que atua sobre uma carga puntiforme colocada na região onde estamos definindo o campo elétrico $\boldsymbol{E}$.

${ }_{22}$ Melhor teria sido dizer que o campo magnético é utilizado na representação de forças sobre cargas em movimento.
} 
que descreve a força sentida por um elemento de corrente $\operatorname{Id} l$ de um condutor metálico na presença de um outro condutor conduzindo uma corrente I', onde $k$ é uma constante de proporcionalidade, a integral é sobre o circuito caracterizado pelo elemento de corrente $I$ 'd $l^{\prime}$ e $\boldsymbol{r}$ é a distância entre $I^{\prime} \mathrm{d} \boldsymbol{l}^{\prime} \mathrm{e} I \mathrm{~d} \boldsymbol{l}{ }^{[23]}$. Isto não corresponde à realidade histórica. A força de Lorentz não foi obtida originalmente a partir da equação acima. $\mathrm{Na}$ verdade, foram necessários mais de 70(setenta) anos, a partir dos trabalhos de Ampère, para a consideração da força sobre um condutor conduzindo corrente em uma região de campo magnético perpendicular ao condutor como sendo a força sobre as partículas responsáveis pela corrente.

No sistema internacional de unidades (S.I.), a Eq. (1) é escrita na forma:

$$
\mathrm{d} \mathbf{F}=I \mathrm{~d} \boldsymbol{l} \times(\mu / 4 \pi) \oint I^{\prime} d \boldsymbol{l}^{\prime} \times \frac{\boldsymbol{r}}{r^{3}}
$$

onde $\mu$ é a permeabilidade do meio entre os fios.

Tendo em vista a definição de Maxwell de $\mathbf{H}$ (de forma simplificada, a razão entre a força sentida por um "pólo" magnético devida a fatores magnéticos e a intensidade do "pólo", tendo o ar como meio) e que a integral da fórmula (2) aplicada a um fio muito longo é, a menos de uma constante, justamente o resultado obtido em 1820 por Biot e Savart ${ }^{[24]}$ para a força sobre um "pólo" magnético unitário em decorrência da influência de correntes elétricas externas - ou seja, $\mathbf{H}$ - a fórmula anterior pode ser escrita como:

$$
\mathrm{d} \mathbf{F}=I \mathrm{~d} \boldsymbol{l} \times \mathbf{B},
$$

onde $\mathbf{B}=\mu \mathbf{H}$.

Mesmo muitos anos depois da morte de Ampère ainda não se sabia qual a natureza da corrente elétrica. Havia apenas especulações a respeito. Seria ela decorrente do movimento de fluidos imponderáveis ou do movimento de partículas de pequeníssima massa? E teríamos cargas de sinais opostos movimentando-se em sentidos opostos ou cargas de um mesmo sinal movimentando-se em um sentido único? Pairavam dúvidas... Vejamos um pouco desta curiosa história.

\footnotetext{
${ }^{23}$ Esta fórmula decorre da expressão proposta por André-Marie Ampère (1775-1836) na década de 20 do século XIX para a força entre dois elementos de corrente de fios metálicos, podendo também ser obtida da fórmula que Hermann Grassmann (1809-1877) propôs para o mesmo caso [Assis: 90-92]. Para Grassmann, a força entre dois elementos de corrente situados na mesma linha reta seria nula; para Ampère teria como direção a linha que os une [Maxwell ${ }^{(\mathrm{c})}$ : art. 526].

${ }^{24}$ Jean-Baptiste Biot (1774-1862) e Félix Savart (1791-1841), físicos franceses.
} 
Quando da morte de Ampère, em 1836, eram duas as teorias rivais para a natureza da corrente elétrica em metais, ambas baseadas na idéia de que a eletricidade seria algo imponderável: movimento do fluido elétrico, que seria único (de um único sinal), em um sentido determinado, ou movimento de "fluidos elétricos" de sinais opostos em sentidos opostos [Whittaker $\left.{ }^{(\text {a) }}: 58-59\right]$

Em 1845, uma outra teoria entrou em cena: o físico alemão Gustav Theodor Fechner (1801-1887) supôs que a existência de corrente elétrica seria decorrente do movimento em sentidos opostos de partículas ${ }^{[25]}$ eletrizadas de sinais contrários. Acrescentou, ainda, que cargas de mesmo sinal movendo-se no mesmo sentido ou cargas de sinais contrários movendo-se em sentidos contrários se atrairiam devido ao movimento. Além disso, a força entre fios metálicos conduzindo correntes teria sua origem justamente na ação, sobre o condutor, dos entes responsáveis pela corrente. Tais hipóteses foram adotadas por Wilhelm Weber (1804-90) em 1846, possibilitando-o encontrar uma expressão geral para a força entre duas cargas em movimento [Whittaker $\left.{ }^{(a)}: 201-202\right]$. A primeira suposição de Fechner não refletia exatamente a realidade, mas suas outras premissas se confirmaram posteriormente.

Ainda em 1873 existiam dúvidas sobre a natureza da corrente elétrica, como podemos observar do Treatise de Maxwell:

(...) all that we assume here is that the electric current involves motion of some kind (...) $\left[\right.$ Maxwell $\left.{ }^{(\mathrm{c})}: 212(\operatorname{art} .569)\right]$

(...) while we derive great advantage from the recognition of the many analogies between the electric current and a current of material fluid, we must carefully avoid making any assumption not warranted by experimental evidence, and that there is, as yet, no experimental evidence to shew whether the electric current is really a current of a material substance, or a double current [two equal currents of positive and negative electricity, flowing in opposite directions], or whether its velocity is great or small as measured in feet per second. (...) [Maxwell ${ }^{(\mathrm{c})}: 218$ (art.574)]

Mas, contrariando a afirmação anterior, de que não havia evidências experimentais para dizer se a corrente era ou não constituída de substância material, o físico escocês adota

\footnotetext{
${ }^{25}$ Entenda-se entes físicos que para efeitos práticos podem ser considerados pontuais, mas são dotados de massa, ainda que pequena.
} 
a posição de que a corrente elétrica não teria relação com a matéria comum, como fica claro deste trecho:

(...) if electrical motions were in any way comparable with the motions of ordinary matter, terms of the form $\mathrm{T}_{\mathrm{me}}{ }^{[26]}$ would exist, and their existence would be manifested by the mechanical force $\mathrm{X}_{\mathrm{me}}{ }^{[27]}$. (...) Since, however, no evidence has yet been obtained of such terms, I shall now proceed on the assumption that they do not exist, or at least that they produce no sensible effect (...) [Maxwell ${ }^{(\mathrm{c})}$ : 218 (art.574) \& 222 (art.577)]

Maxwell, curiosamente, parece que acreditava que a força de Ampère era devida a uma ação direta sobre o condutor, em decorrência de uma mudança nas propriedades deste pela passagem de corrente elétrica:

It must be carefully remembered that the mechanical force which urges a conductor carrying a current across the lines of magnetic force acts, not on the electric current, but on the conductor which carries it. [Maxwell ${ }^{(\mathrm{c})}: 157$ (art.501)]

Em 1877, o físico alemão Rudolf Clausius (1822-1888), baseando-se em uma fórmula de Helmholtz ${ }^{[28]}$ para a energia total entre duas configurações de correntes e na hipótese de que a força de Ampère seria completamente devida à corrente no condutor ${ }^{[29]}$ (em total desacordo com a afirmação de Maxwell que transcrevemos logo acima, mas concorde com a opinião hoje aceita), encontrou uma expressão geral para a força entre duas partículas carregadas [Whittaker $\left.{ }^{(a)}: 234\right]$.

Em 1879, o físico estadounidense Edwin Hall (1855-1938), na época em que realizava um programa de doutoramento sob orientação de Rowland ${ }^{[30]}$, não concordando

\footnotetext{
${ }^{26}$ Este símbolo representava a parte da energia cinética total do circuito com corrente que teria tanto coordenadas da estrutura metálica do circuito quanto coordenadas dos entes físicos responsáveis pela corrente.

${ }^{27}$ Este símbolo representava a força decorrente da aplicação das equações de Lagrange à energia cinética descrita acima.

${ }^{28}$ Hermann von Helmholtz (1821-94), outro físico alemão.

${ }^{29}$ Que foi interpretada corretamente, como o movimento de partículas carregadas de pequeníssima massa em um único sentido no condutor.

${ }^{30}$ Henry Augustus Rowland (1848-1901), engenheiro civil e físico estadounidense que mostrou pela primeira vez que uma partícula carregada livre em movimento "gera" um campo magnético. Isto em 1876, época em que se encontrava em Berlim, pesquisando no laboratório de Helmholtz [Whittaker ${ }^{(a)}: 305-06$ e http://www.aip.org/history/gap/Rowland/Rowland.html (acesso em 25.08.07)]. Em 1820, Hans Christian Oersted (1777-1851) havia mostrado que uma corrente elétrica afetava bússolas; porém, nesta época, ainda não se sabia ao certo a natureza da corrente elétrica.
} 
(como Clausius) com o último trecho de Maxwell que transcrevemos acima, montou um experimento no qual mostrava que a corrente, ao contrário do que Maxwell imaginava, era, sim, sob certas condições, influenciada por um campo magnético ${ }^{[31]}$. Isto foi feito analisando-se o comportamento da corrente em um condutor metálico plano sujeito a um B perpendicular. Foi verificada uma diferença de potencial entre as laterais do condutor. Tal efeito foi posteriormente denominado Efeito Hall.

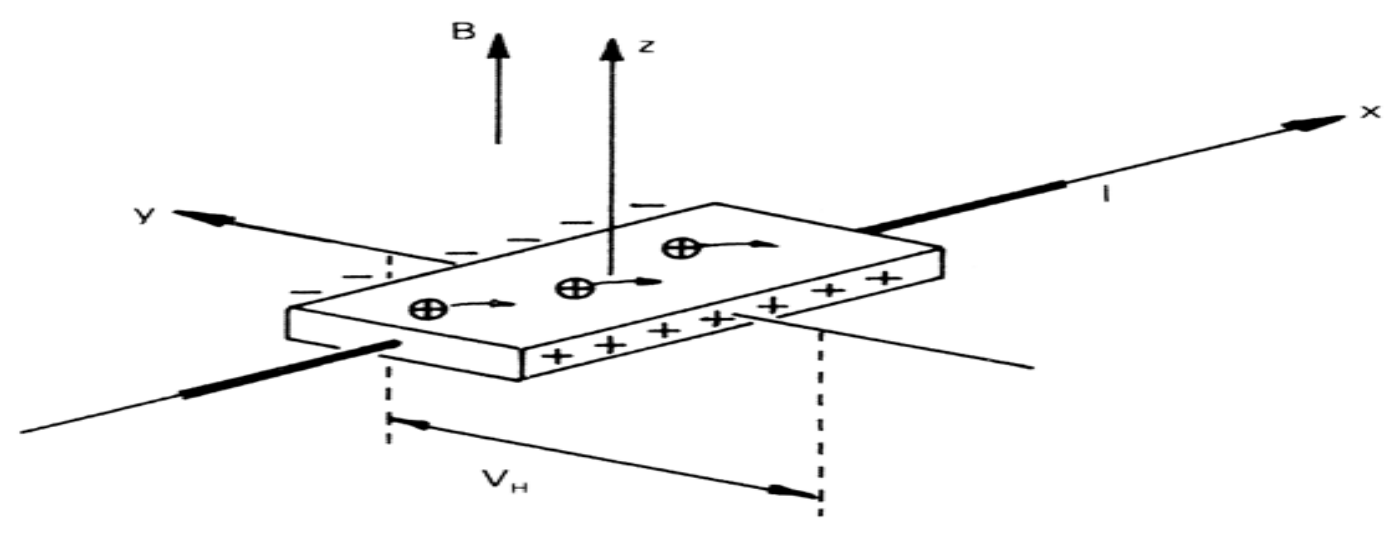

Fig. 2 - O Efeito Hall. Inserida em uma região caracterizada por um campo magnético B na direção z, uma superfície condutora situada no plano $x$-y pela qual flui uma corrente I na direção $x$ tem seus portadores de carga desviados na direção y, o que dá origem a uma diferença de potencial $V_{H}$ nesta direção.

Para físicos tendentes à interpretação da corrente elétrica em condutores metálicos como um fluxo em um único sentido de partículas carregadas existentes no metal, o efeito em questão poderia servir como base para a explicação da força sobre um fio condutor conduzindo corrente e sujeito a um campo magnético perpendicular à direção da mesma: a força sobre o condutor seria mera conseqüência da força sobre os elementos responsáveis pela corrente. No entanto, esta interpretação ainda encontrava fortes reservas. Como vimos, Clausius era um de seus adeptos, mas era comum a interpretação da corrente em metais como cargas opostas movimentando-se em sentidos opostos ${ }^{[32]}$, e a natureza corpuscular da eletricidade ainda não era algo bem aceito ${ }^{[33]}$. A explicação da força sobre um condutor

31 "On a New Action of the Magnet on Electric Currents", Am. Jour. Math. 2, 287 (1879). As pesquisas deste artigo foram continuadas em Am. Jour. Sci. 19, 200 e 20, 161 (1880) e em Phil. Mag. $\underline{9}, 225$ e 10, 301 (1880).

32 O físico inglês J. J. Thomson (1856-1940), descobridor de elétron e nobel de 1906, considerava esta hipótese em 1888 [Whittaker $\left.{ }^{(\text {a) }}: 419\right]$.

${ }^{33}$ Conforme "The abandonment of Maxwellian electrodynamics: Joseph Larmor's theory of the electron II: The abandoning of Maxwellian theory" [Arch. Internat. Hist. Sci. 31(107): 373-438, 1981], artigo de Jed Z. Buchewald, a "conversão" dos físicos à natureza corpuscular da eletricidade parece ter sido fortemente influenciada pelo trabalho de Larmor "A Dynamical Theory of the Electric and Luminiferous Médium", 
conduzindo corrente e sujeito a um campo magnético perpendicular à direção da mesma era buscada em termos de algum mecanismo oculto do éter, como podemos ver de uma resposta de FitzGerald ${ }^{[34]}$ à Rowland, fruto de uma troca de correspondências entre ambos no segundo trimestre de 1894. Remetendo-nos à sua tentativa (1876) de obter o resultado depois conseguido por Hall (1879), Rowland diz a FitzGerald:

(...) I was in the hope of finding that the magnetic action of a current in the wire was due to some change in the wire caused by the current. This seems is not so. And yet the forces are between the wires! This is still a puzzle to me. (...)

\section{E FitzGerald responde:}

It is of course very remarkable that the action is on the matter on which the charge is moving and not on the charge. (...) What we call an electric charge is a quality of the surface of the matter and if this is moving, on the matter or with the matter, makes no difference; if this is moving relatively to the ether in its neighborhood there is a different force on the matter than there would be if this surface quality were not moving. (...) I suppose of one could quite clearly understand all these puzzles one could frame a satisfactory theory as to the structure of ether. (...) [Miller : 23]

Mas físicos como Lorentz, seguindo a tradição de Clausius, acreditavam que a força sobre um condutor conduzindo corrente e sujeito a um campo magnético perpendicular à direção da mesma era devida inteiramente à ação da corrente sobre o condutor ${ }^{[35]}$.

Em 1900, J.J. Thomson, que também adotava a hipótese corpuscular da eletricidade, defendeu a idéia de que o fluxo da corrente ocorreria em um único sentido: são as cargas negativas que se movem entre os átomos do metal; as cargas positivas deveriam ser consideradas como mais ou menos fixas [Whittaker $\left.{ }^{(a)}: 420\right]$.

Em um artigo publicado em 1906, E.F. Nichols mostrou que a massa das partículas responsáveis pela corrente (carregadas negativamente) era menor que a do átomo de hidrogênio [Tolman \& Stewart : 98].

publicado em três partes, entre 1894 e 1897, nos Philosophical Transactions of the Royal Society of London [http://www-history.mcs.st-andrews.ac.uk/Biographies/Larmor.html (acessado em 28.08.07)].

${ }^{34}$ George Francis FitzGerald (1851-1901), físico irlandês.

${ }^{35}$ Isto devido à própria concepção lorentziana de eletricidade. Em um importante artigo de Lorentz de 1892, o físico holandês adota como uma de suas hipóteses fundamentais justamente o fato de que seriam partículas os entes responsáveis pela eletricidade, ou seja: onde houvesse eletricidade, haveria também massa [McCormmach : 463]. 
O trabalho de Nichols foi aperfeiçoado em 1913 por R. C. Tolman, E. W. Osgerby e T. D. Stewart, resultando em um trabalho publicado em 1914 no qual constou que a massa das partículas negativas responsáveis pela corrente era da ordem de 1/200 a massa do átomo de hidrogênio [Tolman \& Stewart : 99].

Finalmente, em 1916, com a publicação de um artigo de Tolman e Stewart tratando da diferença de potencial gerada em metais acelerados, foi praticamente resolvida a questão da natureza dos responsáveis pela corrente em metais e o mecanismo da mesma ${ }^{[36]}$.

De posse destes dados, fica embasada a igualdade $I \mathrm{~d} \boldsymbol{l}=\rho_{-} \boldsymbol{v}_{-} d V$ para um condutor metálico genérico, onde $\rho$. é a densidade de carga dos elementos responsáveis pela

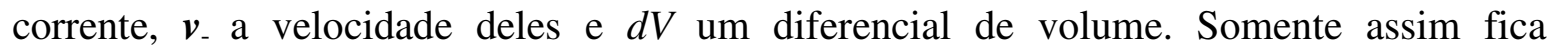
justificado escrever a Eq.(3) na forma

$$
\mathrm{d} \mathbf{F}=\rho v d V \times \mathbf{B},
$$

sendo $\rho$ a densidade de carga associada a um corpo eletrizado em movimento, $\boldsymbol{v}$ a velocidade do mesmo e $d V$ um diferencial de volume.

Como vimos, mais de 70(setenta) anos foram necessários para que a transcrição de (3) na forma (4) fosse aceita em geral. Além disso, historicamente, a primeira obtenção da Eq.(4) não ocorreu devido à uma "tradução" da lei de Ampère, conforme veremos.

Nas seções a seguir, apresentaremos variados caminhos utilizados para a obtenção da expressão hoje denominada "força de Lorentz". Partindo de princípios distintos, chegaram a ela Maxwell(1864) ${ }^{[37]}$ Heaviside $^{[38]}(1889)$, Lorentz(1892) e Larmor(1900). Em nossa apresentação o sistema de unidades utilizado pelos autores será preservado.

\footnotetext{
${ }^{36}$ Vide Tolman \& Stewart na Bibliografia.

37 Apesar de não ter tratado em particular da força sobre uma partícula carregada em movimento em uma região onde estivessem definidos um campo elétrico e um campo magnético.

${ }^{38}$ Oliver Heaviside (1850-1925), físico inglês.
} 


\section{1 "A DYNAMICAL THEORY OF THE ELECTROMAGNETIC FIELD", MAXWELL, 1864}

Em 1864, o físico escocês James Clerk Maxwell apresentou um importante trabalho à Royal Society ${ }^{[39]}$ [Whittaker $\left.^{(\mathrm{a})}: 255\right]$. Em certo ponto deste trabalho depois transformado em artigo, Maxwell analisou a força eletromotiva em um curto condutor retilíneo formando parte de um circuito e livre para mover-se ao longo de dois condutores paralelos, o movimento ocorrendo em uma região em que estivesse definido um campo magnético [Maxwell ${ }^{(\mathrm{a})}:$ 558-59]. Fica implícito que por "força eletromotiva em determinado ponto" Maxwell entendia o quociente entre a força total de origem eletromagnética que uma partícula carregada ficaria sujeita naquele ponto e a carga da mesma.

Segundo o físico escocês, a força eletromotiva no condutor devido ao movimento deste em uma região sem campo elétrico mas com campo magnético seria

$$
\mathbf{R}=\mathbf{v} \times \mathbf{B},
$$

sendo $\mathbf{v}$ a velocidade do condutor em relação ao referencial onde o campo magnético $\mathbf{B}$ foi definido.

Poderíamos resumir a demonstração de Maxwell com a afirmativa de que o resultado acima é uma conseqüência direta de uma generalização da lei de Faraday da indução para o caso em que o circuito (ou parte dele) está em movimento com velocidade constante. Utilizando a notação $C$ para representar um circuito qualquer em movimento com velocidade constante ou um circuito tendo partes em movimento com velocidade constante, continuaríamos tendo a lei verificada experimentalmente para circuitos em repouso, com a única diferença que o campo elétrico $\mathbf{E}$ deveria ser substituído pela força eletromotiva $\mathbf{R}$. Ou seja, a lei mais geral seria dada por:

$$
\oint_{C} \mathbf{R} . d \mathbf{l}=-\frac{d}{d t} \iint_{S} \mathbf{B} . d \mathbf{S},
$$

onde $S$ representaria uma superfície qualquer tendo o circuito como borda.

Para ver que a consideração da Eq. (6) como válida implica na Eq. (5), observemos primeiramente que, pelo fato do circuito estar em movimento,

\footnotetext{
39 "A Dynamical Theory of the Electromagnetic Field", depois publicado nos Philosophical Transactions of the Royal Society 155: 459, 1865. Este artigo pode ser encontrado em The Scientific Papers of James Clerk Maxwell, New York: Dover, 2003, pp. 526-597.
} 


$$
\frac{d}{d t} \iint_{S} \mathbf{B} \cdot d \mathbf{S}=\iint_{S}\left(\frac{\partial \mathbf{B}}{\partial t}+(\mathbf{v} \cdot \nabla) \mathbf{B}\right) \cdot d \mathbf{S}
$$

onde $\mathbf{v}$ é a velocidade do circuito ou de parte dele.

Além disso, a partir da igualdade vetorial

$$
\nabla \times(\boldsymbol{\alpha} \times \boldsymbol{\beta})=\alpha \nabla \cdot \boldsymbol{\beta}-\boldsymbol{\beta} \nabla . \boldsymbol{\alpha}+(\boldsymbol{\beta} . \nabla) \boldsymbol{\alpha}-(\boldsymbol{\alpha} . \nabla) \boldsymbol{\beta},
$$

considerando $\alpha$ como a velocidade $\mathbf{v}$ da parte móvel do circuito estudado por Maxwell e $\boldsymbol{\beta}$ como o campo magnético $\mathbf{B}$, encontramos

$$
(\mathbf{v} . \nabla) \mathbf{B}=\mathbf{v} \nabla . \mathbf{B}-\mathbf{B} \nabla . \mathbf{v}+(\mathbf{B} \cdot \nabla) \mathbf{v}-\nabla \times(\mathbf{v} \times \mathbf{B}) .
$$

Agora, pelo fato da velocidade ser constante e de $\nabla . \mathbf{B}=0$, a igualdade acima fica

$$
(\mathbf{v} . \nabla) \mathbf{B}=-\nabla \times(\mathbf{v} \times \mathbf{B}) .
$$

Então, utilizando (7) e (8) em (6), obtemos

$$
\oint_{C} \mathbf{R} . d \mathbf{l}=-\iint_{S}\left(\frac{\partial \mathbf{B}}{\partial t}+(\mathbf{v} \cdot \nabla) \mathbf{B}\right) \cdot d \mathbf{S}=-\iint_{S} \frac{\partial \mathbf{B}}{\partial t} \cdot d \mathbf{S}+\iint_{S}[\nabla \times(\mathbf{v} \times \mathbf{B})] . d \mathbf{S} .
$$

$\mathrm{E}$, considerando que $\mathbf{B}$ não dependa explicitamente do tempo e sabendo que

$$
\iint_{S}[\nabla \times(\mathbf{v} \times \mathbf{B})] . d \mathbf{S}=\oint_{C}(\mathbf{v} \times \mathbf{B}) . d \mathbf{l},
$$

obtemos

$$
\oint_{C} \mathbf{R} \cdot d \mathbf{l}=\oint_{C}(\mathbf{v} \times \mathbf{B}) \cdot d \mathbf{l}
$$

Como a igualdade acima é válida para circuitos de quaisquer geometrias, encontramos então, finalmente

$$
\mathbf{R}=\mathbf{v} \times \mathbf{B},
$$

que corresponde ao resultado que queríamos demonstrar.

Para a força eletromotiva total dentro do condutor, Maxwell mostrou que

$$
\mathbf{R}=\mathbf{v} \times \mathbf{B}-\partial \mathbf{A} / \partial t-\nabla \psi
$$

sendo $\mathbf{A}$ o potencial-vetor do qual se deriva $\mathbf{B}^{[40]}$ e $\psi$ um dado potencial elétrico $\left[\right.$ Maxwell $\left.^{(\mathrm{a})}: 559\right]$.

Assim, sendo $\mathbf{F}$ a força eletromagnética total sobre uma partícula de carga $e$, teríamos que

$$
\mathbf{F}=e(-\nabla \psi-\partial \mathbf{A} / \partial t)+e(\mathbf{v} \times \mathbf{B})
$$

\footnotetext{
${ }^{40} \mathbf{B}=\nabla \times \mathbf{A}$
} 
desconsiderados efeitos de radiação.

Entretanto, como

$$
-\nabla \psi-\partial \mathbf{A} / \partial t=\mathbf{E}
$$

ficamos com

$$
\mathbf{F}=e(\mathbf{E}+\mathbf{v} \times \mathbf{B}),
$$

justamente a expressão da força de Lorentz, de modo que podemos dizer que Maxwell foi o primeiro a demonstrá-la.

Para terminar esta seção, forneceremos algumas similaridades entre idéias de Mach e Maxwell, e comentaremos sobre um pequeno lapso no Treatise de Maxwell relacionado à força total sobre uma partícula carregada em movimento em uma região caracterizada por campos elétrico e magnético.

É interessante observar a similaridade entre as idéias de Maxwell e Mach no que diz respeito aos princípios básicos da Física. Isto fica muito bem ilustrado dos trechos que serão agora transcritos, retirados do livro Matter and Motion, de Maxwell:

Acceleration, like position and velocity, is a relative term and cannot be interpreted absolutely. (...) It is only if the change of motion occurs in a different manner in the different bodies of the system that any event capable of being observed takes place. [Maxwell $^{(\mathrm{d})}: 25$ (art. 35)]

Relativity of Dynamical Knowledge. Our whole progress up to this point may be described as a gradual development of the doctrine of relativity of all physical phenomena. (...) There are no landmarks in space; one portion of space is exactly like every other portion, so that we cannot tell where we are. (...) we may compute our rate of motion with respect to the neighbouring bodies, but we do not know how these bodies may be moving in space. [Maxwell ${ }^{(\mathrm{d})}:$ 80-81 (art. 102)]

Relativity of Force. We cannot even tell what force may be acting on us; we can only tell the difference between the force acting on one thing and that acting on another. (...) $\left[\right.$ Maxwell $^{(\mathrm{d})}: 81$ (art. 103)]

É também interessante notar que, apesar de ter reproduzido o mesmo resultado (9) no seu Treatise ${ }^{[41]}$, Maxwell não incluiu os termos $-e(\partial \mathbf{A} / \partial t)$ e $e(\mathbf{v} \times \mathbf{B})$ como integrantes da força mecânica geral sobre uma partícula carregada, considerando apenas o termo $-e \nabla \psi^{[42]}$.

\footnotetext{
${ }^{41}$ Maxwell $^{(\mathrm{c})}:$ 239-240 (art.598).

${ }^{42}$ Maxwell $^{(\mathrm{c})}$ : 258 (art.619).
} 
Este lapso foi percebido por FitzGerald e exposto em um encontro da British Association em 1883 [Heaviside : 329].

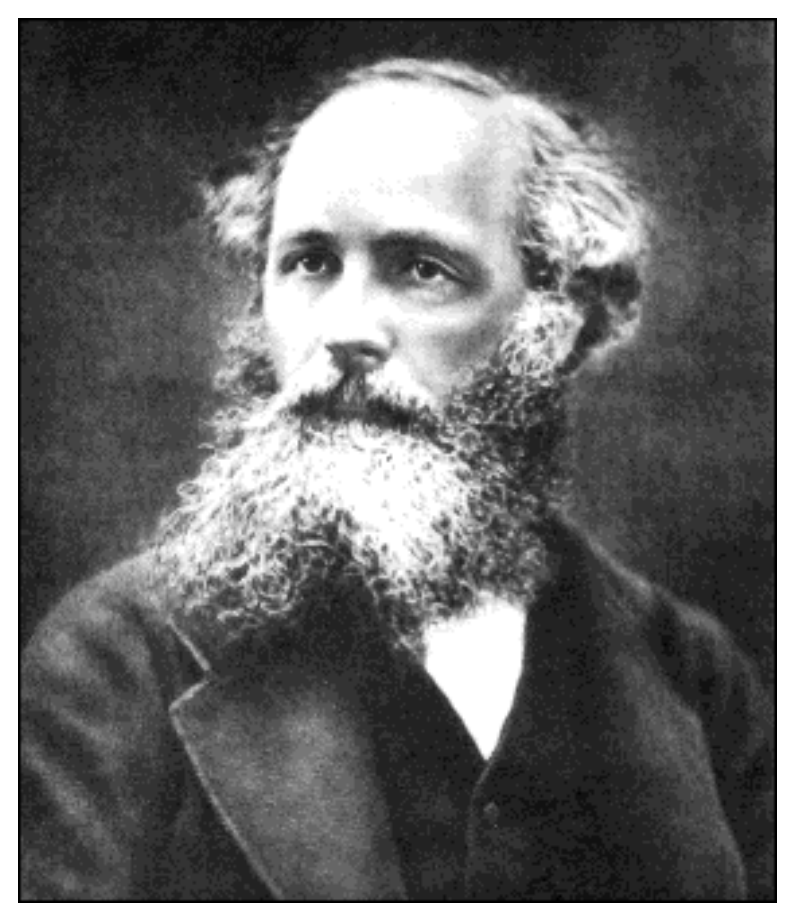

Fig. 3 - James Clerk Maxwell (1831-1879)

\subsection{OS TRABALHOS DE J. J. THOMSON E HEAVISIDE}

Em abril de 1881, no vol. 11 de Philosophical Magazine and Journal of Science, J. J. Thomson publicou um artigo ${ }^{[43]}$ em que encontrava, com base na teoria de Maxwell, a força sentida por uma partícula eletrizada em movimento em uma região na qual um campo magnético estivesse definido.

Thomson, Prêmio Nobel de 1906, partiu da idéia, estabelecida pela teoria de Maxwell, de que a variação temporal do deslocamento elétrico $\mathbf{D}$ em um dielétrico produz efeitos análogos aos de uma corrente de condução [Thomson $\left.{ }^{(a)}: 229\right]$. Assim:

$$
\mu \int \frac{J_{x}}{\rho^{\prime}} d x^{\prime} d y^{\prime} d z^{\prime} \leftrightarrow \mu \int \frac{\partial D_{x} / \partial t}{\rho^{\prime}} d x^{\prime} d y^{\prime} d z^{\prime},
$$

\footnotetext{
43 "On the Electric and Magnetic Effects produced by the Motion of Eletrified Bodies" (págs 229-249 da revista referida).
} 
onde $\mu$ é a permeabilidade magnética do meio, $\rho^{\prime}$ a distância entre os pontos nos quais a corrente de condução (ou, no presente caso, a corrente de deslocamento) está definida e um ponto fixo estabelecido de antemão, e a integração é sobre a região onde estão definidas as correntes (no presente caso, sobre toda a região do dielétrico, pois o deslocamento elétrico está definido em todos os pontos dele). A primeira integral, segundo a teoria de Maxwell, fornece a componente $x$ de um potencial-vetor devido a correntes de condução; a segunda integral, em analogia, foi considerada por Thomson como apropriada para fornecer a componente $x$ de um potencial-vetor devido a correntes de deslocamento.

Entretanto, o divergente do hipotético potencial-vetor para dielétricos, cuja componente $x$ foi calculada pela segunda integral dada por (10), não se anulava. Para obter este anulamento, requerido pela teoria maxwelliana, Thomson adicionou o termo $2 \mu e p / 3 \mathrm{R}$ à componente $x$ do potencial vetor, onde $e$ era o valor da carga da esfera eletrizada, $p$ a componente $x$ da velocidade da mesma, e R a distância entre o centro da esfera e algum ponto do meio. $\mathrm{O}$ argumento para a validade do procedimento foi que o termo acrescentado obedeceria à equação de Laplace ${ }^{[44]}$, o que servia como garantia de que nenhuma outra condição do problema teria sido alterada $\left[\operatorname{Thomson}^{(a)}: 232\right]$.

O resultado obtido para o potencial-vetor foi utilizado para o cálculo do campo indução magnética $\mathbf{B}$ (chamado por Thomson de magnetic induction) devido ao movimento de uma esfera eletrizada, considerada de raio muito pequeno. Thomson verificou que este campo era idêntico àquele devido a uma corrente de condução se a corrente de condução fosse considerada com intensidade $\mu e v$ por unidade de comprimento, sendo $e$ a carga e $v$ o módulo da velocidade da esfera eletrizada (o referencial a que esta velocidade se refere será estudado adiante) [Thomson $\left.{ }^{(a)}: 236\right]$.

Na seção 5 de seu artigo, o físico inglês se propõe a encontrar o efeito produzido por um magneto sobre a esfera eletrizada em movimento em um dielétrico ilimitado. Sejam $\mathbf{H ~ e ~}$ $\mathbf{H}_{\mathbf{0}}$, respectivamente, o campo magnético "gerado" pela esfera eletrizada em movimento e o campo magnético do magneto, e sejam $\mathbf{B}$ e $\mathbf{B}_{\mathbf{0}}$, respectivamente, o campo indução magnética "gerado" pela esfera eletrizada e o campo indução magnética do magneto. Considerando, conforme Maxwell, a energia magnética (devida ao magneto e à esfera movente) como de tipo cinético, podemos escrever:

\footnotetext{
${ }^{44}$ Pierre Simon Laplace (1749-1827), matemático, astrônomo e físico francês.
} 


$$
T=\frac{1}{8 \pi} \int\left(\mathbf{B}_{\mathbf{0}}+\mathbf{B}\right)\left(\mathbf{H}_{\mathbf{0}}+\mathbf{H}\right) d x d y d z .
$$

Thomson pôde obter, então, com base nas equações de Lagrange ${ }^{[45]}$ para uma lagrangeana de tipo cinético (como aquela expressa pela integral acima), uma expressão para a força ${ }^{[46]}$ sentida pela esfera devido à ação do magneto. Para a direção $x$, temos a seguinte equação:

$$
F_{x}=\frac{\partial T}{\partial x}-\frac{d}{d t} \frac{\partial T}{\partial \dot{x}} .
$$

Partindo desta e das equações análogas para $y$ e $z$, Thomson encontrou que

$$
\mathbf{F}=\frac{\mu e}{2} \boldsymbol{v} \times \mathbf{H}_{0},
$$

sendo $\mathbf{H}_{0}$ o campo magnético devido ao magneto [Thomson ${ }^{(a)}$ : 241]. Este resultado é metade do valor hoje considerado.

No fim da seção 6, última de seu artigo, Thomson destaca que a velocidade que aparece em (11) é relativa ao meio em que a partícula se encontra, um dielétrico de permeabilidade magnética $\mu$ [Thomson $\left.^{(\text {a) }}: 248\right]$. Porém, o estado de movimento do meio não poderia ser qualquer, uma vez que Thomson utilizara conceitos derivados de campo magnético fornecidos pela teoria de Maxwell, como a fórmula para o potencial-vetor a partir da corrente de condução [Thomson ${ }^{(a)}: 231$ ] e a fórmula para a energia devida a efeitos magnéticos [Thomson ${ }^{(a)}: 234$ e 239]. Como na teoria de Maxwell a definição de campo magnético é restrita a um referencial em repouso em relação à Terra ou similares em movimento retilíneo uniforme, então o dielétrico ilimitado de Thomson deve ser considerado em repouso em relação à Terra. Assim sendo, a aceleração (implícita) e a velocidade $\boldsymbol{v}$ de (11) devem ser consideradas em relação ao referencial terrestre, onde $\mathbf{H}_{0}$ foi estabelecido.

Um defeito na investigação de Thomson estudada anteriormente foi apontado por FitzGerald em um artigo ${ }^{[47]}$ publicado no vol. 3 dos Proceedings of the Royal Dublin Society, de novembro de 1881, às páginas 250-54: se as correntes (fontes de campo magnético) no problema estudado por Thomson fossem apenas as correntes de

\footnotetext{
${ }^{45}$ Joseph Louis Lagrange (1736-1813), matemático italiano.

${ }^{46} \mathrm{O}$ conceito de força aqui deve ser entendido apenas como $m \mathbf{a}$; a questão dos referenciais será discutida adiante.

47 "Note on Mr. J.J. Thomson's investigation of the electromagnetic action of a moving electrified sphere".
} 
deslocamento, a condição circuital - idéia-base da teoria maxwelliana - não seria satisfeita, pois o divergente da corrente de deslocamento não se anulava. FitzGerald então mostrou que a própria esfera eletrizada em movimento deveria ser entendida como corrente, caso em que a condição circuital seria satisfeita. Além disso, seria possível explicar o campo magnético produzido no dielétrico com base unicamente na existência desta corrente (chamada corrente de convecção), cuja densidade seria dada por $\rho \boldsymbol{v}$, sendo $\rho$ a densidade de carga e $\boldsymbol{v}$ a velocidade da esfera [Whittaker $\left.{ }^{(a)}: 307\right]$.

Em um artigo publicado em abril de 1889 na já mencionada Philosophical Magazine and Journal of Science ${ }^{[48]}$, Oliver Heaviside, adotando a idéia de Fitzgerald de que $\rho \boldsymbol{v}$ seria uma densidade de corrente (densidade de corrente de convecção), estabeleceu, em analogia à chamada "fórmula de Biot-Savart" (que fornece o campo indução magnética gerado por uma corrente de condução), que o campo magnético associado à esfera eletrizada em movimento seria dado por

$$
\mathbf{H}=\frac{q}{r^{2}} v \sin \theta
$$

sendo $q$ a carga da esfera, $r$ a distância do ponto considerado à esfera, $v$ o módulo da velocidade da mesma e $\theta$ o ângulo entre $\boldsymbol{r}$ e $\boldsymbol{v}$.

Mais à frente, na seção 4 do mesmo artigo, Heaviside, partindo da fórmula para a energia magnética mútua $M$ entre a partícula em movimento e um campo magnético externo $\mathbf{H}_{0}$, dada por

$$
M=\frac{1}{4 \pi} \int\left(\mu \mathbf{H} \cdot \mathbf{H}_{0}\right) d x d y d z
$$

e realizando algumas manipulações matemáticas, encontrou que

$$
M=\boldsymbol{A}_{0} v q,
$$

sendo $\boldsymbol{A}_{0}$ tal que $\nabla \times \boldsymbol{A}_{0}=\mu \mathbf{H}_{0}$ e $\nabla \cdot \boldsymbol{A}_{0}=0$ [Heaviside : 326].

Com isso, e utilizando as equações de Lagrange aplicadas a uma lagrangeana dada por $M$, Heaviside obteve que a força sentida por uma esfera eletrizada movimentando-se em um dielétrico ilimitado de permeabilidade magnética $\mu$ (caracterizado por um campo magnético $\mathbf{H}_{0}$ ) seria dada por:

\footnotetext{
${ }^{48}$ Heaviside, O. "On the Electromagnetic Effects due to the Motion of Electrification in a Dielectric", Phil. Mag. 27: 324-339, 1889.
} 


$$
\mathbf{F}=\mu q v \times \mathbf{H}_{0},
$$

ou seja, o dobro do valor encontrado por Thomson para o mesmo caso. Esta é a expressão atualmente aceita para o caso em questão.

A interpretação da velocidade $v$ é a mesma que a do artigo de Thomson de 1881, ou seja, a velocidade é relativa ao meio, que, por sua vez, deve ser considerado em repouso em relação ao referencial terrestre.

Thomson e Heaviside assumiam a existência de um meio responsável pelos fenômenos eletromagnéticos: o éter. E adotavam a idéia, antes já assumida por Maxwell, que a matéria ponderável transmitia seu movimento ao éter emaranhado a ela.

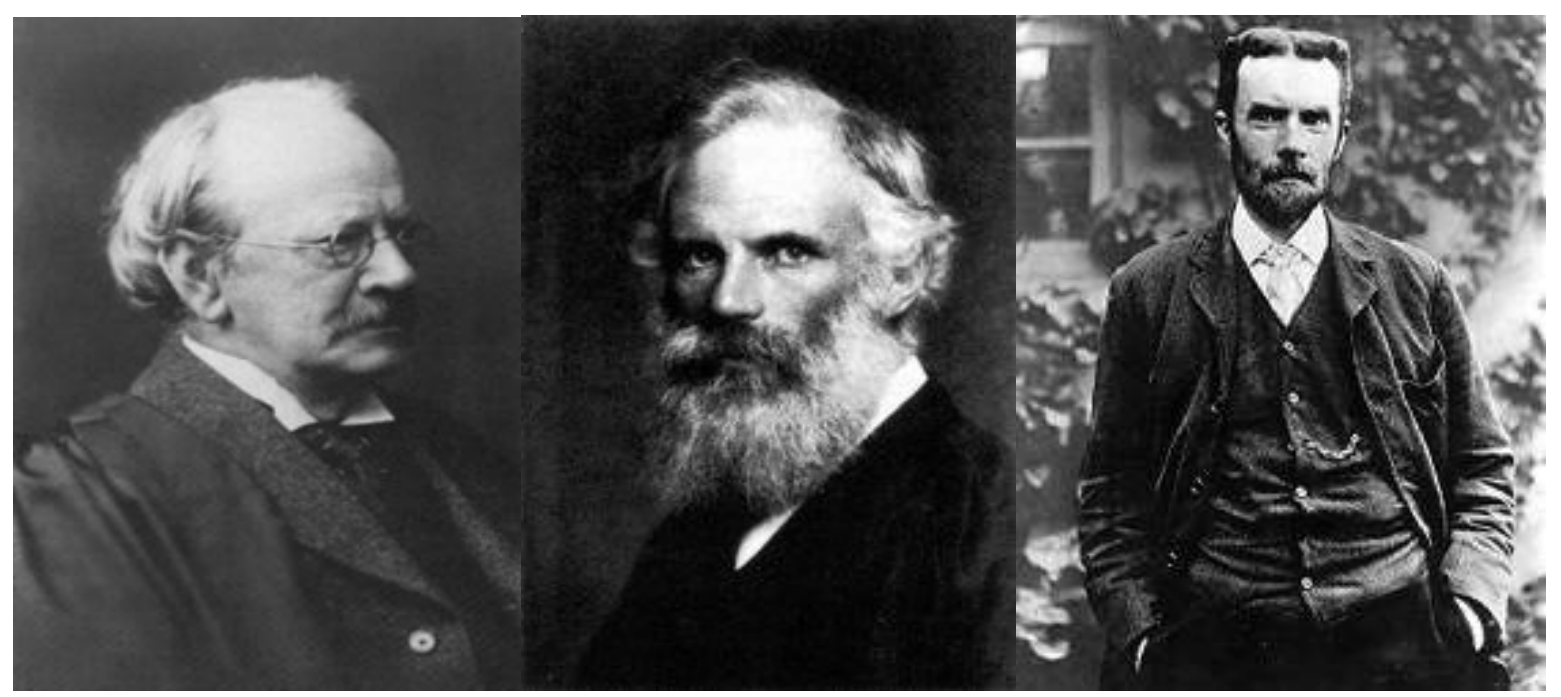

Fig. 4 - Sir J. J. Thomson (1856-1940), George FitzGerald (1851-1901) e Sir O. Heaviside (1850-1925)

\subsection{A DEDUÇÃO DE HENDRIK LORENTZ}

Em 1892, o físico holandês Hendrik Antoon Lorentz (1853-1928), Prêmio Nobel de 1902, publicou no volume 25 dos Archives Néerlandaises des Sciences Exactes et Naturelles um artigo no qual mencionava ter encontrado a força sentida por uma partícula eletrizada em movimento em uma região caracterizada por um campo elétrico e um campo magnético $^{[49]}$.

\footnotetext{
49 "La théorie électromagnetique de Maxwell et son application aux corps mouvants", Archives Néerlandaises des Sciences Exactes et Naturelles, 25: 363ff, 1892; Collected Papers, vol.2, pp.164-343, 1936 [Lorentz ${ }^{(\mathrm{a})}$ ].
} 
Diferentemente de Thomson (1881) e Heaviside (1889), Lorentz considerou, neste artigo, que a "matéria ponderável" não transmitia seu movimento ao éter, apesar de existirem "movimentos internos" nele.

Lorentz propõe 6(seis) hipóteses para iniciar a derivação, a partir de uma perspectiva mecânica, das equações de Maxwell e da força ponderomotiva (hoje denominada força de Lorentz). A primeira delas seria que a eletricidade representa apenas uma propriedade da "matéria ponderável" [Lorentz $\left.{ }^{(a)}: 230\right]$. As três seguintes foram apresentadas por McCormmach em seu artigo "H.A. Lorentz and the Electromagnetic View of Nature, ${ }^{[50]}$ como segue:

The second hypothesis of Lorentz's theory identifies the potential energy of an electromagnetic system with its electric energy, which is, in electromagnetic units, $2 \pi \int\left(f^{2}+g^{2}+h^{2}\right) d \tau^{[51]}$, where $f, g$, $h$ is the dielectric displacement at each point of the ether. The dielectric displacement satisfies $(\partial f / \partial x)+(\partial g / \partial y)+(\partial h / \partial z)=0$ outside the space of a charged particle, and

$$
(\partial f / \partial x)+(\partial g / \partial y)+(\partial h / \partial z)=\rho
$$

inside, where $\rho$ is the density of electric charge. The third hypothesis states that charged particles behave like rigid bodies; moreover, each point of a particle preserves the same value of $\rho$, whatever its motion. The fourth defines the total electric current $(\mathrm{u}, \mathrm{v}, \mathrm{w})$ as $u=$ $=\rho \xi+\partial f / \partial t, v=\rho \eta+\partial g / \partial t, w=\rho \zeta+\partial h / \partial t$, where $(\xi, \eta, \zeta)$ is the velocity of a given point of a charged particle. [McCormmach : 464]

E as duas últimas hipóteses eram:

The fifth hypothesis identifies the kinetic energy with the magnetic energy, $1 / 8 \pi \int\left(\alpha^{2}+\beta^{2}+\gamma^{2}\right) d \tau$, where the magnetic force $(\alpha, \beta, \gamma)^{[52]}$ everywhere satisfies

$$
\frac{\partial \alpha}{\partial x}+\frac{\partial \beta}{\partial y}+\frac{\partial \gamma}{\partial z}=0
$$

and is determined by the total current according to

$$
\frac{\partial \gamma}{\partial y}-\frac{\partial \beta}{\partial z}=4 \pi\left(\rho \xi+\frac{\partial f}{\partial t}\right)
$$

\footnotetext{
50 "H.A. Lorentz and the Electromagnetic View of Nature", Isis, 61(4): 459-497, 1970.

${ }^{51}$ Ficou faltando a constante $c^{2}$ nesta fórmula, onde $c$ é a velocidade da luz no vácuo.

${ }^{52}$ O que Lorentz denomina "força magnética" é o que hoje denominamos "campo magnético" e representamos comumente por $\mathbf{H}$.
} 


$$
\begin{aligned}
& \frac{\partial \alpha}{\partial z}-\frac{\partial \gamma}{\partial x}=4 \pi\left(\rho \eta+\frac{\partial g}{\partial t}\right) \\
& \frac{\partial \beta}{\partial x}-\frac{\partial \alpha}{\partial y}=4 \pi\left(\rho \zeta+\frac{\partial h}{\partial t}\right) .
\end{aligned}
$$

The sixth and last hypothesis is that the location of each point of the ether participating in the electromagnetic motions of the system is determined by the positions of all of the charged particles and by the values of $f, g, h$ at all points in the ether. [McCormmach : 465]

Partindo destas 6(seis) hipóteses e utilizando o princípio de D'Alembert ${ }^{[53]}$, Lorentz obteve as equações de movimento dos pontos do éter:

$$
\begin{aligned}
& 4 \pi c^{2}\left(\frac{\partial g}{\partial z}-\frac{\partial h}{\partial y}\right)=\frac{\partial \alpha}{\partial t} \\
& 4 \pi c^{2}\left(\frac{\partial h}{\partial x}-\frac{\partial f}{\partial z}\right)=\frac{\partial \beta}{\partial t} \\
& 4 \pi c^{2}\left(\frac{\partial f}{\partial y}-\frac{\partial g}{\partial x}\right)=\frac{\partial \gamma}{\partial t}
\end{aligned}
$$

onde $c$ é a velocidade da luz no vácuo [Lorentz $\left.{ }^{(a)}: 235\right]$.

Para encontrar a equação para a força sobre uma partícula em movimento em uma região caracterizada por campos elétrico e magnético, Lorentz fez algumas considerações, que agora passaremos a descrever.

Sejam $(\mathrm{x}, \mathrm{y}, \mathrm{z})$ as coordenadas de uma partícula de massa $m$, e seja $\delta \mathrm{A}$ o trabalho realizado sobre ela durante um deslocamento $(\delta x, \delta y, \delta z)$. Assim sendo, podemos dizer que, para um conjunto de partículas, temos que

$$
\delta A=\sum m(\ddot{x} \delta x+\ddot{y} \delta y+\ddot{z} \delta z) .
$$

Mas a expressão acima pode ser escrita como

$$
\delta A=\frac{d}{d t} \sum m(\dot{x} \delta x+\dot{y} \delta y+\dot{z} \delta z)-\sum m\left(\dot{x} \frac{d \delta x}{d t}+\dot{y} \frac{d \delta y}{d t}+\dot{z} \frac{d \delta z}{d t}\right) .
$$

\footnotetext{
${ }^{53}$ Poderíamos, sucintamente, descrever o princípio de d'Alembert aplicado a um éter mecânico do seguinte modo: considerando um conjunto de $n$ pontos do éter sujeitos a uma condição de vínculo ideal, podemos dizer que o trabalho realizado pelas forças de vínculo por ocasião de deslocamentos virtuais é nulo, ou seja, $\sum\left(d \boldsymbol{p}_{i} / d t-\boldsymbol{F}_{i}\right) \delta \mathbf{r}_{\mathrm{i}}=0$, onde $\boldsymbol{p}_{i}$ é o momento associado ao ponto $i$ do éter, $F_{i}$ é a força exercida sobre este ponto, $\delta \mathbf{r}_{\mathrm{i}}$ é o deslocamento virtual, e o somatório tem como limites $i=1$ e $i=n$.
} 
Então, uma vez que $\frac{d \delta x}{d t}=\delta \dot{x}, \frac{d \delta y}{d t}=\delta \dot{y}, \frac{d \delta z}{d t}=\delta \dot{z} \mathrm{e}$

$$
\delta T \equiv \delta\left[\sum \frac{m}{2}\left(\dot{x}^{2}+\dot{y}^{2}+\dot{z}^{2}\right)\right]=\sum m(\dot{x} \delta \dot{x}+\dot{y} \delta \dot{y}+\dot{z} \delta \dot{z}),
$$

podemos escrever

$$
\delta A=\frac{d}{d t} \sum m(\dot{x} \delta x+\dot{y} \delta y+\dot{z} \delta z)-\delta T .
$$

Assim, denotando

$$
\delta^{\prime} T \equiv \sum m(\dot{x} \delta x+\dot{y} \delta y+\dot{z} \delta z)
$$

temos, portanto:

$$
\delta A=\frac{d \delta^{\prime} T}{d t}-\delta T
$$

Esta relação será considerada válida também para regiões do éter.

Tomando a energia magnética como de tipo cinético, sendo (u, v, w) a corrente elétrica total ${ }^{[54]}$ e $(F, G, H)$ um potencial-vetor do qual podemos derivar o campo magnético externo atuante sobre a corrente, encontramos para determinada região do éter:

$$
T=\int(F u+G v+H w) d \tau,
$$

onde a integral é realizada sobre a região em questão e $d \tau$ é um diferencial de volume.

Então, considerando apenas variações na corrente,

$$
\delta T=\int(F \delta u+G \delta v+H \delta w) d \tau .
$$

Mas $u=\rho \xi+\partial f / \partial t$, de modo que

$$
\delta u=\rho \delta(d x / d t)+\delta(\partial f / \partial t) .
$$

Assim, para obtermos $\delta^{\prime} \mathrm{T}$, basta observarmos a relação analógica entre (12) e (13) e procedermos da mesma forma para (15) com a condição (16) (e similares para $v$ e w). Encontraremos, então:

$$
\delta^{\prime} T=\int\{F(\rho \delta x+\delta f)+G(\rho \delta y+\delta g)+H(\rho \delta z+\delta h)\} d \tau .
$$

A partir daí, Lorentz, para facilitar, passou a considerar apenas variações em $x$ e $f$. Deste modo,

${ }^{54} \mathrm{O}$ valor da corrente elétrica total foi definido na quarta hipótese adotada por Lorentz, descrita acima. 


$$
\delta^{\prime} T=\int F(\rho \delta x+\delta f) d \tau .
$$

Seja $X$ a componente na direção $x$ da força que o éter exerce sobre uma partícula de densidade de carga $\rho$ e seja $\tau$ o volume da mesma. Então, considerando um deslocamento $\delta x$ da partícula, o trabalho realizado sobre o éter delimitado por ela será a diminuição da energia potencial ${ }^{[55]}$ do sistema eletromagnético em questão,

$$
-\delta\left(2 \pi c^{2} \int f^{2} d \tau\right)=-4 \pi c^{2} \int(f \delta f) d \tau,
$$

mais o trabalho realizado pela força de reação que a partícula exerce sobre o éter (-X $\delta x)$. Deste modo, o trabalho total realizado sobre o éter no interior da partícula será

$$
\delta A=-X \delta x-4 \pi c^{2} \int(f \delta f) d \tau .
$$

Lorentz considerou ainda que, no interior da partícula, $\delta f=-\rho \delta x$. Assim, $\delta^{\prime} \mathrm{T}$ se anula, conforme podemos observar de (17). Com isso, (14) acaba resultando em $\delta A=-\delta T$, e (18) torna-se

$$
-\delta T=-X \delta x+4 \pi c^{2} \int(\rho f \delta x) d \tau,
$$

de modo que

$$
X \delta x=4 \pi c^{2} \int(\rho f \delta x) d \tau+\delta T .
$$

Por fim, partindo das hipóteses já mencionadas, Lorentz encontra que

$$
\delta T=\delta x \int \rho(\eta \gamma-\zeta \beta) d \tau .
$$

Inserindo este resultado em (19), encontramos:

$$
X=4 \pi c^{2} \int \rho f d \tau+\int \rho(\eta \gamma-\zeta \beta) d \tau,
$$

que é justamente a expressão para a força de Lorentz na direção $x$. Raciocínio análogo pode ser feito para as outras componentes, e obteremos

$$
\begin{aligned}
& Y=4 \pi c^{2} \int(\rho g) d \tau+\int \rho(\zeta \alpha-\xi \gamma) d \tau \\
& Z=4 \pi c^{2} \int(\rho h) d \tau+\int \rho(\xi \beta-\eta \alpha) d \tau,
\end{aligned}
$$

onde as integrais são tomadas sobre todo o espaço [Lorentz $\left.{ }^{(a)}: 235-238\right]$.

\footnotetext{
${ }^{55} \mathrm{O}$ valor da energia potencial do sistema foi definido na segunda hipótese de Lorentz, mencionada acima.
} 
Observemos que, apesar de expressas de uma forma diferente, estas componentes da força ponderomotiva estão em perfeita concordância com a fórmula obtida por Heaviside $^{[56]}$, sendo $(\xi, \eta, \zeta)$ a velocidade em relação ao éter.

E.T. Whittaker informa-nos que Lorentz teria utilizado uma lagrangeana antes obtida por Clausius para a derivação da força hoje denominada força de Lorentz [Whittaker ${ }^{(a)}$ : 392-394]. Como vimos, não foi este o procedimento adotado pelo físico holandês, apesar de podermos derivar a força de Lorentz sem dificuldades dentro da teoria desenvolvida por Clausius.

Mais tarde, em $1895^{[57]}$, Lorentz mostrou a invariância formal da força ponderomotiva para referenciais movendo-se com velocidade constante em relação ao éter (desconsiderando-se efeitos da ordem de $w^{2} / c^{2}$ e $w v / c^{2}$, onde $\mathbf{v}$ seria a velocidade da partícula e w a velocidade do referencial em relação ao éter). Para isso, ele utilizou fórmulas de transformação para os campos elétrico ${ }^{[58]}$ e magnético ${ }^{[59]}$. Assim, se para uma partícula de carga $q$ movendo-se com velocidade $\mathbf{v}$ em relação ao éter e sujeita à ação de $\mathbf{E}$ e B (definidos também em relação ao éter) temos, no sistema gaussiano de unidades,

$$
\mathbf{F}=q \mathbf{E}+q(\mathbf{v} / \mathbf{c}) \times \mathbf{B},
$$

então, para uma partícula se movendo com velocidade $\mathbf{v}^{\prime}$ em relação à Terra (considerada movendo-se com velocidade $\mathbf{w}$ em relação ao éter ${ }^{[60]}$ ), teríamos

$$
\mathbf{F}=q \mathbf{E}^{\prime}+q\left(\mathbf{v}^{\prime} / \mathrm{c}\right) \times \mathbf{B}^{\prime} .
$$

Nesta expressão devemos considerar as transformações de campos mencionadas. Estas condições e certa transformação na variável tempo garantiriam a invariância das

\footnotetext{
${ }^{56}$ A aparente diferença entre as fórmulas reside no fato do diferente sistema de unidades utilizado por cada um dos físicos.

${ }^{57}$ Versuch einer Theorie der electrischen und optischen Erscheinungen in bewegten Körpern, Leiden: E.J. Brill, 1895.

${ }^{58} \mathbf{E}^{\prime}=\mathbf{E}+(1 / \mathrm{c}) \mathbf{v} \times \mathbf{B}$.

${ }^{59} \mathbf{H}^{\prime}=\mathbf{H}-(1 / \mathrm{c}) \mathbf{v} \times \mathbf{D}$. Esta lei de transformação foi proposta originalmente por Heaviside, por volta de 1885 . O físico inglês insistia em uma simetria na transformação dos campos elétrico e magnético, motivo pelo qual considerou um campo magnético adicional (1/c) $\mathbf{D} \times \mathbf{v}$ para um dielétrico movendo-se com velocidade $\mathbf{v}$ em relação a uma região definida por um deslocamento elétrico $\mathbf{D}$ [Whittaker ${ }^{(a)}: 329-330$ ].

${ }^{60} \mathrm{Na}$ realidade, a velocidade da Terra em relação a um suposto éter estacionário dependeria do tempo. Porém, como sua variação seria muito suave se cotejada, por exemplo, com experimentos levados a cabo em tempos relativamente curtos (se comparados às 24 horas referentes à rotação completa da Terra em torno do próprio eixo), podemos considerá-la constante.
} 
equações de Maxwell desconsiderando-se efeitos da ordem de $w^{2} / c^{2}$ e $w v / c^{2}$ [Whittaker ${ }^{(a)}:$ 405-407].

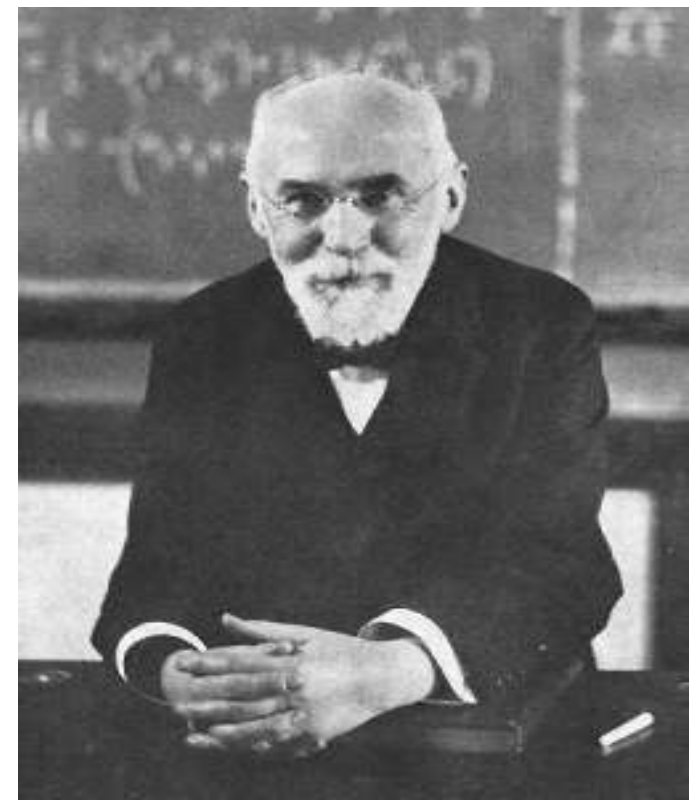

Fig. 5 - Hendrik Antoon Lorentz, (1853-1928)

\subsection{O PRINCÍPIO DA MÍNIMA AÇÃO (ABORDAGEM DE JOSEPH LARMOR E KARL SCHWARZSCHILD)}

Seguindo por um caminho distinto daqueles vistos até o momento, Joseph Larmor, fazendo uso do Princípio da Mínima Ação, também chegou à equação $\mathbf{F}=q \mathbf{E}+q \mathbf{v} \times \mathbf{B}$. Isto ocorreu por volta de 1898, quando ele obteve também as quatro equações de Maxwell utilizando o mesmo princípio $^{[61]}$. Mais tarde, em 1903, independentemente, o físico alemão Karl Schwarzschild (1871-1916) utilizaria a mesma técnica para a obtenção das equações de Maxwell e da força de Lorentz ${ }^{[62]}$ [Jackson \& Okun : 675].

\footnotetext{
61 Aether and Matter, Cambridge University Press, 1900, seções 56-58. Este livro, apesar de publicado somente em 1900, foi terminado em 1898.

62 “Zur Elektrodynamik I. Zwei Formen des Princips der kleinsten Action in der Elektronentheorie", Göttinger Nachr., 1903, pp. 126-131.
} 
Para mostrar este desenvolvimento, partiremos de dois dados sobre o artigo de Schwarzschild, mencionados por Sommerfeld ${ }^{[63]}$ às páginas 269-270 do vol. III (Electrodynamics) de suas Lectures on Theoretical Physics, a saber:

- Que Schwarzschild definiu inicialmente uma grandeza denominada "potencial eletrocinético", dada por

$$
L=\Psi-\mathbf{v} \cdot \mathbf{A},
$$

sendo $\Psi$ e A, respectivamente, o potencial elétrico e o potencial-vetor em determinada região, e $\mathbf{v}$ a velocidade de uma partícula eletrizada em relação ao referencial em que $\Psi$ e $\mathbf{A}$ foram estabelecidos;

- E que, depois, considerando a grandeza

$$
\Lambda=\frac{1}{2} \mathbf{H} \cdot \mathbf{B}-\frac{1}{2} \mathbf{D . E}
$$

e a densidade de energia cinética $\rho_{m} \mathbf{v}^{2} / 2$ da partícula eletrizada, onde $\rho_{m}$ é a densidade de massa da partícula, impôs que

$$
\delta \mathrm{W}=0
$$

onde

$$
W=\iint\left(\rho_{m} \mathbf{v}^{2} / 2-\Lambda-\rho L\right) d V d t,
$$

a integral ocorrendo em uma região de integração na qual deveriam ser satisfeitas três condições:

i) $\Psi, \mathbf{A}$ (implícitos em $L$ e $\Lambda$ ) e as coordenadas de posição da partícula $\left(\mathrm{x}_{1}, \mathrm{x}_{2}, \mathrm{x}_{3}\right)$ estariam sujeitos a pequenas variações;

ii) estas variações se anulariam nos limites das integrais; e

iii) $\Psi, \mathrm{A}$ e as coordenadas da posição da partícula $\left(\mathrm{x}_{1}, \mathrm{x}_{2}, \mathrm{x}_{3}\right)$ variariam independentemente. Primeiro, mostraremos que, considerando $\delta \Psi$ e $\delta \mathbf{A}$ nulos, então $\delta \Lambda=0$. Para isso, faremos uso das noções de quadrivetores e quadri-operadores.

Sejam $\Psi$ e A tais que

$$
\begin{aligned}
& \mathbf{E}=-\nabla \Psi-\partial \mathbf{A} / \partial t \mathrm{e} \\
& \mathbf{B}=\nabla \times \mathbf{A} .
\end{aligned}
$$

\footnotetext{
${ }^{63}$ Arnold Johannes Wilhelm Sommerfeld (1868-1951), físico alemão.
} 
Assim, para um sistema vácuo + partículas carregadas, temos que

$$
\begin{gathered}
\Delta \mathbf{A}-\frac{1}{c^{2}} \frac{\partial^{2} \mathbf{A}}{\partial t^{2}}=-\mu_{0} \rho \mathbf{v} \\
\Delta \Psi-\frac{1}{c^{2}} \frac{\partial^{2} \Psi}{\partial t^{2}}=-\frac{\rho}{\varepsilon_{0}},
\end{gathered}
$$

onde $\Delta$ representa o operador $\partial^{2} / \partial x^{2}+\partial^{2} / \partial y^{2}+\partial^{2} / \partial z^{2}$ (laplaciano), $c, \mu_{0}$ e $\varepsilon_{0}$ são, respectivamente, a velocidade da luz, a permeabilidade magnética e a permissividade elétrica do vácuo. Quanto às outras grandezas, $\rho$ é uma densidade de carga e v é a velocidade associada a esta densidade em relação ao referencial em que foi definido $\mathbf{A}$.

Podemos, então, definindo as quantidades

e o operador

$$
\begin{aligned}
& x_{1}=x, \quad x_{2}=y, \quad x_{3}=z, \quad x_{4}=i c t, \\
& \boldsymbol{\Omega}=(\mathbf{A}, i \Psi / c)^{[64]}, \quad \Gamma=(\rho \mathbf{v}, i c \rho),
\end{aligned}
$$

$$
\square=\sum_{i=4}^{4} \frac{\partial^{2}}{\partial x_{i}^{2}},
$$

dizer que

$$
\square \Omega=-\mu_{0} \Gamma
$$

Agora, sabendo ainda que

$$
\begin{aligned}
& E_{\mathrm{x}}=-\frac{\partial \Psi}{\partial x}-\frac{\partial A_{x}}{\partial t} \mathrm{e} \\
& B_{\mathrm{x}}=\frac{\partial A_{z}}{\partial y}-\frac{\partial A_{y}}{\partial z},
\end{aligned}
$$

teremos, de acordo com (23) e (24),

$$
\begin{aligned}
& E_{\mathrm{x}}=i c\left(\frac{\partial \Omega_{4}}{\partial x_{1}}-\frac{\partial \Omega_{1}}{\partial x_{4}}\right) \mathrm{e} \\
& B_{\mathrm{x}}=\left(\frac{\partial \Omega_{3}}{\partial x_{2}}-\frac{\partial \Omega_{2}}{\partial x_{3}}\right)
\end{aligned}
$$

\footnotetext{
${ }^{64} \mathrm{O}$ fator $i$ em $\Omega_{4}$ é razoável em vista da definição de $x_{4}$, e o fator $1 / c$ é necessário para garantir a dimensionalidade. Ambos são requeridos se desejamos que $\sum_{i=4}^{4} \frac{\partial}{\partial x_{i}} \boldsymbol{\Omega}_{\mathrm{i}}=0$.
} 
Isto nos sugere a introdução de um rotacional quadridimensional tal que:

$$
\operatorname{Rot}_{\mathrm{nm}} \Omega=\left(\frac{\partial \Omega_{m}}{\partial x_{n}}-\frac{\partial \Omega_{n}}{\partial x_{m}}\right)
$$

Os elementos $\left\{\operatorname{Rot}_{\mathrm{nm}} \Omega\right\}$, como podemos observar, podem ser dispostos em uma matriz 4x4. Então, definindo elementos $F_{n m}$ da forma

$$
\mathrm{F}_{\mathrm{nm}}=c \operatorname{Rot}_{\mathrm{nm}} \Omega
$$

e observando que $\operatorname{Rot}_{n m} \Omega=-\operatorname{Rot}_{m n} \Omega$ e $\operatorname{Rot}_{n n} \Omega=0$, encontramos:

$$
F=\left(\begin{array}{cccc}
0 & c B_{z} & -c B_{y} & -i E_{x} \\
-c B_{z} & 0 & c B_{x} & -i E_{y} \\
c B_{y} & -c B_{x} & 0 & -i E_{z} \\
i E_{x} & i E_{y} & i E_{z} & 0
\end{array}\right) .
$$

Veremos agora que considerando $\delta \Psi$ e $\delta \mathbf{A}$ nulos, ou seja, $\delta \Omega=0$, então

$$
\delta \iint \Lambda d V d t=0
$$

Definindo uma grandeza $f$ tal que

$$
f=\varepsilon_{0} F
$$

e um produto escalar $(f . F)$ da forma

$$
f . F=f_{12} F_{12}+f_{23} F_{23}+f_{31} F_{31}+f_{14} F_{14}+f_{24} F_{24}+f_{34} F_{34},
$$

pode ser mostrado que

$$
(1 / 2) f . F=\Lambda \text {. }
$$

Mas, conforme (25), podemos escrever (27) como

$$
f . F=c\left(f_{12} \operatorname{Rot}_{12} \boldsymbol{\Omega}+f_{23} \operatorname{Rot}_{23} \boldsymbol{\Omega}+f_{31} \operatorname{Rot}_{31} \boldsymbol{\Omega}+f_{14} \operatorname{Rot}_{14} \boldsymbol{\Omega}+f_{24} \operatorname{Rot}_{24} \boldsymbol{\Omega}+f_{34} \operatorname{Rot}_{34} \boldsymbol{\Omega}\right) \text {. }
$$

Considerando então, provisoriamente, que de $f$ conhecemos apenas a propriedade de anti-simetria e que somente $\Omega_{1}$ é variável, podemos escrever a expressão acima como

$$
f . F=c\left(-f_{12} \frac{\partial \boldsymbol{\Omega}_{1}}{\partial x_{2}}+f_{31} \frac{\partial \boldsymbol{\Omega}_{1}}{\partial x_{3}}-f_{14} \frac{\partial \boldsymbol{\Omega}_{1}}{\partial x_{4}}\right)=-c\left(f_{12} \frac{\partial \boldsymbol{\Omega}_{1}}{\partial x_{2}}+f_{13} \frac{\partial \boldsymbol{\Omega}_{1}}{\partial x_{3}}+f_{14} \frac{\partial \boldsymbol{\Omega}_{1}}{\partial x_{4}}\right),
$$

uma vez que $\Omega_{2}, \Omega_{3}$ e $\Omega_{4}$ são constantes.

Temos, portanto, considerando (28) e (29),

$$
\delta \iint \Lambda d V d t=-(c / 2) \delta \iint\left(f_{12} \frac{\partial \Omega_{1}}{\partial x_{2}}+f_{13} \frac{\partial \Omega_{1}}{\partial x_{3}}+f_{14} \frac{\partial \Omega_{1}}{\partial x_{4}}\right) d V d t .
$$


Assim, denotando $(c / 2)$ por $k$,

$$
\delta \iint \Lambda d V d t=-k \iint\left(f_{12} \frac{\partial \delta \Omega_{1}}{\partial x_{2}}+f_{13} \frac{\partial \delta \Omega_{1}}{\partial x_{3}}+f_{14} \frac{\partial \delta \Omega_{1}}{\partial x_{4}}\right) d V d t .
$$

Integrando por partes ${ }^{[65]} \mathrm{em} \mathrm{x}_{2}, \mathrm{x}_{3}$ e $\mathrm{x}_{4}$, obtemos

$$
\delta \iint \Lambda d V d t=k \iint\left(\frac{\partial f_{12}}{\partial x_{2}}+\frac{\partial f_{13}}{\partial x_{3}}+\frac{\partial f_{14}}{\partial x_{4}}\right) \delta \Omega_{1} d V d t,
$$

uma vez que $\delta \Omega_{1}$ se anula na fronteira da região do considerada. Este resultado pode ser generalizado para os casos em que $\Omega_{2}, \Omega_{3}$ e $\Omega_{4}$ são variados.

Então, de modo geral, se $\Omega$ não é variado diretamente, ou seja, se $\Psi$ e $\mathbf{A}$ não são variados diretamente, obtemos

$$
\delta \iint \Lambda d V d t=0
$$

justamente o resultado que buscávamos demonstrar.

Veremos agora que, para encontrar a força sobre uma partícula carregada em movimento nesta região, precisamos considerar apenas variações em $\left(\mathrm{x}_{1}, \mathrm{x}_{2}, \mathrm{x}_{3}\right)$, de modo que podemos considerar válida a Eq. (30).

Então, em (22), precisamos analisar somente as variações de $\rho_{m} \mathbf{v}^{2} / 2$ e $\rho L$ conseqüentes das variações de $\left(\mathrm{x}_{1}, \mathrm{x}_{2}, \mathrm{x}_{3}\right)$. Vejamos primeiro a variação de $\rho_{m} \mathbf{v}^{2} / 2$.

Assumindo $\rho_{m}$ constante, encontramos

$$
\delta \iint\left(\rho_{m} / 2\right) \sum_{j=1}^{3}\left(d x_{j} / d t\right)^{2} d V d t=\int(m / 2) \sum_{j=1}^{3} \delta\left(d x_{j} / d t\right)^{2} d t .
$$

Continuando, temos

$$
\delta \iint\left(\rho_{m} / 2\right) \sum_{j=1}^{3}\left(d x_{j} / d t\right)^{2} d V d t=\int m \sum_{j=1}^{3}\left(\frac{d x_{j}}{d t} \frac{d \delta x_{j}}{d t}\right) d t .
$$

Realizando uma integração por partes na última integral e sabendo que, por definição, $\delta x_{j}$ se anula nos limites temporais considerados, encontramos, finalmente

$$
\delta \iint\left(\rho_{m} \mathbf{v}^{2} / 2\right) d V d t=-\int \sum_{j=1}^{3} \frac{d}{d t}\left(m \frac{d x_{j}}{d t}\right) \delta x_{j} d t .
$$

\footnotetext{
${ }^{65}$ Em nossa representação, um dos símbolos de integração corresponde, na realidade, a três integrais: sobre $x$, $y$ e $z$, respectivamente.
} 
Vejamos agora a variação de $\rho L$. Considerando $L$ dado por (20), podemos escrever

$$
\delta \iint \rho L d V d t=\delta \iint \rho(\Psi-\mathbf{v . A}) d V d t=e \iint\left[\delta^{\prime} \Psi-\delta^{\prime}(\mathbf{v} \cdot \mathbf{A})\right] d V d t,
$$

onde

$$
\begin{aligned}
& \delta^{\prime} \Psi=\sum_{j=1}^{3} \frac{\partial \Psi}{\partial \mathrm{x}_{\mathrm{j}}} \delta x_{j} \text { e } \\
& \delta^{\prime}(\mathbf{v . A})=\delta^{\prime}\left(\sum_{j=1}^{3} \frac{d x_{j}}{d t} A_{j}\right)=\sum_{j=1}^{3}\left(\frac{d \delta x_{j}}{d t} A_{j}+\sum_{k=1}^{3} \frac{d x_{j}}{d t} \frac{\partial A_{j}}{\partial x_{k}} \delta x_{k}\right) .
\end{aligned}
$$

Com isso, obtemos

$$
\delta \iint \rho L d V d t=e \int\left[\sum_{j=1}^{3}\left(\frac{\partial \Psi}{\partial \mathrm{x}_{\mathrm{j}}} \delta x_{j}-\left(\frac{d \delta x_{j}}{d t} A_{j}+\sum_{k=1}^{3} \frac{d x_{j}}{d t} \frac{\partial A_{j}}{\partial x_{k}} \delta x_{k}\right)\right)\right] d t
$$

Integrando por partes os termos $\left(d \delta x_{j} / d t\right) A_{j}$, obtemos que

$$
\int\left(\sum_{j=1}^{3} \frac{d \delta x_{j}}{d t} A_{j}\right) d t=-\int\left(\sum_{j=1}^{3} \frac{d A_{j}}{d t} \delta x_{j}\right) d t
$$

devido ao fato de $\delta x_{j}$ se anular nos extremos de integração.

E, como

$$
\frac{d A_{j}}{d t}=\frac{\partial A_{j}}{\partial t}+\sum_{k=1}^{3} \frac{\partial A_{j}}{\partial x_{k}} \frac{d x_{k}}{d t}
$$

então (35) torna-se

$$
\int\left(\sum_{j=1}^{3} \frac{d \delta x_{j}}{d t} A_{j}\right) d t=-\int\left(\sum_{j=1}^{3}\left(\frac{\partial A_{j}}{\partial t}+\sum_{k=1}^{3} \frac{\partial A_{j}}{\partial x_{k}} \frac{d x_{k}}{d t}\right) \delta x_{j}\right) d t
$$

Assim, (34) fica

$$
\delta \iint \rho L d V d t=e \int \sum_{j=1}^{3}\left(\frac{\partial \Psi}{\partial \mathrm{x}_{\mathrm{j}}} \delta x_{j}+\frac{\partial A_{j}}{\partial t} \delta x_{j}-\sum_{k=1}^{3} \frac{d x_{k}}{d t}\left(\frac{\partial A_{k}}{\partial x_{j}}-\frac{\partial A_{j}}{\partial x_{k}}\right) \delta x_{j}\right) d t
$$

Então, impondo a condição (21) à Eq. (22), e utilizando os resultados (32) e (37), chegamos a

$$
\delta W=-\int\left\{\sum_{j=1}^{3} \frac{d}{d t}\left(m \frac{d x_{j}}{d t}\right)+e\left[\frac{\partial \Psi}{\partial \mathrm{x}_{\mathrm{j}}}+\frac{\partial A_{j}}{\partial t}-\sum_{k=1}^{3} \frac{d x_{k}}{d t}\left(\frac{\partial A_{k}}{\partial x_{j}}-\frac{\partial A_{j}}{\partial x_{k}}\right)\right]\right\} \delta x_{j} d t=0 .
$$


Uma vez que o deslocamento $\delta x_{j}$ é arbitrário, a condição $\delta \mathrm{W}=0$ implica necessariamente que o termo entre chaves deve se anular. Desta forma, para cada $j$,

$$
\frac{d}{d t}\left(m \frac{d x_{j}}{d t}\right)=e\left(-\frac{\partial \Psi}{\partial \mathrm{x}_{\mathrm{j}}}-\frac{\partial A_{j}}{\partial t}+\sum_{k=1}^{3} \frac{d x_{k}}{d t}\left(\frac{\partial A_{k}}{\partial x_{j}}-\frac{\partial A_{j}}{\partial x_{k}}\right)\right) .
$$

Considerando, por exemplo, $j=1$, temos

$$
\frac{d}{d t}\left(m \frac{d x_{1}}{d t}\right)=e\left[-\frac{\partial \Psi}{\partial x_{1}}-\frac{\partial A_{1}}{\partial t}+\frac{d x_{2}}{d t}\left(\frac{\partial A_{2}}{\partial x_{1}}-\frac{\partial A_{1}}{\partial x_{2}}\right)-\frac{d x_{3}}{d t}\left(\frac{\partial A_{1}}{\partial x_{3}}-\frac{\partial A_{3}}{\partial x_{1}}\right)\right] .
$$

Mas isto é justamente um dos termos da equação da força de Lorentz! E pode ser verificado que os outros termos também são idênticos aos correspondentes da expressão da força de Lorentz. Deste modo, (39) é completamente equivalente a

$$
\frac{d}{d t}\left(m \frac{d \boldsymbol{r}}{d t}\right)=e(\mathbf{E}+\mathbf{v} \times \mathbf{B}) \text {. }
$$

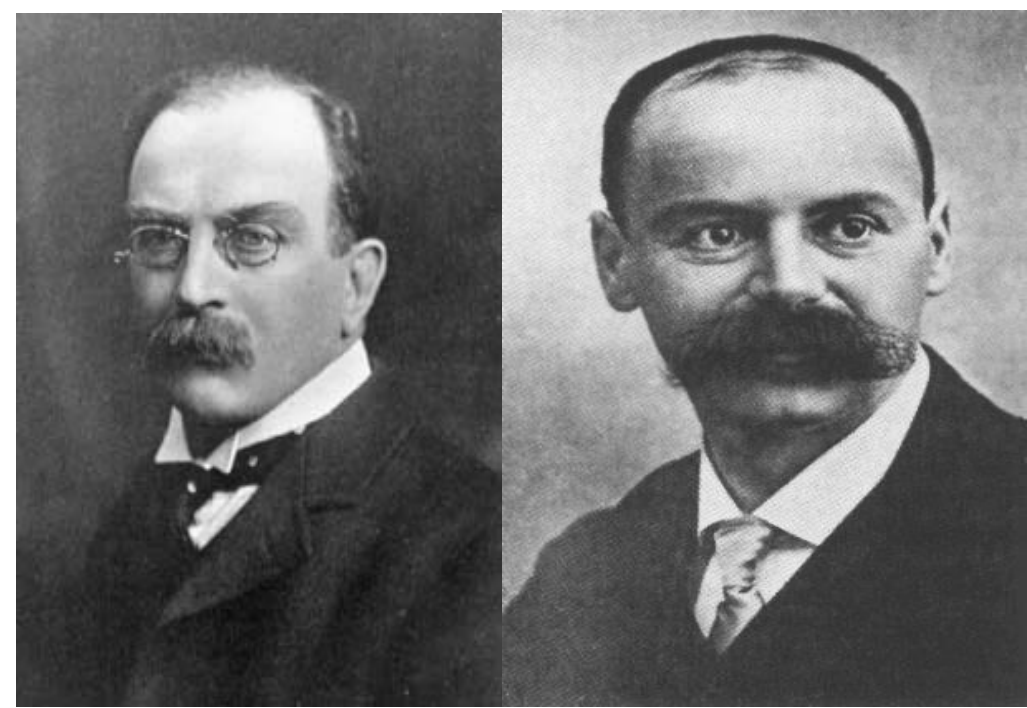

Fig. 6 - Joseph Larmor (1857-1942) e Karl Schwarzschild (1871-1916) 


\section{3 - CAMPO: DEFINIÇÕES MÚLTIPLAS E TRATAMENTO NOS LIVROS DIDÁTICOS}

No capítulo anterior, onde analisamos o aspecto histórico e a fundamentação conceitual da força de Lorentz, os significados das expressões campo elétrico e campo magnético foram bem precisos: campo elétrico seria o nome dado ao campo vetorial $\mathbf{E}(\mathbf{r}, \mathrm{t})$, cuja definição estabelecemos, e campo magnético designaria o campo vetorial $\mathbf{H}(\mathbf{r}, \mathrm{t})$ ou, por vezes, o campo vetorial $\mathbf{B}(\mathbf{r}, \mathrm{t})$, ambos também já definidos. Neste capítulo, por outro lado, mostraremos que a expressão campo acabou adquirindo várias conotações no contexto do Eletromagnetismo Clássico; além disso, apontaremos o que nos parece incoerente em livros didáticos de graduação e pós-graduação em Física no que se refere à aplicação do termo campo.

\subsection{UMA QUESTÃO LINGÜÍSTICA: AS NOÇÕES DE CAMPO ONTEM E HOJE}

Vejamos a profunda alteração de significado que sofreu a palavra campo, no contexto da Física, dos tempos de Michael Faraday (1791-1867) aos dias atuais.

Faraday, que pensava os fenômenos eletromagnéticos em termos das linhas de força (linhas de potência), curvas cujas tangentes indicariam a direção da força sobre uma partícula carregada (linha de força elétrica) ou sobre um "pólo" magnético (linha de força magnética), denominava campo à porção do espaço considerada com relação ao fenômeno elétrico e/ou magnético em análise. Em certo ponto do seu Experimental Researches in Electricity, ele faz a seguinte colocação:

(...) I will now endeavour to consider what is the influence which paramagnetic and diamagnetic bodies, viewed as conductors, exert upon the lines of force in a magnetic field. Any portion of space traversed by lines of magnetic power may be taken as such a field, and there is probably no space without them (...) [Faraday : §2806]. 
Este conceito de campo foi mantido por Maxwell, como nos mostra sua definição de campo elétrico:

(...) the Electric Field is the portion of space in the neighbourhood of electrified bodies, considered with reference to electric phenomena. [Maxwell ${ }^{(\mathrm{b})}: 44$ (art.44)].

Analogamente o fizeram Sir J. J. Thomson e Sir James Jeans (1877-1946), conforme podemos ver nestes trechos:

(...) the region in which the [electric] attractions and repulsions are observed is called the electric field. [Thomson ${ }^{(\mathrm{c})}: 1$ ],

(...) the space in the neighbourhood of charges of electricity, considered with reference to the electric phenomena occurring in this space, is spoken of as the electric field. [Jeans : 24].

Observamos, então, que havia um forte consenso entre grandes físicos do passado sobre o conceito de campo. Não é de se estranhar isto, uma vez que se trata apenas do significado de uma palavra. Com o tempo, porém, a noção de campo, em Física, praticamente perdeu seu significado original, e esse termo ganhou diversas outras acepções. Por exemplo, nos últimos 70 anos, no que se refere aos fenômenos eletromagnéticos, encontramos nos livros didáticos os seguintes significados para campo:

1) Região em que partículas carregadas e/ou correntes ficam sujeitas a forças (acepção original, raramente utilizada hoje em dia);

2) Quantidade física vetorial definida por uma função matemática $(\mathbf{E}(\mathbf{r}, t)$ - campo elétrico; $\mathbf{B}(\mathbf{r}, t)$ - campo magnético);

3) Conjunto das linhas de força (elétricas ou magnéticas) em determinada região;

4) "Estado" do espaço, "condição" no espaço ${ }^{[66]}$;

5) Meio imaterial suscetível de sofrer a ação de partículas e/ou correntes elétricas ${ }^{[67]}$;

6) $\mathbf{E}(\mathbf{r}, t)$ e/ou $\mathbf{B}(\mathbf{r}, t)$ entendidos como entes físicos ${ }^{[68]}$.

\footnotetext{
${ }^{66}$ Espaço, aqui, deve ser entendido de uma maneira bastante peculiar. Discutiremos sobre isto na nota de rodapé de um dos trechos utilizados para ilustrar este conceito.

${ }^{67}$ Este conceito, de certo modo, pode ser incluso na acepção 1, se consideramos que a região referida naquela acepção é "preenchida" com algo imaterial.
} 
Antes de exemplificarmos estas acepções com trechos de livros, observemos que os conceitos $\mathbf{2}$ e $\mathbf{3}$ são apenas instrumentos que nos possibilitam o manejamento dos fatos com os quais estamos lidando, enquanto as acepções $\mathbf{4}$ e $\mathbf{5}$ referem-se à própria realidade física em questão ${ }^{[69]}$.

A utilização de desenhos e de ferramentas matemáticas para o entendimento dos processos físicos envolvendo partículas carregadas possibilitou grandes avanços para o Eletromagnetismo Clássico. Estes elementos (desenhos e ferramentas matemáticas), criados conscientemente pela mente humana, não fazem parte da realidade física em si, independentemente do que entendamos por realidade física. Mesmo que cogitemos a realidade como consensual, ainda assim os elementos referidos pertenceriam a uma outra classe de coisas, uma vez que são frutos de esforços conscientes.

Feita esta ressalva, vejamos agora alguns exemplos das utilizações do termo campo em artigos e livros relativamente recentes:

1) Campo como parte do espaço nas vizinhanças de um corpo carregado.

Field in general signifies a region of space considered in respect to the potential behaviour of test bodies moved about in it; the electricians of 1780 lacked the word but not the concept, which they called "sphere of influence", sphaera activitatis, or wirkungskreis. [Heilbron : 187]

2) Campo como quantidade física vetorial representante de processos físicos subjacentes.

(...) these electric charges therefore generate an electric field vector at all points of space (in vacuo). (...) The electric field vector will be denoted by $\boldsymbol{E}$ (...) [Atkin : 1]

An electric point charge produces in its vicinity an electric field $\mathbf{E}$ (...) [Becker : 63]

We can write the force $\boldsymbol{F}$ on a charge $q$ moving with a velocity $\boldsymbol{v}$ as $\boldsymbol{F}=q(\boldsymbol{E}+\boldsymbol{v} \times \boldsymbol{B})$. We call $\boldsymbol{E}$ the electric field and $\boldsymbol{B}$ the magnetic field at the location of the charge. [Feynman et al. ${ }^{(\mathrm{b})}: 2$ (do cap.1)]

\footnotetext{
${ }^{68}$ Esta acepção, incoerente por si mesma, será discutida adiante.

${ }^{69}$ Discutiremos as acepções $\mathbf{4}$ e $\mathbf{5}$ no último capítulo desta dissertação.
} 
The electric and magnetic fields $\boldsymbol{E}$ e $\boldsymbol{B}$ (...) [Jackson : 3]

(...) Suponhamos a existência de uma carga q no espaço. Podemos associar a cada ponto distante $r$ de $q$ um vetor de valor $q / 4 \pi \varepsilon_{0} r^{2}$ e apontado radialmente. Temos então definido um campo vetorial, o qual chamaremos campo eletrostático e simbolizaremos por $\boldsymbol{E}$. [Quevedo : 32]

\subsection{The Magnetic Field, B [Shadowitz : 118]}

3) Campo como linhas de força.

(...) Continuous lines may be imagined to spread out from every elementary electric charge in such a way as to diverge uniformly in all directions when viewed from the system in which, at the instant considered, the charge is at rest. These lines are called lines of force and, taken together, they constitute the charge's field. [Page : 20]

(...) For the moment, all the lines of force, or briefly speaking, the field, indicate only how a test body would behave if brought into the vicinity of the sphere for which the field is constructed. [Einstein \& Infeld : 131]

4) Campo como “estado" do espaço, como uma espécie de distorção do espaço.

(...) because in the final analysis in a theory of fields the ponderable matter, or the elementary particles that constitute this matter, also have to be considered as 'fields' of a particular kind, or as particular 'states' of the space. [Einstein $\left.{ }^{(\mathrm{d})}: 13\right]^{[70]}$

The natural interpretation of electrical interaction is that two objects simply attract each other: plus against minus. However, this was discovered to be an inadequate idea to represent it. A more adequate representation of the situation is to say that the existence of the positive charge, in some sense, distorts, or creates a "condition" in space ${ }^{[71]}$, so that when we put the negative charge in it feels a force. This potenciality for producing a force is called an electric field. [Feynman et al. ${ }^{\text {(a) }}$ : 4 (do cap. 2)]

\footnotetext{
${ }^{70}$ No artigo (traduzido) de onde este trecho foi retirado, a palavra espaço se refere a um ente físico.

${ }^{71}$ Aqui, também, espaço deve ser entendido de forma peculiar, como no trecho anterior.
} 
5) Campo como meio imaterial responsável pela interação entre cargas.

If the field is considered as the symbolic medium for the action between charges, equation (4.2) expresses the effect of the charges on the field, or, if one likes, they express the message given by the charges to the field. (...) We see that for the electromagnetic field the invariant diagonal sum of the tensor of the stresses and energy is zero. This agrees with the view that the field is a non-material symbolic medium for momentum and energy. In Chapter VII, 1, we called such media with zero mass telehapses. In quantum theory the telehapses related to the electromagnetic field are photons, which are immaterial, without mass.(...) [Fokker : 127 e 129]

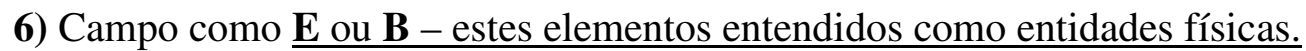

Ever since Faraday, the laws of electricity and magnetism have been expressed in terms of electric and magnetic fields, $\boldsymbol{E}$ and $\boldsymbol{B}$. (...) [Griffiths : 52]

What exactly is an electric field? I have deliberately begun with what you might call the "minimal" interpretation of $\boldsymbol{E}$, as an intermediate step in the calculation of electric forces. But I encourage you to think of the field as a "real" physical entity, filling the space in the neighborhood of any electric charge. (...) [Griffiths : 61]

Esta concepção merece uma análise. Primeiramente, Faraday nunca chegara a utilizar explicitamente os campos vetoriais E e B para expressar as leis da eletricidade e do magnetismo. Depois, a pergunta sobre o que é exatamente $\mathbf{E}$ não procede dentro do contexto em análise. Sabemos exatamente o que ele é: um campo vetorial que satisfaz as equações de Maxwell. Acreditamos que a pergunta mais adequada talvez fosse: "What exactly represents an electric field?". Além disso, pensar o campo elétrico (E) como uma entidade física "real", conforme indica o autor, também não nos parece adequado. Por ser um ente vetorial, $\mathbf{E}$ pode até representar uma entidade física, mas é uma impossibilidade lógica considerá-lo como a própria entidade. Talvez as aspas em real indiquem justamente isso... De qualquer forma, achamos que Griffiths poderia ter sido mais claro em seu texto.

Existem também artigos e livros em que a utilização da palavra campo não possibilita uma exata idéia sobre o que está sendo entendido por este termo. Vejamos os seguintes trechos: 
(...) arises in the neighbourhood of the magnet an electric field with a certain definite energy. [Einstein $\left.{ }^{(a)}: 35\right]$

The interaction of particles can be described with the help of the concept of a field of force. Namely, instead of saying that one particle acts on another, we may say that the particles creates a field around itself; a certain force then acts on every other particle located in this field. [Landau \& Lifshitz : 41]

Nas obras em que estes trechos estão inseridos, nada mais é explanado sobre o conceito de campo. Deles observamos que campo tanto pode ser entendido como uma espécie de distorção do espaço (acepção 4) quanto como uma "aura" permeando o espaço ao redor da partícula (acepção 5).

Do exposto nesta seção, observamos que em livros e artigos tratando sobre Eletromagnetismo a palavra campo não possui significado único. Isto pode causar alguma confusão e levar a interpretações não muito precisas, se não analisamos o contexto.

\subsection{IMPRECISÕES, INCOERÊNCIAS E DISTORÇÕES HISTÓRICAS EM ARTIGOS E LIVROS}

Já mostramos, anteriormente, os vários significados atualmente atribuídos, dentro do contexto da Física, ao termo campo. Quando tal multiplicidade de significados aparece sem as devidas ressalvas de que conceitos distintos associados a uma mesma palavra estão sendo utilizados, interpretações não muito corretas podem ocorrer.

Vejamos alguns exemplos que ilustram esta dificuldade dos livros didáticos em associar um conceito preciso à palavra campo. 
The Feynman's Lectures on Physics, vols. 1 e 2 (1963/1964)

No volume 1 de The Feynman Lectures on Physics, consta o seguinte:

Another tremendous amalgamation was the discovery of the relation between electricity, magnetism, and light, which found to be different aspects of same thing, which we call today the electromagnetic field. (Pág. 2 do Cap. 2 [2-2])

É curioso observar que Feynman fez esta consideração sem primeiro definir quaisquer dos principais elementos envolvidos nela: eletricidade, magnetismo, luz e campo eletromagnético. De luz, a princípio, nós temos uma concepção intuitiva; dos outros termos, porém, não existe um consenso absoluto sobre seus significados. Assim, parece-nos que a afirmação do autor, de que eletricidade, magnetismo e luz são aspectos do campo eletromagnético, não foi muito clara.

Neste mesmo livro, encontramos:

The natural interpretation of electrical interaction is that two objects simply attract each other: plus against minus. However, this was discovered to be an inadequate idea to represent it. A more adequate representation of the situation is to say that the existence of the positive charge, in some sense, distorts, or creates a "condition" in space, so that when we put the negative charge in it feels a force. This potenciality for producing a force is called an electric field. (Pág.4 do cap.2 [2-4])

No trecho acima transcrito, os autores utilizam nossa acepção 4 para campo. Mas vejamos o que eles dizem no volume 2 da obra já mencionada:

We can write the force $\boldsymbol{F}$ on a charge $q$ moving with a velocity $\boldsymbol{v}$ as $\boldsymbol{F}=q(\boldsymbol{E}+\boldsymbol{v} \times \boldsymbol{B})$. We call $\underline{\boldsymbol{E}}$ the electric field and $\underline{\boldsymbol{B}}$ the magnetic field at the location of the charge. (1-2)

It is precisely because $\boldsymbol{E}$ (or $\boldsymbol{B})$ can be specified at every point in space that it is called a 'field'. A 'field' is any physical quantity which takes on different values at different points in space. (...) There have been various inventions to help the mind visualize the behavior of fields. The most correct is also the most abstract: we simply consider the fields as mathematical functions of position and time. (Pág.4 do cap.1 [1-4])

(...) The only sensible question is what is the most convenient way to look at electrical effects. Some people prefer to represent them as the interaction at a distance of charges, and to use a complicated law. Others love the field lines (...) The best way is to use the abstract field idea. That it is abstract is unfortunate, but necessary. (Pág.9 do cap.1 [1-9]) 
Aqui os autores deixam claro que estão utilizando nossa acepção 2 (quantidade física vetorial) para campo, e explanam muito bem sobre isto. Porém, não ressaltam que há uma diferença entre esta concepção e a do volume 1. Enquanto neste último os autores denominam campo elétrico à "condição" em uma região do espaço que permite uma partícula carregada ali inserida sentir a ação de uma força, no vol. 2 denominam campo elétrico à representação matemática desta "potencialidade". Ainda que a ambigüidade transpareça apenas da análise conjunta dos dois volumes, seria ideal que pudesse ser contornada. Isto poderia ser feito com uma simples ressalva.

\section{Introduction to Electrodynamics (1999), de David J. Griffiths}

Neste livro encontramos afirmações como:

(...) We say that space around an electric charge is permeated by electric and magnetic fields (the electromagnetic "odor", as it where, of the charge). A second charge, in the presence of the fields, experiences a force; the fields, then, transmit the influence from one charge to the other-they mediate the interaction. (Pág. xiii)

Ever since Faraday, the laws of electricity and magnetism have been expressed in terms of electric and magnetic fields, $\boldsymbol{E}$ and $\boldsymbol{B}$. (...) (Pág. 52)

Reparemos, primeiramente, que a palavra electric charge, presente no primeiro trecho, refere-se a partícula carregada, não à quantidade carga elétrica, que é associada à propriedade característica de partículas carregadas. Isto pode ser percebido do fato do autor ter separado ontologicamente uma carga de outra, tratando-as como entes físicos. Uma vez entendido isto, qualquer possibilidade de que campo deva ser entendido in abstracto neste trecho fica excluída, uma vez que aos campos é atribuído o papel de mediadores da influência entre partículas carregadas. Assim, a contradição: enquanto no primeiro trecho transmite-se a idéia de que os campos são realidades físicas, mediadores da interação entre partículas carregadas, no outro o campo é tratado como quantidade vetorial, o que pode caracterizar determinada realidade física, mas obviamente não é uma realidade física. 


\section{Classical Electrodynamics (1999), de John D. Jackson}

Analisaremos agora alguns trechos desta obra, que serão numerados, os comentários vindo a seguir.

1 - (...) Biot and Savart (1820), first, and Ampère (1820-1825), in much more elaborate and thorough experiments, established the basic experimental laws relating the magnetic induction $\boldsymbol{B}$ to the currents and established the law of force between one current and another (...) (Pág. 175)

Biot, Savart e Ampére não lidaram com B quando analisaram os resultados dos seus experimentos, segundo J. R. Hofmann, biógrafo de Ampère. Biot e Savart estudaram o torque exercido por um longo fio retilíneo com corrente sobre um ímã, e Ampère analisou, dentre outras coisas, a ação mútua entre correntes elétricas, baseando-se em uma teoria de ação à distância. Além disso, os resultados das primeiras experiências de Ampère a este respeito foram apresentados dias antes daqueles de Biot e Savart [Hofmann : 236-238].

2 - (...) Then we can interpret Poynting's theorem for the microscopic fields $(\boldsymbol{E}, \boldsymbol{B})$ as a statement of conservation of energy of the combined system of particles and fields. (...) (Págs. 259-260)

Rigorosamente, as palavras finais deveriam ser, em nossa opinião, algo do tipo: the combined system of particles and entities characterized by fields. Do contrário, poderíamos estar criando uma assimetria, uma vez que partículas são entes físicos, enquanto campos, segundo as definições fornecidas no livro em análise, são entes matemáticos, abstratos.

\section{$\underline{\text { Idéias de Albert Einstein (1879-1955) }}$}

1) Comparação entre um trecho do discurso "Äther und Relativitäts-Theorie" (1920) e trechos do artigo "Über den Äther" (1924), ambos de Albert Einstein. ${ }^{[72]}$

\footnotetext{
${ }^{72}$ Utilizaremos as versões inglesas dos textos ("Ether and the Theory of Relativity" e "On the Ether"), encontradas, respectivamente, no livrete Sidelights on Relativity, que consta de dois discursos de Einstein traduzidos para o inglês e encontra-se disponível em
} 
No discurso citado, Einstein diz o seguinte, em certo ponto:

(...) The electromagnetic fields are not states of a medium, and are not bound down to any bearer, but they are independent realities which are not reducible to anything else, exactly like the atoms of ponderable matter. [Einstein ${ }^{(\mathrm{c})}$ : 9]

Porém, no artigo mencionado, encontramos trechos como estes:

(...) because in the final analysis in a theory of fields the ponderable matter, or the elementary particles that constitute this matter, also have to be considered as 'fields' of a particular kind, or as particular 'states' of the space ${ }^{[73]}$. [Einstein $\left.{ }^{(\mathrm{d})}: 13\right]$

(...) The metric tensor which determines both gravitational and inertial phenomena on the one hand, and the tensor of the electromagnetic field on the other, still appear as fundamentally different expressions of the state of the ether; but their logical independence is probably more to be attributed to the imperfection of our theoretical edifice than to a complex structure of reality itself. [Einstein $\left.{ }^{(\mathrm{d})}: 18\right]$

(...) But even if these possibilities should mature into genuine theories, we will not able to do without the ether in theoretical physics, i.e. a continuum which is equipped with physical properties. [Einstein $\left.{ }^{(\mathrm{d})}: 20\right]$

Ou seja: enquanto no discurso de 1920, que Einstein pronunciou na Universidade de Leiden, Alemanha, o físico alemão considera que os campos eletromagnéticos são realidades independentes, que não são estados de um meio, em seu artigo de 1924 afirma que eles são estados de um continuиm equipado de propriedades físicas. Mas um continuиm dotado de propriedades físicas não deixa de ser um meio...

2) Artigo "Über den Äther" (1924) ${ }^{[74]}$, de Albert Einstein.

No item anterior, realizamos um cotejo entre um trecho do discurso de Einstein de 1920 na Universidade de Leiden e trechos de seu artigo "Über den Äther" (1924). Agora, faremos uma análise da coerência interna deste artigo. Vejamos alguns trechos:

www.ibiblio.org/ebooks/Einstein/Sidelights/Einstein_Sidelights.pdf (acessado em 05.08.07), e no livro editado por S. Saunders e H.R. Brown The Philosophy of Vacuum, págs. 13-20 [Einstein ${ }^{(\mathrm{d})}$ ].

${ }^{73}$ Vide nota 70.

${ }^{74}$ Foi utilizada a versão inglesa deste artigo, "On the Ether", que se encontra no livro The Philosophy of Vacuum, págs. 13-20 [Einstein ${ }^{(\mathrm{d})}$ ]. 
(...) because in the final analysis in a theory of fields the ponderable matter, or the elementary particles that constitute this matter, also have to be considered as 'fields' of a particular kind, or as particular 'states' of the space. (Pág. 13) ${ }^{[75]}$

(...) The metric tensor which determines both gravitational and inertial phenomena on the one hand, and the tensor of the electromagnetic field on the other, still appear as fundamentally different expressions of the state of the ether (...) (Pág. 18)

Nos trechos acima, observamos que Einstein está utilizando nossa acepção 4, de campo como "estado" do espaço ou éter, termo também utilizado pelo físico alemão. Mas observemos este trecho:

The earth and the sun have magnetic fields, the orientation and sense of which stand in approximate relationship to the axes of rotation of these heavenly bodies. (Págs. 18-19)

Aqui, Einstein utiliza nossas acepções 2 ou 3, uma vez que fala de orientação e sentido dos campos, características que não caberiam nos significados $\mathbf{4}$ e $\mathbf{5}$.

Então, seria interessante nos perguntarmos: o que Einstein entendia nesta época (1924) por campo? "Estado" do espaço ou éter (conforme trechos das págs. 13 e 18 de seu artigo) ou caracterização matemática de uma realidade subjacente (conforme trecho das págs. 18-19)? Estas duas conceituações são excludentes, de modo que não se poderia dizer que cabe a campo os dois significados, ou seja: campo não poderia ser considerado, ao mesmo tempo, estado e ente matemático.

Nota: Parece-nos que há ao menos dois pequenos erros de tradução na versão inglesa do artigo de Einstein, escrito originalmente em alemão. O primeiro, que nos parece um pouco mais sério, está relacionado ao que segue:

(...) Under this burden of failure, the electromagnetic fields were gradually considered as final, irreducible physical realities, which are not to be further explained as states of the ether. (Pág. 16)

\footnotetext{
${ }^{75}$ Vide nota 70
} 
Acreditamos que o trecho grifado deveria ter sido traduzido algo como no more looked as explicable states of the ether, pois é a tradução de als nicht mehr weiter erklärbare Zustände des Äther betrachtet. Notemos que o significado é diverso; enquanto na tradução inglesa transmite-se a idéia de que os campos eletromagnéticos não são mais considerados estados do éter, o pensamento que acreditamos ter sido apresentado na versão original é que os campos são estados do éter e que nada mais poderíamos dizer.

Interessante observar que existe uma tradução italiana do $\operatorname{artigo~}^{[76]}$ que reproduz mais fielmente o conteúdo do artigo original: “come uno stato non ulteriormente spiegabile dell'etere”, ou seja, “como um estado do éter não mais explicável”.

O outro deslize da tradução inglesa, menos sério, pois que facilmente perceptível, está relacionado ao trecho seguinte:

(...) Because it was no longer possible to speak of simultaneous states in different places in the ether in any absolute sense, the ether became, so to speak, four-dimensional, because there was no objective arrangement of its space in accordance with time alone. (Pág. 17)

As palavras grifadas deveriam ser $\underline{\text { events }}$ (tradução de Ereignisse). A tradução italiana dá o significado correto: “(...) poiche non si poteva piu parlare in senso assoluto di eventi contemporanei in posizioni diverse dell'etere, l'etere risultava in un certo senso tetradimensionale, e non si aveva alcun ordine obbiettivo dei suoi eventi in funzione soltanto del tempo”, ou seja, “(...) porque não era mais possível falar em sentido absoluto de simultâneos eventos em posições diversas do éter, o éter tornou-se de certo modo tetradimensional, e não havia qualquer ordenamento objetivo de seus eventos em função somente do tempo".

3) Livro The Evolution of Physics, de Albert Einstein e Leopold Infeld.

No capítulo III (intitulado Field, Relativity), a primeira seção, iniciada na página 129, é denominada The field as representation. Notamos, então, já de início, que o

\footnotetext{
${ }^{76} \mathrm{In}$

http://209.85.165.104/search?q=cache:EZpfYREvmyEJ:ipparco.roma1.infn.it/pagine/deposito/archivio/einstei n/einstein24.ps.gz+\%22Uber+den+Ather\%22+Einstein\&hl=pt-BR\&ct=clnk\&cd=2\&gl=br (acessado em 06.11.07)
} 
texto não é muito claro. Nada havia sido dito anteriormente, até aquela página, sobre campo. Como este termo, já na época da publicação do livro (1938), trazia consigo vários possíveis significados, dizer the field não nos parece adequado. Um bom título seria algo como Field: a representation.

Nesta seção do livro, são condizentes com a idéia de campo como representação, por exemplo, os seguintes trechos:

(...) For the moment, all the lines of force, or briefly speaking, the field, indicate only how a test body would behave if brought into the vicinity of the sphere for which the field is constructed. (Pág. 131)

(...) In this way, the lines of force, or in other words, the field (...) (Pág. 135)

Nos trechos acima, campo é entendido em nossa acepção 3, no sentido de linhas de força. Porém, os seguintes trechos da mesma seção nos fornecem outra idéia:

(...) The drawing of the field, correctly interpreted, represents (...) This field representation, as we shall call it (...) (Pág. 131)

The field of a bar magnet can be represented on the same way as that of current. (...) (Pág. 136)

Nestes trechos os autores não mais se referem a campo como representação, mas como algo passível de ser representado; no caso, a maneira segundo a qual um corpo-teste se comportaria na região de estudo. Assim fazendo, parece-nos que desviam-se do título da seção (The field as representation) e firmam uma ambigüidade: ora campo se refere ao conjunto das linhas de força, ora se refere à maneira como um corpo-teste se comportaria na região em análise.

Vejamos alguns outros trechos desta seção.

The concept of field can now be put to a much more severe test. (Pág. 137)

Nenhum dos dois sentidos utilizados anteriormente no livro (maneira como um corpo-teste se comporta em uma região específica ou representação deste comportamento) indica haver necessidade de "mais severos testes". E os autores continuam: 
We shall soon see whether it is anything more than new representation of the acting forces. We could reason: assume, for a moment, that the field characterizes all actions determined by its sources in a unique way. This is only a guess. It would mean that if a solenoid and a bar magnet have the same field, then all their influences must also be the same. It would mean that two solenoids, carrying electric currents, behave like two bar magnets, that they attract or repel each other depending, exactly as in the case of bars, on their relative positions. (...) Experiment fully confirms our guess! (Págs. 137-138)

A partir da pág. 132 do livro, a noção de campo esteve restrita ao estudo de forças sobre "pólos" magnéticos, de modo que afirmações como "the field characterizes all actions determined by its sources in a unique way" ou "if a solenoid and a bar magnet have the same field, then all their influences must also be the same" não nos parecem aceitáveis. Os autores deveriam ter deixado mais claro: “(...) all magnetic actions (...)”, “(...) all their magnetic influences (...)”. Além disso, tratando-se de interações específicas (magnéticas, por exemplo), se o campo de um magneto em barra e o de um solenóide são análogos (ou seja, se as linhas de força magnética de um magneto em barra são análogas àquelas de um solenóide), não precisamos de experimentos para concluir que a força de origem magnética entre dois solenóides também poderá ser descrita da mesma maneira. O simples fato de que um solenóide tem campo magnético análogo ao de uma barra imantada acreditamos que já o torna "magneticamente" indistinguível deste último. Mais à frente:

(...) The properties of the field alone appear to be essential for the description of phenomena (...) (Pág. 138)

Mas as noções de campo mencionadas pelos autores se baseiam em fenômenos. Precisaríamos conhecer o comportamento de "pólos" magnéticos em uma dada região para definir o campo magnético ali. Seria importante que os autores tivessem apresentado algum fenômeno em que as propriedades associadas ao conceito de campo tivessem sido realmente essenciais. Depois:

(...) The concept of field reveals its importance by leading to new experimental facts. (Pág. 138) 
Teria sido interessante os autores exemplificarem esta afirmação. Antes deste trecho, realmente foi feita uma menção a um fato experimental novo: solenóides interagemse mutuamente do mesmo modo que barras imantadas. Mas isto não foi inferido teoricamente do simples conceito de campo (ambíguo na discussão de Einstein e Infeld), mas da hipótese que, se dois entes físicos possuem o mesmo campo, todas as suas influências devem ser as mesmas. E, mais além, escrevem:

The field proved a very helpful concept. It began as something placed between the source and the magnetic needle in order to describe the acting force. It was thought of as an "agent" of the current, through which all action of the current was performed. But now the agent also acts as an interpreter, one who translates the laws into a simple, clear language, easily understood. (Págs. 138-9)

A evolução conceitual aqui atribuída a campo não é totalmente condizente com aquilo que foi desenvolvido no livro anteriormente a este trecho. Parece-nos que em nenhum momento ficou claro que campo passara a ser entendido como "agente" da corrente e, depois, como "intérprete" da corrente.

Destes trechos do livro podemos observar que o conceito de campo ora é entendido como uma representação (o que é coerente com o título da seção), ora é entendido como algo real, passível de ser representado, ora é proposto como sendo objeto de uma evolução conceitual - não mostrada - que culmina na noção de "intérprete"...

$\mathrm{Na}$ seção seguinte do mesmo capítulo, denominada The two pilars of the field theory, podemos observar que a noção de campo apresentada não é a de uma representação, mas a de um ente físico. Acreditamos que isto não é coerente com o título da seção anterior (The field as representation) e com o posicionamento central defendido na mesma. Vejamos alguns trechos onde isto nos parece evidente:

It is quite a different matter if we use the field language and again trust our principle that the action [corrente em uma espira devida à variação temporal do campo magnético] is determined by the field. (Pág. 144)

Starting as a helpful model the field became more and more real. It helped us to understand old facts and led us to new ones. The attribution of energy to the field is one 
step further in the development in which the field concept was stressed more and more (...) (Pág. 148)

Se campo determina ações e ainda é possível atribuir energia a ele, então campo está sendo entendido como realidade, não como representação. Mas é uma impossibilidade lógica uma representação tornar-se realidade física. Assim, neste caso, não podemos falar em evolução conceitual; houve mudança conceitual, e esta mudança não foi discutida no livro.

Quando os autores mencionam que o campo começou como um modelo útil e foi se tornando real, talvez pareça, à primeira vista, que eles apontam justamente para a mudança conceitual que afirmamos não ter sido esclarecida. Mas parece não ser este o caso. Os autores se referem ao fato de que o "algo" físico que faz uma partícula carregada perceber a presença de outra pode, sob certas circunstâncias, ter realidade própria, tornando-se independente de sua fonte.

A terceira seção do cap. III é denominada The reality of the field. Notemos que neste título campo não está sendo considerado como representação. Mas vejamos este trecho da seção:

We have already seen, from Oersted's experiment, how a magnetic field coils itself around a changing electric field. We have seen, from Faraday's experiment, how an electric field coils itself around a changing magnetic field. (Pág. 149)

Estas afirmações não nos parecem condizentes com o título da seção. O que "espirala" são as linhas de força, que são representações da realidade do processo físico em questão. Se campo é entendido como realidade, o que "espirala" são as representações do campo; no caso, as linhas de força.

Porém, há também trechos que confirmam a idéia esboçada no título, como este:

(...) But Maxwell's new theoretical idea goes beyond these experimental facts. The electric and magnetic field, or, in short, the electromagnetic field, is, in Maxwell's theory, something real. The electric field is produced by a changing magnetic field, quite independently whether or not there is a wire to test its existence; a magnetic field is produced by a changing electric field, whether or not there is a magnetic pole to test its existence. (Pág. 151) 
Entretanto, como proposto por Maxwell, a realidade do "algo" responsável pela ação de cargas elétricas e correntes, que atua além dos limites físicos destas, seria devida exclusivamente ao fato da aceitação da existência de um éter. Os autores não mencionaram isto na seção, e, novamente, como nas seções precedentes, o conceito de campo permaneceu incerto.

Na seção posterior desse mesmo cap. III, denominada Field and ether, os autores confirmam a idéia da realidade do campo. Esta concepção se encaixa nas acepções $\mathbf{4}$ e $\mathbf{5}$ definidas no início do capítulo. Podemos citar como exemplo o seguinte trecho:

The electromagnetic field is, for the modern physicist, as real as the chair on which he sits. (Pág. 158)

Mas a questão sobre qual particular acepção de campo está sendo utilizada só é aparentemente resolvida no fim da seção:

(...) The field was at first considered as something which might later be interpreted mechanically with the help of ether. By the time it was realized that this program could not be carried out, the achievements of the field theory had already become too striking and important for it to be exchanged for a mechanical dogma. On the other hand, the problem of devising the mechanical model of ether seemed to become less and less interesting and the result, in view of the forced and artificial character of the assumptions, more and more discouraging.

Our only way out seems to be to take for granted the fact that space has the physical property of transmitting electromagnetic waves, and not to bother too much about the meaning of this statement. (...) (Pág. 159)

Pode ser concluído daí que os autores, ao se referirem a campo como uma realidade, estão utilizando nossa acepção 4: campo como "modificação" do espaço.

O tema campo só é retomado na última seção do capítulo que viemos estudando, denominada Field and matter. Nela os autores fazem jus ao conceito de campo discutido na seção Field and ether, entendendo-o como realidade, e discutem sobre a dualidade campomatéria. 
De tudo o que foi analisado nesta seção, podemos concluir que nem mesmo livros de importantes físicos estão livres de imprecisões, incoerências e equívocos históricos.

NOTA: No restante desta dissertação, voltaremos a utilizar campo no sentido dado pela acepção 2 (apresentada no início do capítulo), ou seja, como uma quantidade física vetorial específica descrita por uma função matemática. Casos que fugirem a esta regra serão explicitamente mencionados.

\subsection{A RELAÇÃO ENTRE ENERGIA E CAMPO NOS LIVROS DIDÁTICOS}

A quantidade física energia tem como propriedade especial o fato de ter valor constante para sistemas isolados. Sendo apenas uma quantidade física, se desejamos atribuir uma "localização" a ela precisamos estabelecer critérios para definir isto. Consideremos, então, que a energia está localizada onde o sistema físico ao qual ela está associada se encontra. Assim, por exemplo, se para determinada distribuição estática de carga assumimos que a região onde o campo elétrico $\mathbf{E}$ está definido deve ser considerada parte do sistema físico, podemos dizer que a energia elétrica associada à distribuição está localizada onde o campo elétrico $\mathbf{E}$ está definido. Mas isto não é expresso de maneira muito clara em algumas obras.

Analisemos alguns trechos dos livros The Feynman's Lectures on Physics (vol. 2), de Richard P. Feynman, Robert B. Leighton e Matthew Sands, Classical Electrodynamics, de J.D. Jackson, e Introduction to Electrodynamics, de D.J. Griffiths. Todos utilizam a expressão campo no sentido de quantidade física vetorial, conforme podemos ver:

(...) We call $\mathbf{E}$ the electric field and $\mathbf{B}$ the magnetic field at the location of the charge. (...) [Feynman ${ }^{(\text {b) }}: 2$ (do cap.1)]

The electric and magnetic fields $\boldsymbol{E}$ and $\boldsymbol{B}(. .$.$) [Jackson : 3]$ 
Ever since Faraday, the laws of electricity and magnetism have been expressed in terms of electric and magnetic fields, $\boldsymbol{E}$ and $\boldsymbol{B}$. (...) [Griffiths : 52]

Nenhum problema até aí. Porém, nestes mesmos livros, encontramos, sem quaisquer ressalvas de que o conceito de campo deveria ser interpretado diferentemente ou de que as expressões "energia armazenada" e "energia transportada" deveriam ser entendidas figuradamente, trechos como:

Energy in the electrostatic field ${ }^{[77]}\left[\right.$ Feynman $^{(b)}: 9$ (do cap.8)]

(...) Where is the energy, then? Is it stored in the field, as Eq. 2.45 seems suggest, or is it stored in the charge, as Eq. 2.43 implies? [Griffiths : 96]

(...) They [os campos eletromagnéticos] can carry energy, momentum, and angular momentum and so have an existence totally independent of charges and currents. (...) An alternative, and very fruitful, approach is to emphasize the electric field and to interpret the energy as being stored in the electric field surrounding the charges (...) 5.16 Energy in the Magnetic Field (...) [Jackson : 3, 41 e 212]

Mas entendemos que a energia não pode estar armazenada em uma quantidade física ou ser transportada por uma quantidade física. Deste modo, as afirmações acima, no contexto em que estão inseridas, não fazem muito sentido, a menos que interpretemos "energia armazenada no campo" como "energia localizada onde o campo está definido e descrita em termos dele" e "energia transportada pelos campos" como "energia 'fluindo' na direção caracterizada por $\mathbf{E} \times \mathbf{H}^{\prime}$.

Griffiths, em um trecho posterior àquele transcrito, utilizou aspas em uma das expressões que poderiam causar um mal entendimento, talvez justamente para ressaltar seu caráter figurado:

(...) In view of this result, we say the energy is "stored in the magnetic field" (...) [Griffiths : 318]

De qualquer forma, pensamos que ele poderia ter sido mais claro ou ter utilizado o recurso das aspas também no outro trecho que transcrevemos anteriormente.

\footnotetext{
${ }^{77}$ Título da seção 8-5 do livro de Feynman.
} 
Concluindo a seção, diríamos que seria importante que os livros didáticos fossem mais coerentes no que se refere às explicações das relações entre energia e os campos vetoriais eletromagnéticos. 


\section{4 - E PARA ALÉM DO FORMALISMO MATEMÁTICO?}

No capítulo 2, em que tratamos sobre a força de Lorentz, fizemos constantes referências aos campos vetoriais $\mathbf{E}(\mathbf{r}, t)$ e $\mathbf{B}(\mathbf{r}, t)$, mas sem indagações sobre o(s) ente(s) físico(s) caracterizado(s) por eles. Neste capítulo, por outro lado, procuraremos justamente levantar algumas considerações sobre a questão.

Tomemos uma região onde esteja definido um campo ${ }^{[78]}$ elétrico $\mathbf{E}(\mathbf{r}, t)$. Não nos parece fazer muito sentido afirmar que $\mathbf{E}(\mathbf{r}, t) e ́$ a própria realidade física em questão: uma função vetorial não pode ser realidade física. Entretanto, $\mathbf{E}(\mathbf{r}, t)$ pode representar alguma propriedade local, ou seja, esta função vetorial pode caracterizar uma propriedade da região onde está definida, sendo independente dos eventuais corpos-teste que inicialmente sugeriram sua definição ${ }^{[79]}$. Neste contexto, surgem algumas perguntas: propriedade do quê? De uma substância imponderável dispersa uniformemente em todo o universo (éter) $?^{[80]} \mathrm{Ou}$ de um ente físico "gerado" pela matéria eletrizada? Não encontramos referências e/ou discussões sobre perguntas como estas nos livros de Eletromagnetismo. É com o objetivo de pelo menos revivescer estes questionamentos - que consideramos essenciais - que escrevemos este capítulo, onde analisamos algumas concepções de ação contígua dentro do contexto do Eletromagnetismo e discutimos alguns experimentos aos quais se atribui o mérito de terem refutado a hipótese da existência de um substrato para os fenômenos eletromagnéticos.

Mesmo após o advento da Teoria da Relatividade Restrita e seu sucesso na explicação de vários fenômenos, físicos de renome como Henri Poincaré ${ }^{81]}$ (primeiro propositor do Princípio de Relatividade), Hendrik Lorentz (Nobel de $1902^{[82]}$ ), Sir Oliver Lodge $^{[83]}$ (que conseguiu a transmissão sinais de rádio dois anos antes de Marconi, a quem é freqüentemente atribuído este mérito) e Sir Joseph Larmor (primeiro propositor das

\footnotetext{
${ }^{78}$ Conforme dito no fim da seção 3.2, restringiremos o uso desta palavra para designar os campos vetoriais $\mathbf{E}(\mathbf{r}, \mathrm{t})$ e $\mathbf{B}(\mathbf{r}, \mathrm{t})$.

${ }^{79}$ Isto equivale a dizer que estamos assumindo uma teoria de ação contígua. Como referência para teorias de ação à distância, existem, por exemplo, os trabalhos de André K.T. Assis, disponíveis em sua home page http://www.ifi.unicamp.br/ assis/.

${ }^{80}$ Esta idéia não foi refutada, como em geral se pensa. Discutiremo-la mais adiante.

${ }^{81}$ Jules Henri Poincaré (1854-1912), matemático de formação, mas também físico e filósofo da ciência.

${ }^{82}$ Dividido com Pieter Zeeman.

${ }^{83}$ Oliver Joseph Lodge (1851-1940), físico e escritor espiritualista inglês.
} 
equações hoje denominadas transformações de Lorentz) ainda consideravam a existência de um éter eletromagnético. Por exemplo, encontramos freqüentes referências ao éter no último livro de Poincaré, Dernières Pensées ${ }^{[84]}$ (Últimos Pensamentos), publicado postumamente em 1913.

Pode parecer, à primeira vista, que os físicos mencionados eram simplesmente conservadores. Porém, pensamos de forma distinta: conservadores ou não, na realidade eles buscavam algo além dos campos vetoriais, algo de substancial por detrás dos processos eletromagnéticos.

Aqui, podemos citar um trecho de Lorentz que ilustra muito bem isto, e com o qual estamos de pleno acordo:

(...) The modern physicists, as Einstein and Minkowski, speak no longer about the aether at all. This, however, is a question of taste and of words. For, whether there is an aether or not, electromagnetic fields certainly exist, and so also does the energy of the electrical oscillations. If we do not like the name of "aether", we must use another word as a peg to hang all these things upon. It is not certain whether "space" can be so extended as to take care not only of the geometrical properties but also of the electric ones. (...) [Lorentz ${ }^{(\mathrm{d})}:$ 211]

Nas duas seções a seguir, tratamos sobre algumas teorias clássicas de ação contígua propostas para explicar os fundamentos do Eletromagnetismo. Na primeira apresentamos a teoria etérea de Lorentz, que tomou forma acabada em 1904, o artigo de Einstein "On the Electrodynamics of Moving Bodies", de 1905, e uma comparação entre as idéias de ambos os físicos, incluindo uma curiosa versão do próprio Einstein sobre a "essência" do Eletromagnetismo, contida em seu artigo "On the Ether" (1924). Já na segunda seção, apresentamos idéias sobre o éter (diferentes daquelas de Lorentz) estudadas após 1910 ${ }^{[85]}$ que parecem ainda não terem sido refutadas, além de termos fornecido uma apresentação ligeira sobre as opiniões de dois físicos que viram na então nascente Mecânica Quântica a teoria promissora que fundamentaria a existência de um éter (o que ocorreu, conforme opinião de físicos como Paul Dirac ${ }^{[86]}$ ).

\footnotetext{
${ }^{84}$ Há uma versão inglesa, Mathematics and Science: Last Essays, publicada em 1963 pela Editora Dover, disponível em http://www.archive.org/details/mathematicsandsc001861mbp (acessado em 24.10.07).

${ }^{85}$ Ano em que a Relatividade Especial começou a ser melhor considerada e o éter estacionário abandonado [McCormmach : 491].

${ }^{86}$ Paul Adrien Maurice Dirac (1902-1984), físico inglês.
} 


\subsection{LORENTZ E EINSTEIN: VISÕES DIFERENTES SOBRE OS FUNDAMENTOS DO ELETROMAGNETISMO}

Nesta seção apresentaremos, primeiramente, as idéias de Einstein e Lorentz a respeito dos fundamentos do Eletromagnetismo, e depois realizaremos uma análise comparativa entre ambas.

\subsubsection{Os fundamentos do Eletromagnetismo segundo Lorentz}

Cremos não ser uma idéia muito acertada pensar que a hipótese da existência de um éter nunca fizera parte de teorias de ação à distância. Lorentz, por exemplo, que foi partidário de teorias de ação à distância até o início da década de 90(noventa) do século XIX, aceitava ao menos desde 1875 a existência de um meio onipresente e responsável pelas interações eletromagnéticas (éter):

This was in 1875 (...) But they [Helmholtz and Lorentz] already believed in the existence of some medium, because it was required of the wave theory of light. Not because the action must be contiguous, but because the reality of light, the medium must exist. [Saunders \& Brown : 30]

E foi ainda enquanto adepto de teorias de ação à distância, em 1886, que Lorentz concluiu em favor da idéia de um éter estacionário, ou seja, de que o universo todo seria "preenchido" uniformemente com algo que não compartilharia do movimento dos corpos materiais:

In 1886, in an investigation of the aberration of light - the seasonal shift in the positions of stars due to the earth's orbital motion - he [Lorentz] concluded that Augustin Fresnel's stationary ether ${ }^{[87]}$ was superior to G. G. Stokes' dragged ether. [McCormmach : 462]

\footnotetext{
${ }^{87} \mathrm{Na}$ teoria de Fresnel, somente o excesso de éter dentro dos corpos seria "levado" pelos mesmos.
} 
O desenvolvimento da teoria de Lorentz, que baseou-se na hipótese de um éter estacionário, culminou em um artigo, em $1892^{[88]}$, no qual o físico holandês obtinha, dentre outros resultados, a força sobre uma partícula carregada em movimento em uma região onde estivessem definidos um campo elétrico e um campo magnético, resultado já discutido no capítulo 2 desta dissertação. Neste artigo, Lorentz procurou conciliar a idéia de partículas elétricas indivisíveis com um modelo de forças eletromagnéticas contíguas:

Beginning with a stationary ether he [Lorentz] reintroduced, in a manner consistent with contiguous forces, a modified version of those atomistic electric fluids which Hertz thought must be banished at the same time that distance forces were. [McCormmach : 463]

Apesar de Lorentz ter utilizado recursos mecânicos em sua teoria, ela não foi, de maneira alguma, uma teoria puramente mecânica. Por exemplo, a carga elétrica e o éter eram considerados entidades não-mecânicas. Isto reflete a própria ideologia de Lorentz, que não procurava pelos constituintes eletromagnéticos últimos:

He [Lorentz] did not probe deeper into the possible nature of these ultimate electromagnetic constituents, an attitude that was rooted in his understanding of the character of physical theories ${ }^{[89]}$. (...) He anticipated that readers might find his theory colorless and unsatisfying, since it did not unveil the mechanism of the phenomena. (...) Lorentz himself did not search for it and in general remained apart from preoccupations with the constitution of the ether and its hidden mechanisms. [McCormmach : 463-464]

E o éter de Lorentz não tinha quaisquer relações de dependência com a matéria comum, de modo que os corpos ordinários mover-se-iam através dele sem modificar seu estado. Mas este éter não seria completamente sem movimento. Nas palavras de McCormmach:

(...) it has internal motions, since it is a dynamical substance, even though it is not analogous in its properties to the mechanical bodies of ordinary experience. [McCormmach : 464]

\footnotetext{
88 "La théorie électromagnetique de Maxwell et son application aux corps mouvants", Archives Néerlandaises des Sciences Exactes et Naturelles, 25: 363ff, 1892; Collected Papers, vol.2, pp. 164-343, 1936 [Lorentz ${ }^{(\mathrm{a})}$ ].

${ }^{89}$ Para fundamentar esta idéia, o autor dá como referência o artigo de Lorentz "Molecular Theories in Physics", publicado originalmente em 1878 e encontrado em Collected Papers, Vol. 9, pp. 26-49.
} 
A teoria de Lorentz apresentada em seu trabalho de 1892 que mencionamos, apesar de bem-sucedida em muitos aspectos, não explicava o experimento de interferometria realizado por Michelson ${ }^{[90]}$ em 1881; experimento que depois foi refinado e contou com a participação de Edward Morley, culminando em um artigo publicado em 1887. Neste último artigo, Michelson e Morley mostraram que efeitos de segunda ordem em $v / V^{[91]}$ relacionados a um possível movimento da Terra relativamente ao éter foram nulos nas experiências realizadas. McCormmach descreve, da maneira que segue, o experimento em questão:

The experiment is based on the following analysis, accurate to second-order magnitudes. The time that it takes light to travel once each way over a distance $l$ in a direction parallel to the earth's motion should be $(2 \mathrm{l} / \mathrm{V})\left(1+\mathrm{p}^{2} / \mathrm{V}^{2}\right)$, where $\mathrm{p}$ is the earth's speed. When light travels at right angles to the earth's motion the time is (21/V) $\left(1+\mathrm{p}^{2} / 2 \mathrm{~V}^{2}\right)$. In 1881 Michelson tried to measure the difference between the two times, l $\mathrm{p}^{2} \mathrm{~N}^{3}$, by passing light along two paths normal to each other and recombining the reflected beams to produce an interference pattern. When the apparatus is rotated by ninety degrees there should be a phase shift in the interference lines equivalent to twice the predicted time difference. Michelson and Morley found no such shift. [McCormmach : 467-468]

Lorentz discutiu sobre esta dificuldade de sua teoria, em explicar os resultados das experiências de Michelson e Morley, em um de seus últimos artigos de $1892^{[92]}$. Segundo o físico holandês, a única maneira que ele imaginava para conciliar o experimento de Michelson-Morley com o éter estacionário era supor que os braços do interferômetro contraiam-se na direção do movimento da Terra em relação ao éter por um certo fator $\alpha^{[93]}$ :

The different times, Lorentz said, for traversing the two arms, are $(2 \mathrm{I} / \mathrm{V})\left(1+\mathrm{p}^{2} / 2 \mathrm{~V}^{2}\right)$ and $[2 \mathrm{l}(1-\alpha) / \mathrm{V}]\left(1+\mathrm{p}^{2} / \mathrm{V}^{2}\right)$; this difference disappears if $\alpha=\mathrm{p}^{2} / 2 \mathrm{~V}^{2}$, neglecting a small term of fourth order in $\mathrm{p} / \mathrm{V}$. [McCormmach : 467-468]

\footnotetext{
${ }^{90}$ Albert Abraham Michelson (1852-1931), físico norte-americano.

${ }^{91}$ Onde $v$ é a velocidade do corpo em análise e $V$ a velocidade da luz.

${ }^{92}$ H. A. Lorentz, "The Relative Motion of the Earth and the Ether", Versl. Kon. Akad. Wet. Amst., 1: 74, 1892; Collected Papers, Vol. 4, pp. 219-223.

${ }^{93}$ Esta hipótese, porém, já havia sido proposta em 1889 por George FitzGerald (Science, 13: 390, 1889).
} 
A partir do seu tratado de $1895^{[94]}$, Lorentz abandonou o método de derivação mecânica das equações de Maxwell e da força ponderomotiva, passando a considerar tais equações como hipotéticas. McCormmach comenta sobre isto:

He did not elaborate on the reasons for proceeding in this new way. For one thing, he no longer needed a theoretical guide for himself or for others, having already established his basic equations. For another, he, like others, was becoming used to starting with the field equations, not repudiating their relation to mechanics, but not troubling about it either. Yet another possible reason is that he now knew, if he had not before, that his theory violated Newton's third law of motion. [McCormmach : 468]

Foi neste tratado de 1895, conforme já comentamos em outra oportunidade, que Lorentz propôs pela primeira vez uma transformação para a variável tempo, tendo apresentado uma expressão modificada para esta transformação em $1899^{[95]}$. A menos de um fator dependente da velocidade do corpo/referencial em análise, a fórmula obtida por Lorentz é justamente aquela considerada no contexto da Relatividade Restrita para a transformação desta variável.

O conjunto completo das transformações das coordenadas de espaço e tempo obtido por Lorentz foi:

$$
x^{\prime}=e k(x-v t), y^{\prime}=e y, z^{\prime}=e z, t^{\prime}=e k\left(t-v x / V^{2}\right),
$$

onde $e$ é um fator dependente da velocidade do corpo em questão, que difere da unidade por uma quantidade de segunda ordem em $v / V$, e $k=1 /\left[1-(v / V)^{2}\right]^{1 / 2}$. Este resultado foi um pouco mais refinado em $1904^{[96]}$, quando Lorentz teceu alguns argumentos para considerar $e=1$ e demonstrou suas transformações de maneira mais rigorosa, obtendo:

$$
x^{\prime}=k(x-v t), y^{\prime}=y, z^{\prime}=z, t^{\prime}=k\left(t-v x / V^{2}\right),
$$

resultado idêntico ao encontrado no contexto da Relatividade Especial, de Einstein.

Apesar de Lorentz ter obtido uma transformação para a variável tempo (como vimos), alguns livros não mencionam este fato. Vejamos, por exemplo, a obra Classical Electricity and Magnetism (2a ed., 1962), de Panofsky \& Phillips. Na seção 15-3,

\footnotetext{
${ }^{94}$ Versuch einer Theorie der electrischen und optischen Erscheinungen in bewegten Körpern, Leiden: E.J. Brill, 1895.

${ }^{95}$ H. A. Lorentz, "Simplified Theory of Electrical and Optical Phenomena in Moving Systems", Proc. Acad. Sciences Amsterdam (edição inglesa), 1: 427-42, 1899.

${ }^{96}$ H. A. Lorentz, "Electromagnetic Phenomena in a System Moving with any Velocity Less than that of Light", Proc. Acad. Sciences Amsterdam, 6: 809-30, 1904.
} 
denominada "The Lorentz-Fitzgerald contraction hypothesis", os autores explicam a hipótese referida, citam um experimento levado a cabo por Roy Kennedy ${ }^{[97]}$ e terminam dizendo que "neither effect was observed, in contradiction to the Lorentz contraction hypothesis". Isto pode levar à falsa idéia de que a hipótese da contração de Lorentz teria sido refutada pelo experimento mencionado. Entretanto, o que a experiência mostrou foi apenas que a hipótese da contração sozinha era insuficiente para manter a validade de alguma teoria que levasse em conta um éter estacionário. Mas considerada conjuntamente com uma transformação adequada na variável tempo - o que foi feito, independentemente, por Larmor (1897) e Lorentz (1904) -, a hipótese da contração não seria refutada pelo experimento de Kennedy. Pelo contrário: uma teoria baseada em um éter estacionário e levando em conta estas duas hipóteses (contração espacial e lei de transformação adequada para a variável tempo) explicaria o resultado do experimento em questão, qual seja, o fato de Kennedy não ter observado nenhum desvio nas franjas de interferência entre feixes luminosos durante os meses em que a experiência foi realizada.

Notamos também alguns lapsos em tabelas deste livro em análise. Por exemplo, na tabela 15-2, que esboça a concordância ou não de teorias do éter, teorias de emissão ${ }^{[98]} \mathrm{e}$ da relatividade especial com experimentos específicos, no que se refere a "ether theories" os autores apenas alocam três exemplos: "ether attached to ponderable bodies", "stationary ether, no contraction" e "stationary ether, Lorentz contraction". Porém, ao invés desta última teoria, cremos que os autores poderiam ter colocado "stationary ether, Lorentz transformations", uma vez que a idéia do físico holandês de considerar apenas a contração de objetos em movimento em relação ao éter $\left(1892^{[99]}\right)$ foi passageira, sendo logo acrescida de uma transformação na variável tempo $\left(1895^{[100]}\right)$, que foi aperfeiçoada em $1899^{[101]} \mathrm{e}$

\footnotetext{
${ }^{97}$ R. J. Kennedy and E. M. Thorndike, "Experimental Establishment of the Relativity of Time”, Phys. Rev., 42: 400, 1932. O experimento de Kennedy e Thorndike consistiu em estudar uma possível variação do padrão de interferência de dois feixes de luz antes constituintes de um único em conseqüência da rotação e da translação da Terra em relação ao Sol. Se nenhuma variação fosse encontrada, poderia ser concluído que não existe efeito algum relacionado a um suposto "tempo absoluto" a menos que a velocidade do sistema solar em relação às estrelas fixas fosse menor que metade da velocidade translacional da Terra.

${ }^{98}$ Este é um nome genérico para as teorias que assumem que a velocidade da luz é uma constante em relação à fonte de emissão.

99 "Verslagen van der gewone Vergaderingen der Wisen Natuurkundige Afdeeling", Konink. Akadetnie van Wetenschappen te Amsterdam, 1:74ff, 1892; "The Relative Motion of the Earth and the Ether", Collected Papers, Vol. 4, pp. 219-223.

${ }^{100}$ Versuch einer Theorie der electrischen und optischen Erscheinungen in bewegten Körpern, Leiden: E.J. Brill, 1895.
} 
tomou a forma que hoje conhecemos em $1904^{[102]}$. Nesta tabela ainda consta que as teorias de éter estacionário estariam em desacordo com experimentos de indução homopolar usando magnetos permanentes, o que não parece ser verdadeiro, pois segundo E.H. Kennard, por exemplo, a teoria do éter estacionário de Lorentz seria a mais adequada para explicar a indução homopolar ${ }^{[103]}$. E também encontramos problemas na tabela 15-3. Nela estão alocadas três teorias: "emission theory", "classical ether theory" e "special theory of relativity". Porém, não existe, verdadeiramente, uma teoria específica que possa ser chamada de "emission theory", como também não existe uma teoria específica que possa ser chamada de "classical ether theory": hipóteses com os mais diversos modelos de éter poderiam ser enquadradas sob estas nomenclaturas. Os autores não foram claros na confecção de tabelas comparativas entre a Relatividade Restrita e as teorias baseadas na hipótese de um éter.

\subsubsection{Os fundamentos do Eletromagnetismo segundo Einstein}

Faremos agora uma pequena descrição do artigo de Einstein de 1905 no qual ele obtém, por meios diferentes daqueles de Lorentz, as mesmas transformações (41).

Einstein, neste artigo ${ }^{[104]}$, afirmou que "a introdução de um éter luminífero seria supérflua" para a teoria eletromagnética. Segundo o físico alemão, as idéias que ele havia desenvolvido no artigo não requeriam um espaço absolutamente estacionário dotado de propriedades físicas ou a consideração de vetores-velocidade associados a pontos do espaço nos quais processos eletromagnéticos estivessem ocorrendo. Einstein ainda mostrou que a invariância formal das equações de Maxwell poderia ser considerada conseqüência de duas leis fundamentais: 1) as leis físicas são invariantes para todos os referenciais "nos quais as

\footnotetext{
101 "Simplified Theory of Electrical and Optical Phenomena in Moving Systems", Proc. Acad. Sciences Amsterdam (edição inglesa), 1: 427-42, 1899.

102 "Electromagnetic Phenomena in a System Moving with any Velocity Less than that of Light", Proc. Acad. Sciences Amsterdam, 6: 809-30, 1904.

103 "On Unipolar Induction: Another Experiment and its Significance as Evidence for the Existence of the Aether”, Phil. Mag. 33: 179-90, 1917.

104 “Zur Elektrodynamik bewegter Körper”, Annalem der Physik, 17: 891-921, 1905. Foi utilizada a versão inglesa deste artigo, "On the Electrodynamics of Moving Bodies", encontrada no livro The Principle of Relativity, publicado em 1923. Este livro consiste em uma compilação de artigos de Lorentz, Einstein, Hermann Minkowski e Hermann Weyl sobre Relatividade.
} 
equações da mecânica newtoniana valham bem"[105] (Princípio de Relatividade); 2) a velocidade da luz no "espaço vazio" é uma constante independente do movimento da fonte. Além disso, foi mostrado que a expressão para a força ponderomotiva (força de Lorentz) surgia como um corolário do Princípio de Relatividade aplicado à lei de Coulomb.

Partindo das premissas já mencionadas, Einstein encontrou as equações que regeriam as mudanças nas coordenadas de espaço e tempo decorrentes da consideração de diferentes referenciais inerciais. Tais equações são conhecidas como transformações de Lorentz, por terem sido alcançadas por Lorentz em $1904^{[106]}$, antes de Einstein. Mas, apesar de Lorentz ter obtido estas transformações antes de Einstein, parece que o físico alemão não tomou conhecimento de nenhum artigo de Lorentz publicado no período 1895-1905 [Saunders \& Brown : 42-43].

Vale mencionar, também, que Larmor já havia obtido as mesmas expressões em $1897^{[107]}$, fato que parece ser muito pouco conhecido [Macrossan, 232-34]. As transformações de Lorentz garantem, para sistemas inerciais quaisquer, que as equações de Maxwell permaneçam invariantes, apesar de não serem as únicas transformações que servem a este mister. Temos como exemplo as chamadas transformações de Voigt, propostas em $1887^{[108]}$ pelo físico alemão Woldemar Voigt (1850-1919), que são dadas por:

$$
x^{\prime}=x-V t, \quad y^{\prime}=\left(1-V^{2} / c^{2}\right)^{1 / 2} y, \quad z^{\prime}=\left(1-V^{2} / c^{2}\right)^{1 / 2} z, \quad t^{\prime}=t-V x / c^{2},
$$

sendo $V$ a velocidade do referencial $S^{\prime \prime}$ (ao qual se referem as coordenadas com linha) em relação ao éter. Estas transformações também garantem a invariância formal das equações

\footnotetext{
${ }^{105}$ Panofsky e Phillips teceram um pertinente comentário sobre isto: The postulates of special relativity leave the question of the meaning of an "inertial frame" in the same unsatisfactory state as in the principle of Galilean relativity. Specifically, the characterization of an inertial frame in terms of absence of acceleration in the absence of forces remains essentially a "circular" argument, since it leaves open the definition of a force. An inertial frame in this context is a frame in which bodies remain in uniform motion if the influence of known (!) forces is negligible. This clearly unsatisfactory definition cannot be avoided unless the broader framework of general relativity is introduced [Panofsky \& Phillips : 283].

106 "Electromagnetic Phenomena in a System Moving with any Velocity Less than that of Light", Proc. Acad. Sciences Amsterdam (edição inglesa), $\underline{6}: 809-30,1904$.

107 Whittaker, referindo-se ao livro de Larmor Aether and Matter, equivocou-se ao dizer que as transformações de Larmor eram acuradas somente até segunda ordem em $(w / c), w$ sendo a velocidade de um dos referenciais em relação ao outro e $c$ sendo a velocidade da luz no vácuo [Whittaker ${ }^{(b)}: 31$ e 37]. Apesar do objetivo de Larmor ter realmente sido obter transformações exatas até segunda ordem em $(w / c)$, suas transformações, obtidas já em 1897, são exatas também para termos de ordens superiores, sendo idênticas às que hoje denominamos "transformações de Lorentz" (cf. p.174 de Aether and Matter) [Macrossan, 233].

108 "Über das Doppler'sche Princip", Nachrichten von der Königlichen Gesellschaft der Wissenschaften zu Göttingen, 2:41-51, 1887; reimpresso com comentários adicionais por Voigt em Physikalische Zeitschrift, 16: 381-386, 1915. Consta uma tradução deste artigo em ERNST \& HSU, pp. 217-25.
} 
de Maxwell ${ }^{[109]}$. Realizando uma generalização apropriada, Ernst e Hsu mostraram que a teoria de Voigt é consistente com as predições da relatividade para o desvio Doppler e com os experimentos de Fizeau e Michelson-Morley [Ernst \& Hsu : 226-28]. Além disso, mostraram que as transformações de Voigt na forma generalizada formam um grupo [Ernst \& Hsu : 228-29], diferentemente do que foi afirmado por H. Poincaré ${ }^{[110]}$ e A.G. Gluckman $^{[111]}$.

$\mathrm{O}$ artigo de Einstein se divide em duas partes: uma tratando da cinemática relativística, e outra tratando de eletrodinâmica. Ambas constam de 5(cinco) seções cada.

Na primeira seção do artigo, Einstein define simultaneidade, argumentando que não faz muito sentido falar em tempo absoluto, sendo tempo uma grandeza dependente do referencial considerado. Assim, por definição, dois eventos seriam simultâneos em determinado referencial se os relógios situados nas vizinhanças dos pontos (designados por $A$ e $B$ ) onde estes eventos ocorressem fossem tais que, para um raio de luz partindo de $A$, chegando à $B$ e retornando à $A$, o tempo gasto em cada etapa satisfaria a igualdade

$$
t_{B}-t_{A}=t_{A^{\prime}} t_{B}
$$

onde $t_{A}$ seria o tempo medido pelo relógio do referencial $A$ quando da partida do raio de luz, $t_{B}$ o tempo do relógio do referencial $B$ quando o raio de luz ali chegasse, e $t_{A^{\prime}}$ o tempo no referencial $A$ quando o raio de luz retornasse.

Na seção 2, Einstein trata da relatividade de comprimentos e tempos. Considerando determinado referencial inercial (chamado por Einstein de sistema estacionário) e uma barra de comprimento $l$ coincidente com a direção $x$, o físico alemão nos diz que, pelo Princípio de Relatividade, se a barra passa a mover-se com velocidade $v$ na direção $x$, seu comprimento no referencial próprio continua sendo $l$. Einstein também explicita que, sincronizando relógios situados nos extremos $A$ e $B$ da barra com relógios do referencial estacionário, para a barra em movimento teríamos que

$$
t_{B}-t_{A}=\frac{\tau_{A B}}{c-v} \text { e } t_{A^{\prime}}-t_{B}=\frac{\tau_{A B}}{c+v}
$$

\footnotetext{
${ }^{109}$ Deve ser ressaltado, porém, que Voigt utilizou suas transformações para garantir a invariância da equação de onda para um éter elástico e incompressível, não para mostrar a invariância das equações de Maxwell, conforme consta, equivocadamente, em SAUNDERS \& BROWN, p. 42.

${ }^{110}$ Discurso em junho de 1905 na Academia de Ciências de Paris; tradução em KESWANI \& KILMISTER, pp. 350-53.

111 "Coordinate Transformations of Voigt, W. and Principle of Special Relativity", Am. J. Phys. 36 (3): 226ff, 1968.
} 
onde $\tau_{A B}$ denota o comprimento no referencial estacionário da barra em movimento e os tempos são medidos no referencial da barra. Isto pode ser mostrado da seguinte forma. Consideremos, primeiramente, o segundo postulado de Einstein, de que a velocidade da luz em relação ao referencial estacionário independe do movimento da fonte, e que os relógios do sistema estacionário estão sincronizados entre si. Assim, sendo $t_{1}$ o tempo no relógio situado no ponto deste sistema que coincide momentaneamente com $A$ quando da saída do feixe de luz de $A$, e $t_{2}$ o tempo no relógio situado no ponto deste sistema que coincide momentaneamente com $B$ quando da chegada do feixe de luz em $B$, temos que $t_{2}-t_{1}=\left[\tau_{A B}+v\left(t_{2}-t_{1}\right)\right] / c$. Denotando por $t_{3}$ o tempo no ponto do sistema estacionário que coincide momentaneamente com $A$ quando do retorno do feixe de luz à $A$, temos que $t_{3}-t_{2}=\left[\tau_{A B}-v\left(t_{3}-t_{2}\right)\right] / c$. Como, por hipótese, os relógios da barra são sincrônicos com os relógios do referencial estacionário, chegamos então às igualdades (42). Ou seja, conquanto os relógios dos extremos da barra estejam em sincronicidade para o referencial estacionário, para observadores movendo-se com a barra tais relógios não estão sincrônicos: a noção de simultaneidade, portanto, seria relativa.

Na seção 3, o físico alemão, partindo das considerações anteriores e supondo linearidade na relação entre coordenadas espaciais e temporais, mostrou a plausibilidade entre a constância da velocidade da luz no vácuo (em relação a um referencial inercial) e o Princípio da Relatividade. Além disso, tomando $(x, y, z, t)$ como as coordenadas de um evento no referencial estacionário e $(\xi, \eta, \zeta, \tau)$ como as coordenadas deste mesmo evento em um referencial se movendo com velocidade $v$ na direção $\mathrm{x}$, chegou às chamadas transformações de Lorentz:

$$
\begin{aligned}
\tau & =\beta\left(t-v / c \frac{x}{c}\right) \\
\xi & =\beta(x-v t) \\
\eta & =y \\
\zeta & =z,
\end{aligned}
$$

onde $\beta=\frac{1}{\sqrt{1-(v / c)^{2}}}$.

Na seção 6 do artigo, já na "Parte Eletrodinâmica", Einstein mostra então que a invariância formal das equações de Maxwell pode ser considerada conseqüência das 
transformações de Lorentz (que, na teoria do físico alemão, surgiram como corolário dos dois postulados básicos já citados e da definição de simultaneidade). Além disso, considerando a força eletromagnética sentida por uma partícula de carga $q$ como $\mathbf{F}=q \mathbf{E}^{\prime}$, onde $\mathbf{E}^{\prime}$ seria o campo elétrico no referencial próprio da partícula, a expressão da força ponderomotiva (força de Lorentz), tal qual nós a conhecemos, surgiria naturalmente. Para efeitos de segunda ordem em $v / c$ desprezados:

$$
\mathbf{F}=q \mathbf{E}+q(\mathbf{v} / \mathrm{c}) \times \mathbf{B} .
$$

Isto aconteceria porque $\mathbf{E}^{\prime}=\beta[\mathbf{E}+(1 / c) \mathbf{v} \times \mathbf{B}]$, onde $\mathbf{v}$ é a velocidade da partícula em relação ao referencial estacionário. A transformação do campo magnético, por sua vez, seria dada por $\mathbf{B}^{\prime}=\beta[\mathbf{B}-(1 / c) \mathbf{v} \times \mathbf{E}]$, sendo $\mathbf{B}^{\prime}$ o campo magnético no referencial da partícula. Em ambos os casos, $\mathbf{E}$ e $\mathbf{B}$ são os campos elétrico e magnético no referencial estacionário.

\subsubsection{Comparando as idéias de Lorentz e Einstein}

Agora que já apresentamos as principais idéias de Lorentz (1904) e Einstein (1905) sobre os fundamentos do Eletromagnetismo, analisaremos sucintamente as diferenças entre as teorias de ambos. Veremos também que, curiosamente, Einstein publicou em 1924 um artigo contendo uma concepção dos fundamentos do Eletromagnetismo bastante distinta daquela de seu artigo de 1905.

Enquanto Lorentz elaborou as transformações já mencionadas (41) para que houvesse concordância com os fatos experimentais - e insistia na existência do éter como elemento importante na consideração dos fenômenos eletromagnéticos - Einstein, em 1905, considerou o éter como elemento desnecessário e encontrou as transformações referidas como corolário dos axiomas já mencionados: de que a velocidade da luz é sempre uma mesma constante, independente do movimento da fonte, e de que as leis físicas são invariantes para todos os referenciais inerciais. 
Einstein, que havia considerado em 1905 o éter luminífero apenas como hipótese desnecessária, foi mais enfático no capítulo que escreveu para o livro Physik ${ }^{[112]}$, primeiro da coleção Die Kultur der Gegenwart. Ihre Entwicklung und ihre Ziele ${ }^{[113]}$ (A Cultura do Presente. Seu Desenvolvimento e seus Objetivos), constituída de 8(oito) livros e publicada em 1915 em Leipzig, Alemanha. Em um dos trechos (faremos uso da tradução inglesa) deste capítulo, Einstein nos diz:

(...) Lorentz's theory arouses our mistrut in that it seems to contradict the relativity principle. The following argument show this. (...) [Einstein $\left.{ }^{(b)}: 250\right]$

E, após tecer algumas considerações e ressaltar que, na teoria de Lorentz, a luz no vácuo teria uma velocidade $c$ em relação ao éter, continua:

\section{Inadmissibility of the Ether Hypothesis}

(...) it is easy to see that we must also abandon the idea of introducing a luminiferous ether into the theory. Because if every light ray in vacuum is suppose to propagate with the velocity $\mathrm{c}$ with respect to $\mathrm{K}$, then we must conceive of this luminiferous ether as being everywhere at rest with respect to $\mathrm{K}$. However, if the laws of the propagation of light with respect to the system $\mathrm{K}^{\prime}$ (in motion ${ }^{[114]}$ relative to $\mathrm{K}$ ) are the same as those with respect to $\mathrm{K}$, then we would have to assume with as much right the existence of a luminiferous ether that is at rest with respect to $\mathrm{K}^{\prime}$. (...) [Einstein ${ }^{(\mathrm{b})}$ : 250 e 252],

concluindo então ser absurdo o éter estar em repouso, simultaneamente, em relação a dois sistemas de referência em diferentes estados de movimento.

Realmente, uma proposição ou teoria que nos levasse inequivocamente a esta conclusão deveria ser descartada, mas não é este o caso da hipótese de Lorentz da existência de um éter estacionário. O impasse surgiu devido à interpretação de Einstein do Princípio de Relatividade aplicado à velocidade da luz no contexto em que a existência de um éter é levada em conta, e a "inadmissibilidade" da hipótese de um éter estacionário seria verdadeira se a interpretação de Einstein fosse a única possível. Porém, o fato da luz propagar-se com velocidade $c$ em relação a um suposto éter luminífero não implica necessariamente que qualquer outro sistema de referência, em relação ao qual a luz também

\footnotetext{
112 Editado por Emil Warburg.

${ }^{113}$ Editada por Paul Hinneberg.

${ }^{114}$ Com velocidade constante.
} 
se propague com velocidade $c$, deva estar em repouso em relação ao suposto éter. Ou seja, não há contradição entre a hipótese de um éter estacionário e o Princípio de Relatividade. O próprio Poincaré, propositor do Princípio de Relatividade, considerava o éter como elemento real, apenas ressaltando que nenhum experimento poderia determinar movimentos relativos a este meio [Poincaré( $\left.{ }^{(a)}: 75\right]$.

A independência da velocidade da luz em relação a referenciais movendo-se com velocidades constantes relativamente a um suposto éter é uma consequiência direta das transformações de Lorentz, que na teoria do físico holandês é ponto de partida:

(...) That the velocity of light c presents the special feature that it is not changed by a relativity transformation is, of course, due to the fact that c enters in the transformation formulae. (...) [Lorentz $\left.{ }^{(\mathrm{d})}: 100\right]$

Assim, a hipótese de um éter estacionário não é “inadmissível”. Já a afirmação de Einstein de que a hipótese da existência de um éter seria supérflua, contida em seu artigo de 1905 sobre Eletrodinâmica, é essencialmente filosófica, aparentando atender ao critério da economia de pensamento ${ }^{[115]}$. Mas notemos que, apesar de abdicar do éter, Einstein passou a considerar um outro ente físico como irredutível, que ele denominou campo eletromagnético:

(...) Certainly, from the standpoint of the special theory of relativity, the ether hypothesis appears at first to be an empty hypothesis. In the equations of the electromagnetic field there occur, in addition to the densities of the electric charge, only the intensities of the field. The career of electromagnetic processes in vacuo appears to be completely determined by these equations, uninfluenced by other physical quantities. The electromagnetic fields appear as ultimate, irreducible realities, and at first it seems superfluous to postulate a homogeneous, isotropic ether-medium, and to envisage electromagnetic fields as states of this medium. (...) [Einstein ${ }^{(\mathrm{c})}$ : 11]

Observemos que aquilo que Einstein denomina campo eletromagnético não é o conjunto formado por $\mathbf{E}$ e $\mathbf{B}^{[116]}$, mas o ente físico ao qual o conjunto $\{\mathbf{E}, \mathbf{B}\}$ estaria

\footnotetext{
${ }^{115}$ Para maiores detalhes sobre o critério da "economia de pensamento", veja seção IV, "The Economy of Science", do cap. IV de The Science of Mechanics, de Ernst Mach. As teorias eletromagnéticas mais "econômicas" são aquelas de ação à distância, como a Eletrodinâmica de Weber, pouco consideradas hoje em dia pela comunidade científica.

${ }^{116} \mathbf{E}$ e $\mathbf{B}$ foram chamados intensidades do campo pelo físico alemão, como pode ser observado do trecho que foi transcrito.
} 
associado. Realmente, se postulamos a existência de tal entidade, como Einstein, não há necessidade alguma de considerá-la estado de um meio mais fundamental, e o éter eletromagnético seria supérfluo. Mas então esta entidade (que o físico alemão denomina campo eletromagnético) estaria apenas substituindo o papel atribuído ao éter na teoria de Lorentz, com a única diferença que, para Lorentz, éter e matéria pertenceriam a classes distintas de coisas, enquanto que, para Einstein, matéria e campo eletromagnético não seriam completamente dissociados. Assim, as teorias de Einstein e Lorentz utilizam o mesmo número de entidades físicas essenciais.

$\mathrm{O}$ argumento que a teoria de Einstein é mais "econômica", uma vez que, em uma região do espaço onde não houvesse $\mathbf{E}$ e $\mathbf{B}$, também não existiriam campos eletromagnéticos $^{[124]}$ (na teoria de Lorentz haveria éter), é passível de discórdia, pois sabemos que em nenhuma região temos $\mathbf{E}$ e/ou $\mathbf{B}$ (definidos em relação a algum referencial) exatamente nulo(s): eles podem ser muito pequenos, mas não nulos, o que implicaria na existência do ente denominado campo eletromagnético por Einstein.

Outro ponto que merece ser ressaltado, quanto às diferenças entre as teorias destes dois físicos, está ligado à maneira como as suas teorias foram estruturadas. Lorentz considerou no início de seu importante artigo de 1904 já mencionado (no qual sua teoria atingiu uma forma bem acabada) que a análise realizada, sobre fenômenos eletromagnéticos em sistemas de referência em movimento em relação ao éter, seria restrita a referenciais movendo-se com velocidade menor que a da luz no vácuo (em relação ao éter) $\left[\right.$ Lorentz $\left.^{(b)}: 811\right]$. É interessante notar que ele não afirmou que a velocidade da luz seria um limite $e^{[125]}$.

Lorentz então propõe suas transformações e mostra, dentre outras coisas, que "muitas ações eletromagnéticas" são independentes de translações com movimento retilíneo uniforme (em relação ao éter) do sistema de referência considerado, o que é concorde com o Princípio de Relatividade.

\footnotetext{
${ }^{124}$ Aqui entendidos segundo a terminologia utilizada por Einstein em seu discurso de 1920.

125 Isto fica ainda mais claro da tradução inglesa de um trecho da p. 23 do livro de Lorentz Das Relativitätsprinzip (1913). Referindo-se a Einstein, o físico holandês nos diz: (...) Finally, it should be noted that the daring assertion that one can never observe velocities larger than the velocity of light contains a hypothetical restriction of what is acessible to us, which cannot be accepted without some reservation [Saunders \& Brown : 46].
} 
Einstein, diferentemente, conforme já afirmamos, toma o Princípio de Relatividade como ponto de partida de sua teoria, obtendo as transformações de Lorentz como consequiência deste princípio e da unicidade da constante da velocidade da luz.

Havendo diferenças entre as concepções de Lorentz (1904) e Einstein (1905, 1920) relativas ao Eletromagnetismo, poderíamos então nos perguntar: qual delas melhor corresponde à realidade física? Como as duas abordagens fornecem os mesmos resultados, responderíamos que ambas descrevem igualmente bem a realidade, mesmo a teoria do físico holandês tendo recebido críticas como esta, de James Jeans:

(...) For instance, if the gravitational field did not shrink, the geoid, or surface of mean sea-level on the earth, might be a gravitational equipotential for some one velocity through the ether, but could not remain an equipotential as the earth's velocity through the ether changed from point to point of its orbit. Thus we might antecipate seasonal and daily tidal surgings as a result of the earth's motion through the ether. No such events are observed. It is true that even if these occurred the earth's motion through the ether might not be sufficiently rapid for them to be capable of observation, but the generalised theory of relativity, explained in the next section, makes it clear that such events could not be observed whatever the earth's motion might be. There is no longer any room for reasonable doubt that gravitational phenomena conform to the relativity condition.

If, then, we continue to believe in the existence of an ether we are compelled to believe not only that all electromagnetic phenomena are in a conspiracy to conceal from us the speed of our motion through the ether, but also that gravitational phenomena, which so far as is known have nothing to do with the ether, are parties to the same conspiracy. The simpler view seems to be that there is no ether. If we accept this view, there is no conspiracy of concealment for the simple reason that there is no longer anything to conceal. [Jeans : 619-621]

Ainda que a existência do éter implique em uma conspiração da Natureza, impedindo-nos de identificá-lo, nenhum experimento provou que ele não exista. Então, uma vez que os resultados experimentais não refutaram a teoria de Lorentz (e de outros adeptos da realidade do éter), é possível que exista um éter. Como Roberto Martins enfatiza em um de seus artigos:

(...) Se fosse possível medir a velocidade da Terra em relação ao éter, não seria apenas a teoria de Einstein que teria que ser abandonada: as de Lorentz e Poincaré também cairiam por terra. Todos os experimentos que confirmaram a teoria de Einstein confirmaram também as teorias de Lorentz e Poincaré. Na verdade, nem mesmo se deve dizer que essas são teorias diferentes. É melhor dizer que são interpretações diferentes da mesma teoria física, pois suas conseqüências observáveis são idênticas. [Martins : 22] 
E vale ressaltar, também, que Einstein, em seu discurso na Universidade de Leiden em 1920, apesar de ter mantido a opinião sobre os campos eletromagnéticos ${ }^{[117]}$ que esteve implícita em seu artigo de 1905 sobre Eletrodinâmica, não descartou completamente a idéia de um éter, como em geral se pensa. Em suas próprias palavras:

(...) More careful reflection teaches us, however, that the special theory of relativity does not compel us to deny ether. We may assume the existence of an ether; only we must give up ascribing a definite state of motion to it, i.e. we must by abstraction take from it the last mechanical characteristics which Lorentz had still left it (...) [There] is a weightly argument to be adduced in favour of the ether hypothesis. To deny ether is ultimately to assume that empty space has no physical qualities whatever. The fundamental facts of mechanics do not harmonize with this view. (...) According to the general theory of relativity space without ether is unthinkable; for in such space there would not only no propagation of light, but also no possibility of existence for standards of space and time (measuring-rods and clocks), nor therefore any space-time intervals in the physical sense. [Einstein ${ }^{(\mathrm{c})}: 9-11$ e 14]

Em um outro artigo, de $1924^{[118]}$ - já mencionado no capítulo 3 -, o físico alemão vai ainda mais além. Ele não só considera a existência de um éter ("continuum equipado de propriedades físicas", em suas próprias palavras), como submete os campos eletromagnéticos a este continuum. É interessante observar que este último ponto está em franca contradição com o que foi afirmado pelo próprio Einstein em seu discurso na Universidade de Leiden em 1920, quando reafirmou a idéia (implícita em seu artigo sobre Eletrodinâmica de 1905) que os campos eletromagnéticos seriam entidades físicas independentes. Estes trechos do artigo de 1924 ilustram o que acabamos de afirmar quanto à mudança de concepção de Einstein:

(...) because in the final analysis in a theory of fields the ponderable matter, or the elementary particles that constitute this matter, also have to be considered as 'fields' of a particular kind, or as particular 'states' of the space [Einstein $\left.{ }^{(\mathrm{d})}: 13\right]^{[119]}$

(...) The metric tensor which determines both gravitational and inertial phenomena on the one hand, and the tensor of the electromagnetic field on the other, still appear as

\footnotetext{
${ }^{117}$ Aqui entendidos como entes físicos.

118 “Über den Äther”, Schweizerische naturforschende Gesellschaft Verhanflungen, 105: 85-93, 1924.

${ }^{119}$ No artigo (traduzido) de onde este trecho foi retirado, a palavra espaço se refere a um ente físico, também denominado éter por Einstein.
} 
fundamentally different expressions of the state of the ether ${ }^{[120]}$; but their logical independence is probably more to be attributed to the imperfection of our theoretical edifice than to a complex structure of reality itself. [Einstein $\left.{ }^{(\mathrm{d})}: 18\right]$

(...) the ether in theoretical physics, i.e. a continuum which is equipped with physical properties (...) $\left[\right.$ Einstein $\left.^{(\mathrm{d})}: 20\right]$

Ou seja: segundo os trechos acima, os campos eletromagnéticos seriam estados do éter...

\subsection{A TEORIA ETÉREA DE CUNNINGHAM}

Interessante verificar que, na segunda década do século XX, alguns cientistas ainda procuravam uma teoria eletromagnética que fosse baseada em um éter no qual certas relações pudessem ser interpretadas mecanicamente. Dentre estes cientistas, vale mencionar o matemático inglês Ebenezer Cunningham ${ }^{[121]}$, autor de The Principle of Relativity (1914), primeiro livro sobre Relatividade em língua inglesa ${ }^{[122]}$. Nas palavras de W. H. McCrea:

(...) He [Cunningham] tended to the view that the arguments for what he called an "objective aether" as the carrier of the electromagnetic field were not invalidated by the coming of relativity theory. So he considered that it ought to be possible to construct an aether model whose properties are relativistically covariant. [McCrea : 123]

E o matemático inglês conseguiu ao menos parcialmente seu intento, tendo publicado sua proposta no capítulo XV ("Relativity and an Objective Aether") de seu livro The Principle of Relativity, mostrando que para alguns casos a hipótese de um "éter objetivo" podia ser conciliada com a Teoria da Relatividade. As mesmas idéias foram reproduzidas no capítulo VIII (também chamado "Relativity and an Objective Aether") de

\footnotetext{
${ }^{120}$ Neste artigo, Einstein, ao invés de atribuir o termo éter àquilo que daria qualidades físicas ao espaço, como no discurso de 1920 na Universidade de Leiden, passa a utilizá-lo para designar o próprio espaço dotado de qualidades físicas.

${ }^{121}$ E. Cunningham (1881-1977), matemático de formação, mas também físico.

${ }^{122}$ Cf. McCrea : $117-118$.
} 
seu livro seguinte, Relativity and the Electron Theory (1915). Abaixo descreveremos sucintamente a motivação, a proposta e os exemplos de validade da teoria de Cunningham.

Convicto da existência de um éter luminífero, Cunningham, por outro lado, não partilhava da opinião de Lorentz que este éter deveria ser "absolutamente estacionário", pois, apesar de se falar em "momento eletromagnético", "fluxo de energia" e "tensão no éter" na teoria do físico holandês, estas idéias não eram associadas com movimentos do meio. Ou seja, nenhuma relação similar à transmissão mecânica de energia havia entre tensão, velocidade e fluxo de energia na teoria, o que não parecia razoável para o matemático inglês.

Cunningham, então, propôs um modelo de éter em que todos os pontos do mesmo teriam a velocidade da luz $c$ como velocidade total em relação a qualquer referencial inercial. Este éter teria ainda a propriedade de que as relações entre tensão, velocidade e fluxo de energia poderiam ser interpretadas mecanicamente.

Havendo fluxo de energia eletromagnética, a velocidade do éter poderia ser considerada como composta de duas componentes: uma $\left(v_{g}\right)$ na direção do vetor de Poynting $^{[123]}$, dada pela menor raiz da equação

$$
g v_{g}^{2}-2 w v_{g}+g c^{2}=0^{[124]}
$$

sendo $g$ o módulo do momento eletromagnético $(1 / c)(\mathbf{E} \times \mathbf{H})$ e $w$ a densidade de energia eletromagnética; a outra em uma posição do plano definido perpendicularmente ao vetor de Poynting, possuindo magnitude $\left(\mathrm{c}^{2}-\mathrm{v}_{\mathrm{g}}\right)^{1 / 2}$ [Cunningham $^{(\mathrm{a})}: 196$ e 199]. Todo o esquema seria relativisticamente invariante.

$\mathrm{Na}$ teoria de Cunningham, teríamos um stress total ("true stress") que seria constituído de uma tensão $P$, definida pela equação

$$
P=\sqrt{w^{2}-(g c)^{2}}
$$

na direção da componente da velocidade do éter no plano definido por $\mathbf{E}$ e $\mathbf{H}$, e de iguais pressões $P$ em todas as direções perpendiculares à direção da velocidade referida [Cunningham $^{(b)}$ : 91]. O responsável pelo transporte de energia seria este "true stress" (diferindo do stress de Faraday-Maxwell por levar em conta o termo cinético $g c$ ).

\footnotetext{
123 John Henry Poynting (1852-1914), físico, matemático e inventor inglês.

${ }^{124}$ A outra raiz é maior que $c$ e, portanto, deveria ser descartada.
} 
O matemático inglês fornece dois exemplos de determinação da velocidade do éter: quando um trem de ondas eletromagnéticas planas se propaga no meio e quando uma carga pontual se movimenta nele. No primeiro caso, a tensão $P$ se anula e o éter move-se como um todo na direção das ondas; no segundo, o éter move-se como se fosse continuamente emitido a partir da carga com velocidade $c^{[125]} \quad$ [Cunningham $^{(a)}:$ 199-201; Cunningham $^{(b)}:$ 93-94].

Em seu livro de 1914, Cunningham termina o capítulo XV dizendo que foi mostrado que um éter objetivo não é algo incompatível com o Princípio de Relatividade, acrescentando ainda:

If this view of the aether is accepted, the aether becomes much more nearly assimilated to our conception of an objective reality than on the older view where the relations expressed by the differential equations for the field were vaguely conceived as representing a quasi-elastic motionless medium, which served at the same time as a space frame of reference. At the same time the framework of time and space relative to which the aether moves in the presentation given above is restored to its true place as a mental construct embodying one aspect of the uniformities observed in the physical realm. [Cunningham $^{(\mathrm{a})}:$ 204]

E no capítulo VIII de seu livro 1915, após ressaltar que não podia ser dito que um completo modelo mecânico de éter tinha sido construído, o matemático inglês finaliza:

The above examples are suggestive of a new form of emission theory of electrical action; but it should be borne in mind that no substantially new facts have been introduced; everything depends upon the fundamental and commonly accepted equations of the electromagnetic field in free spaces. Nor can we return from the mechanical relations to the electromagnetic. The mechanical specification of the aether is not sufficient to determine the ordinary electro-magnetic specification. [Cunningham(b) : 94]

Por não ter possibilitado a previsão de novos fatos, Cunningham não levou adiante seu modelo de éter, que foi inclusive omitido em seu livro Relativity, the Electron Theory, and Gravitation (1921), segunda edição aumentada de seu livro de 1915 [McCrea : 123]. Mas vale ressaltar que sua teoria não foi refutada, merecendo melhores estudos.

\footnotetext{
${ }^{125}$ Em 1914, outro físico, o estadounidense Leigh Page, propôs uma teoria eletromagnética tendo como premissa básica justamente a emissão de corpúsculos com velocidade $c$ por partículas carregadas. Para Page, os corpúsculos seriam identificados com velocidade $c$ por todos os referenciais inerciais. Foram encontrados resultados concordes com os fornecidos pela teoria de Maxwell-Lorentz para o caso de um elétron movendo-se com dada velocidade e aceleração [Whittaker $\left.{ }^{(b)}: 249\right]$.
} 


\subsection{IDÉIAS DE LARMOR, LODGE E DIRAC SOBRE O ÉTER}

Oliver Lodge e Joseph Larmor participaram ativamente do efervescente período que antecipou a Teoria da Relatividade, o primeiro tendo realizado importantes experiências relacionadas à procura do possível movimento da Terra em relação a um suposto éter, e o último contribuindo com trabalhos teóricos e sendo, inclusive, o primeiro propositor das hoje denominadas transformações de Lorentz. Ambos também acompanharam todo o desenvolvimento da Teoria da Relatividade e, dentre as opiniões em comum, partilhavam da idéia que algo importante não era levado em conta na teoria mencionada: a Relatividade evitava o problema do éter ao invés de enfrentá-1o ${ }^{[126]}$.

Outro ponto em comum entre ambos os físicos, além da convicção na existência de um éter, era o fato de acreditarem na existência de "elétrons positivos" (os anti-elétrons ou pósitrons). Por exemplo, em 1922 Lodge escreve:

(...) According to Larmor's theory the positive and the negative electrons can only differ, or at least must chiefly differ, in one being the mirror-image of the other. One for example might be a concentrated locked right-handed screw twist in the Ether while the other would be a left-handed contortion of the same kind, simultaneously and inevitably produced, and contorted with its fellow by transferable lines of force. (...) Why negative electricity should differ from positive so greatly, or in any respect save in sign, is not at all clear; and it is difficult to understand how one of these entities can have been constructed out of the ether, without the simultaneous production of its opposite partner. [Lodge ${ }^{(\mathrm{a})}: 696$ ]

Em 1928 Dirac prevê a existência dos pósitrons ${ }^{[127]}$, conseqüência de sua equação relativística para a função de onda do elétron (equação de Dirac), proposta em dois artigos publicados no mesmo ano. Esta previsão foi verificada experimentalmente em 1932, por Carl Anderson ${ }^{[128]}$.

Curiosamente, em 1929, após a publicação dos dois trabalhos de Dirac já mencionados, Lodge afirmou que a mecânica quântica era "o começo de uma compreensiva teoria do éter".

\footnotetext{
${ }^{126} \mathrm{Cf}$. http://www.iop.org/activity/groups/subject/hp/Archive/Newsletters/page_22095.html [Rowlands 2005].

${ }^{127}$ Cf. http://physicsworld.com/cws/article/print/1705 (acessado em 31/10/07).

${ }^{128}$ Carl David Anderson (1905-1991), físico estadounidense.
} 
Transcrevemos abaixo alguns trechos de Lodge sobre o éter. Como podemos ver, suas últimas concepções não era baseadas em modelos mecânicos:

(...) Objections to the ether are really objections to the nineteenth century conception based in terms of mechanical models. No such ether exists (...) [Lodge ${ }^{(b)}$ : 645-646]

(...) I have abandoned the old material ether of Lord Kelvin and the nineteenth century in favour of some hydrodynamic or other perfect mechanism at present unknown. [Lodge $\left.{ }^{(c)}: 804\right]$

Ao que nos parece, as idéias de Larmor e Lodge não foram de todo desarrazoadas. Prova disso é que, cerca de 20(vinte) anos após afirmação de Lodge de que a Mecânica Quântica era o começo de uma teoria compreensiva do éter, Paul Dirac iria dizer praticamente o mesmo:

(...) Physical knowledge has advanced very much since 1905, notably by the arrival of quantum mechanics, and the situation has again changed. If one examines the question in the light of present-day knowledge, one finds that the aether is no longer ruled out by relativity, and good reasons can now be advanced for postulating an aether (...) [Dirac : 906] 


\section{CONCLUSÃO}

O objetivo principal deste trabalho foi o de analisar a força de Lorentz $[\mathbf{F}=q(\mathbf{E} \times \mathbf{B})]$ no seu aspecto histórico e conceitual. Por relacionar conjuntamente as quantidades físicas F (força), E e B (comumente denominadas campo elétrico e campo magnético, respectivamente), procuramos analisar historicamente os conceitos de força e campo. Como forma de apresentação, optamos por dividir o trabalho realizado em 4(quatro) partes: uma analisando historicamente o conceito de força (em que analisamos também a apresentação deste conceito e correlatos em um livro didático), outra tratando especificamente sobre a força de Lorentz, a terceira parte analisando os diversos significados de campo no contexto da Física (e incoerências na utilização deste termo), e o capítulo final apresentando um modelo de éter para a explicação dos processos eletromagnéticos (formulado na segunda década do século XX), além de levantar algumas questões sobre a existência de um éter luminífero. De maneira mais específica, nesta dissertação foram abordados os tópicos que serão agora discutidos.

No primeiro capítulo, os dois principais pontos levantados foram:

1 - Os Principia possuem, aparentemente, alguns problemas lógicos, parecendo-nos que a formulação de Mach seria preferível à de Newton;

2 - A apresentação das "leis de Newton" em certos livros didáticos poderia ser mais cuidadosa;

Estes itens apontam para a necessidade de um maior cuidado na confecção e na escolha dos livros que serão utilizados em disciplinas relacionadas aos fundamentos da Mecânica Clássica.

No segundo capítulo, atemo-nos aos seguintes pontos:

1 - Importantes livros didáticos cometem equívocos ao considerarem a parte magnética da

força de Lorentz como tendo definido historicamente $\mathbf{B}$ ou como tendo sido obtida a partir da força entre dois fios com corrente descrita em termos de $\mathbf{B}$;

2 - A força de Lorentz foi obtida antes de Lorentz, e por duas maneiras distintas (Maxwell, 1864; Heaviside, 1889). Além disso, após sua obtenção pelo físico holandês, Larmor (aprox. 1898) e Schwarzschild (1903), independentemente, também obtiveram-na, utilizando o Princípio da Mínima Ação. 
O item 1 aponta, analogamente aos itens que associamos ao primeiro capítulo, para a necessidade de um maior cuidado na confecção e na escolha dos livros que serão utilizados em disciplinas relacionadas à Eletrodinâmica Clássica, sejam estas disciplinas básicas ou avançadas. Já o item 2, ressaltando as várias maneiras possíveis de encontrarmos a força de Lorentz, ilustrou bem a riqueza de procedimentos que a Física permite-nos utilizar para a descrição dos fenômenos da natureza.

No terceiro capítulo, restringimo-nos a mostrar que: 1 - O significado para campo é diversificado em Física, exigindo-nos muito cuidado quanto ao contexto no qual o termo está inserido para um real entendimento daquilo que está sendo apresentado;

2 - Artigos, livros didáticos e livros de divulgação muitas vezes apresentam incoerências relacionadas à utilização da palavra campo.

Estes pontos deixaram-nos com uma forte impressão de que os fundamentos do Eletromagnetismo, longe de constituírem assunto acabado, ainda demandam maiores reflexões.

Finalmente, no último capítulo, em que buscamos em especial ressaltar o trabalho de físicos que se dedicaram à procura de uma base física para a explicação dos campos vetoriais $\mathbf{E}(\mathbf{r}, \mathbf{t})$ e $\mathbf{B}(\mathbf{r}, \mathrm{t})$, apresentamos:

1 - Um paralelo entre os trabalho de Lorentz e Einstein;

2 - Um modelo de éter eletromagnético do início do século XX, elaborado por E. Cunningham, que é condizente com o Princípio de Relatividade e que não parece ter sido ainda refutado;

3 - O fato de que a idéia de um éter eletromagnético não só não foi refutada como foi tida como uma boa hipótese, ainda na segunda metade do século XX, por físicos de grande credibilidade, como Paul Dirac.

Estes itens tiveram como objetivo principal mostrar que a opinião atualmente prevalecente sobre o éter - que seria um anacronismo falar em éter, uma vez que a existência deste meio teria sido refutada - pode não corresponder completamente à realidade. Acreditamos que mais profundos estudos a este respeito, tratando da conexão entre as opiniões sobre o éter que resistiram à Teoria da Relatividade e as concepções 
modernas sobre o vácuo, seriam de grande valia para uma melhor compreensão da história do Eletromagnetismo, de seus conceitos e da própria natureza física. 


\section{BIBLIOGRAFIA}

ASSIS, A.K.T. Eletrodinâmica de Weber. Campinas: Editora da Unicamp, 1995.

ATKIN, R.H. Theoretical Electromagnetism. New York: John Wiley \& Sons Inc., 1962.

BECKER, R. Electromagnetic Fields and Interactions (trad. do alemão). New York: Dover

Publications, 1982 (unabridged of the 1964 translation first published by Blaisdell, New York) ${ }^{[129]}$

CHAIB, J.P.M.C. and ASSIS, A.K.T. "Distorção da obra eletromagnética de Ampére nos livros didáticos", Revista Brasileira de Ensino de Física, 29(1): 65-70, 2007.

CUNNINGHAM $^{(\mathbf{a})}$, E. The Principle of Relativity. Cambridge: University Press, 1914.

CUNNINGHAM $^{(\mathbf{b})}$, E. Relativity and the Electron Theory. London: Longmans, Green and Co., 1915.

DIRAC, Paul. “Is there an aether?”. Nature, 168: 906-907, 1951.

EINSTEIN $^{(\mathbf{a})}$, A. "On the Electrodynamics of Moving Bodies" (trad. do original "Zur Elektrodynamik bewegter Körper”, Annalem der Physik, 17: 891-921, 1905). In LORENTZ, H.A., EINSTEIN, A., MINKOWSKI, H., and WEYL, H.: The Principle of Relativity, London: Methuen, 1923, e disponível em http://www.fourmilab.ch/etexts/ einstein/specrel/www/ (acessado em 14.09.07).

EINSTEIN $^{(\mathbf{b})}$, A. “Theory of Relativity". In EINSTEIN, A.: The Collected Papers, vol. 4

(Writings, 1912-14) (trad. do alemão), Princeton: Princeton University Press, 1996.

EINSTEIN $^{(\mathbf{c})}$, Albert. "Ether and the Theory of Relativity", tradução de um discurso de Einstein pronunciado a 5 de maio de 1920 na Universidade de Leiden, Alemanha. In EINSTEIN, A.: Sidelights on Relativity (tradução de dois discursos de Einstein publicada em 1922), disponível em www.ibiblio.org/ebooks/Einstein/ Sidelights/Einstein_Sidelights.pdf (acessado em 05.08.07).

\footnotetext{
${ }^{129}$ Este livro é de autoria de três físicos: August Föppl, Max Abraham e Richard Becker. Por razões que desconhecemos, apenas um deles aparece como autor na capa. Felizmente, no foreword à primeira tradução inglesa (de 1964), alguma coisa está explicada: “August Föppl's Introduction to Maxwell's Theory appeared in the year 1894. A completely revised second edition followed ten years later, this being the first volume of Max Abraham's Theory of Electricity. This, in turn, was followed a year later by a second volume, on the electron theory. From the year 1930 onward, with the appearance of the eight edition, Richard Becker took over the further editing of the work which, in succeeding years, underwent several basic changes".
} 
$\operatorname{EINSTEIN}^{(\mathrm{d})}$, A. "On the Ether" (trad. do original "Über den Äther", Schweizerische naturforschende Gesellschaft Verhanflungen, 105: 85-93, 1924). In SAUNDERS, S. \& BROWN, H.R. (eds): The Philosophy of Vacuum. Oxford: Clarendon Press, 1991.

EINSTEIN, A. \& INFELD, L. The Evolution of Physics. New York: Simon and Schuster, 1938.

ERNST, A. \& HSU, J.-P. "First proposal of the universal speed of light by Voigt in 1887", Chinese Journal of Physics, $\underline{\text { 39(3): 211-230, } 2001 .}$

FARADAY, Michael. Experimental Researches in Electricity, vol. III. New York: Dover Publications, 1965 (unabridged of the $1^{\text {st }}$ edition, of 1855, published by Taylor and Francis).

FEYNMAN $^{(\mathrm{a})}$, R. P., LEIGHTON, R. B., and SANDS, M. The Feynman Lectures on Physics, vol. I. Reading (Massachusetts, U.S.A.): Addison-Wesley, 1963.

FEYNMAN $^{(\mathbf{b})}$, R. P., LEIGHTON, R. B., and SANDS, M. The Feynman Lectures on Physics, vol. II. Reading (Massachusetts, U.S.A.): Addison-Wesley, 1964.

FOKKER, A.D. Time and Space, Weight and Inertia (trad. do holandês). Oxford: Pergamon Press, 1965.

GRIFFITHS, D.J. Introduction to Electrodynamics. Upper Saddle River (New Jersey, U.S.A.): Prentice Hall, 1999 ( $3^{\text {rd }}$ edition).

HEAVISIDE, O. "On the Electromagnetic Effects due to the Motion of Electrification in a Dielectric". Philosophical Magazine, 27: 324-339, 1889.

HEILBRON, J.L. "The Electrical Field before Faraday". In CANTOR, G.N. \& HODGE, M.J.S. (eds.): Conceptions of Ether. Cambridge: Cambridge University Press, 1981.

HOFMANN, J.R. André-Marie Ampère - Enlightenment and Electrodynamics. Cambridge: Cambridge University Press, 1996.

JACKSON, J. D. Classical Electrodynamics. New York: John Wiley, 1999 ( $3^{\text {rd }}$ edition).

JACKSON, J.D. \& OKUN, L.B. "Historical roots of gauge invariance". Rev. Mod. Phys. 73: 663-80, 2001, disponível em http://arxiv.org/vc/hep-ph/papers/0012/0012061v1.pdf (acessado em 31.08.07)

JAMMER, Max. Concepts of Mass in Classical and Modern Physics. New York: Dover, 1997 (corrected republication of the $1^{\text {st }}$ edition, of 1961). 
JEANS, Sir James. The Mathematical Theory of Electricity and Magnetism. Cambridge: Cambridge University Press, 1941 ( $3^{\text {rd }}$ reimpression of the $5^{\text {nd }}$ edition, of 1925).

KESWANI, G. H. \& KILMISTER, C. W. "Intimations of Relativity. Relativity before Einstein". British Journal of Philosophy of Science, 34: 343-54, 1983.

LANDAU, L.D. \& LIFSHITZ, E.M. The Classical Theory of Fields - vol. 2 of Course of Theoretical Physics (trad. do russo). Reading (Massachusetts, U.S.A.): AddisonWesley, $1959\left(2^{\text {nd }}\right.$ printing of the $1^{\text {st }}$ edition, of $\left.\mathbf{1 9 5 1}\right)$.

LODGE $^{(\mathbf{a})}$, Oliver J. "Speculation concerning the Positive Electron". In "Letters to the Editor", Nature, 110: 696-697, 1922.

LODGE $^{(\mathbf{b})}$, Oliver J. "Science and Hypothesis", Nature, 123: 645-648, 1929.

LODGE $^{(\mathbf{c})}$, Oliver J. "The Ether and Relativity". In "Letters to the Editor", Nature, 126 : 804-805, 1930.

LORENTZ $^{(a)}$, H.A. "La Théorie Électromagnétique de Maxwell et son application aux corps mouvants". Archives Néerlandaises des Sciences Exactes et Naturelles, 25: 363ff, 1892. In LORENTZ, H.A.: Collected Papers, vol. 2. The Hague: Martinus Nijhoff, 1936.

LORENTZ $^{(\mathbf{b})}$, H.A. "Electromagnetic Phenomena in a System Moving with any Velocity Less than that of Light". Proceedings of the Royal Netherlands Academy of Arts and Sciences (edição inglesa), 6: 809-831, 1904.

LORENTZ $^{(\mathbf{c})}$, H.A. Lectures on Theoretical Physics, vol. 1 (trad. do original em holandês, publicado em 1922). London: MacMillan and Co., 1927.

LORENTZ $^{(\mathbf{d})}$, H.A. Lectures on Theoretical Physics, vol. 3 (trad. do original em holandês, publicado em 1922). London: MacMillan and Co., 1931.

LORENTZ $^{(\mathbf{e})}$, H.A. Problems of the Modern Physics - A Course of Lectures Delivered in the California Institute of Technology in the beginning of 1922. New York: Dover, 1967 (unabridged republication of the work originally published by Ginn and Co. in 1927).

MACH, Ernst. The Science of Mechanics (trad. do alemão). Londres: The Open Court Publishing Co., 1942 ( $5^{\text {th }}$ ed.)

MACROSSAN, M.N. "A note on relativity before Einstein". British Journal of Philosophy

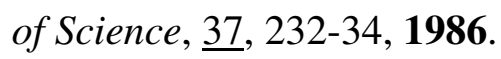


MARION, Jerry B. \& HEALD, Mark A. Classical Electromagnetic Radiation. Orlando (Florida, U.S.A.): Saunders College Publishing, 1995 ( $3^{\text {rd }}$ edition).

MARTINS, Roberto de Andrade. “A Dinâmica Relativística antes de Einstein”. Revista Brasileira de Ensino de Física, 27(1), 11-26, 2005.

MAXWELL ${ }^{\text {(a) }}$, James C. The Scientific Papers of James Clerk Maxwell. New York: Dover, 2003 (unabridged republication of the 1965 Dover reprint of the work first published by Cambridge University Press in 1890).

MAXWELL ${ }^{(\mathbf{b})}$, James C. A Treatise on Electricity and Magnetism, vol. I. New York: Dover, 1954 (unabridged of the $3^{\text {rd }}$ edition, published by the Clarendon Press in 1891).

MAXWELL ${ }^{(\mathbf{c})}$, James C. A Treatise on Electricity and Magnetism, vol. II. New York: Dover, 1954 (unabridged of the $3^{\text {rd }}$ edition, published by the Clarendon Press in 1891).

MAXWELL $^{(\mathbf{d})}$, James C. Matter and Motion. New York: Dover, 1991 (republication of the reprint, published in 1920, with notes and appendices by Sir J. Larmor, of the original work, published in 1877).

MC CORMACH, Russell. "H. A. Lorentz and the Electromagnetic View of Nature". Isis, $\underline{61}$ (4), 459-497, Winter, 1970.

MC CREA, W. H. "Ebenezer Cunningham". Bulletin of the London Mathematical Society, $\underline{10}, 116-126,1978$.

MILLER, John D. "Rowland and the Nature of the Electric Currents". Isis, 63(1): 4-27, Mar. 1972.

NEWTON, Isaac. The Mathematical Principles of Natural Philosophy (tradução de 1729 da 3a. edição em latim, de 1726). New York: Prometheus Books, 1995.

NUSSENZVEIG $^{(\mathbf{a})}$, H. M. Curso de Física Básica, vol. 1: Mecânica. S. Paulo: Edgard Blücher, 1996 (3a edição).

NUSSENZVEIG $^{(\mathbf{b})}$, H. M. Curso de Física Básica, vol. 3: Eletromagnetismo. S. Paulo: Edgard Blücher, 1997.

PAGE, Leigh. An Introduction to Electrodynamics. Boston: Ginn and Co., 1922.

PANOFSKY, Wolfgang K.H. \& PHILLIPS, Melba. Classical Electricity and Magnetism. Reading: Addison-Wesley Publishing Co., 1962 ( $2^{\text {nd }}$ ed.). 
POINCARÉ(a) ${ }^{(a)}$ Jules Henri. Science and Hypothesis (trad. do original em francês). New York: The Walter Scott Publishing Co., 1905. Esta obra encontra-se disponível em http://www.archive.org/details/scienceandhypoth00poinuoft (acessado em 29.10.07).

POINCARÉ(b) ${ }^{(\mathbf{b})}$ Jules Henri. Mathematics and Science: Last Essays (tradução aumentada de Dernières Pensées, livro de Poincaré publicado postumamente em 1913). New York: Dover, 1963. Esta obra encontra-se disponível em http://www.archive.org/ details/mathematicsandsc001861mbp (acessado em 24.10.07).

RESNICK, R., HALLIDAY, D., and WALKER, J. Fundamentos de Física, vol. 1: Mecânica (trad. da $4^{\text {a }}$ edição em língua inglesa, de 1993). Rio de Janeiro: Livros Técnicos e Científicos Editora Ltda., 1996.

RESNICK, R. \& HALLIDAY, D. Física, vol. 2 (trad. da $3^{\text {a }}$ edição em língua inglesa, de 1978). Rio de Janeiro: Livros Técnicos e Científicos Editora Ltda., 1984 (4ª edição).

ROWLANDS, Peter. "Sir Oliver Lodge and Relativity". History of Physics Group Newsletter 18: 19-29, 2005. em http://www.iop.org/activity/groups/subject/hp/Archive/ Newsletters/page_22095.html (acessado em 31.10.07).

SAUNDERS, S. \& BROWN, H.R. "Reflections on Ether". In SAUNDERS, S. \& BROWN, H.R. (eds): The Philosophy of Vacuum. Oxford: Clarendon Press, 1991.

SHADOWITZ, A. The Electromagnetic Field. New York: Dover, 1988 ( $2^{\text {nd }}$ ed.).

SOMMERFELD, Arnold. Lectures on Theoretical Physics, vol. III - Electrodynamics (trad. do alemão). New York: Academic Press, 1964.

SPENCER, Ross. A Ridiculously Brief History of Electricity and Magnetism. In http://maxwell.byu.edu/ spencerr/phys442/node4.html (acessado em 09.09.07)

THOMSON $^{(\mathbf{a})}$, Sir J. J. "On the Electric and Magnetic Effects produced by the Motion of Electrified Bodies”. Philosophical Magazine 11: 229-49, 1881.

THOMSON $^{(\mathbf{b})}$, Sir J. J. Recent Researches in Electricity and Magnetism. Oxford: University Press, 1893.

THOMSON $^{(\mathbf{c})}$, Sir J. J. Elements of the Mathematical Theory of Electricity and Magnetism. Cambridge: Cambridge University Press, 1921 ( $5^{\text {th }}$ ed.).

TOLMAN, R. C. \& STEWART, T. D. "The Electromotive Force Produced by the Acceleration of the Metals". The Physical Review $\underline{8}$ : 97-116, 1916. 
WHITTAKER $^{(\mathrm{a})}$, Sir Edmund. A History of the Theories of Aether and Electricity, Vol. 1:

The Classical Theories. London: Thomas Nelson and Sons Ltd., 1951 (revised and enlarged edition of the publication of 1910).

WHITTAKER $^{(\mathbf{b})}$, Sir Edmund. A History of the Theories of Aether and Electricity, Vol. 2:

The Modern Theories. London: Thomas Nelson and Sons Ltd., 1953. 